RESEARCH AND DEVELOPMENT FOR THE

GEOPRESSURED-GEOTHERMAL ENERGY PROGRAM

\title{
FLOW TESTS OF THE WILLIS HULIN WELL
}

Final Report for the Period October 1985-October 1990

Prepared by

INSTITUTE OF GAS TECHNOLOGY

for

EATON OPERATING COMPANY

\author{
IGT/EOC Subcontract \\ IGT/EOC-85-4 \\ DOE Prime Contract \\ DE-AC07-85ID12578
}

February 1992 


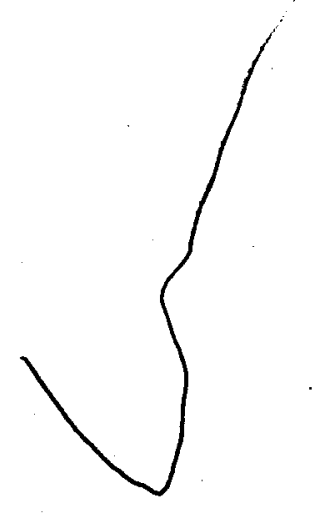




\section{RECEIVED JUN 211393 OSTI}

\section{APPENDIX C \\ WILLIS HULIN SITE}

INSTITUTE OF GAS TECHNOLOGY (IGT)

FINAL SITE REPORT 
RESEARCH AND DEVELOPMENT FOR THE

GEOPRESSURED-GEOTHERMAL ENERGY PROGRAM

FLOW TESTS OF THE WILLIS HULIN WELL

Final Report for the Period October 1985-October 1990

Prepared by

P. L. Randolph

C. G. Hayden

L. A. Rogers

INSTITUTE OF GAS TECHNOLOGY

3424 South State Street

Chicago, Illinois 60616

IGT Project No. 65071

for

EATON OPERATING COMPANY

1240 Blalock

Suite 100

Houston, Texas 77055

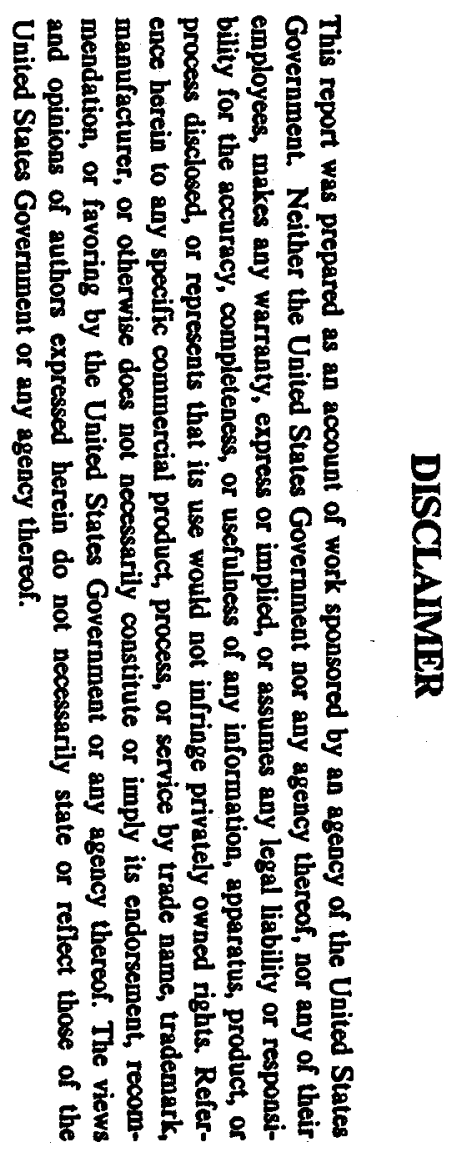

IGT/EOC Subcontract

IGT/EOC-85-4

DOE Prime Contract

DE-AC07-85ID12578 ,

February 1992 , 


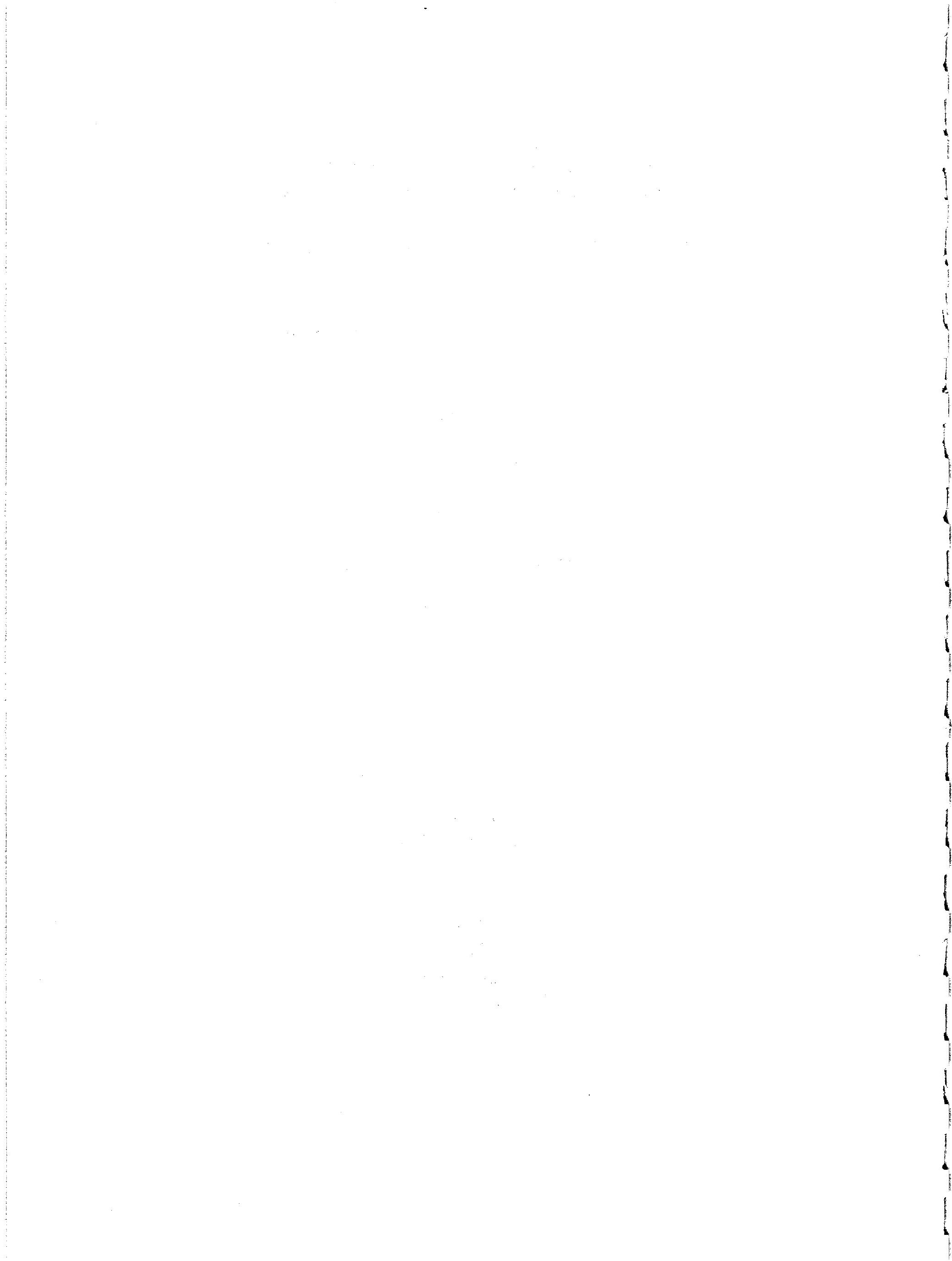




\section{EXECUTIVE SUMMARY}

The Willis Hulin well, located in Vermilion Parish, Louisiana, is the deepest, hottest, and highest pressured well to be tested in the U.S. Department of Energy's Geopressured-Geothermal Program. The interval of interest for testing in the Hulin well is the massive aquifer sand between 20,100 and 20,700 feet. This geologic section is comprised mostly of layers of brine-saturated, clean sand with occasional intervening layers or lenses of shale. The objective of the test was to determine the characteristics of the brine and gas in this interval and to make an initial determination of the reservoir properties.

The lowermost 20 feet of the lowest sand member in the interval of interest $(20,670$ to 20,690 feet) was perforated first and given a cleanup flow in February 1989. Instrumented shortterm draw-down and buildup tests using rental equipment were delayed because of budget constraints until December 1989.

The first instrumented test was a 1-day flow test to obtain brine and gas samples and to obtain a first indication of the reservoir properties. A bottomhole pressure gauge was in the hole to record both the pressure drawdown and following buildup. The remaining part of the lowest sand member $(20,602$ to 20,666 feet $)$ was then perforated, and the entire 90 -foot interval was tested with a 4-day flow and 12-day buildup test. The bottomhole pressure was also recorded for this test. The static bottomhole pressure (at 20,600 feet) was 17,308 psia prior to the 1-day flow test and 17,283 psi prior to the 4-day flow test. The bottomhole temperature was $339^{\circ} \mathrm{F}$ and the initial wellhead pressure was $7460 \mathrm{psi}$. The produced brine had a total dissolved solids content (mostly sodium chloride) of $207,000 \mathrm{mg} / \mathrm{L}$ and was at or near saturation with gas at 31 to $32 \mathrm{SCF} / \mathrm{STB}$ (standard cubic feet/stock tank barrel). The gas was leaner in the heavy hydrocarbons than the gas from other geopressured-geothermal wells and was about one-sixth by volume carbon dioxide. No free gas was produced. The amount, if any, of produced condensate or oil was small compared to the amount of diesel pumped into the wellhead to prevent hydrates after shut-ins.

Analysis of bottomhole pressure data for the lowermost sand member by S-Cubed gave a transmissivity of about $1050 \mathrm{md}-\mathrm{ft}$ (millidarcy-feet). From this, a permeability of $13 \mathrm{md}$ was calculated for the reservoir. The lateral extent of the reservoir was not determined, although the analysis of the data indicated a fault at a distance of 100 to 200 feet from the well. A skin factor of 15 was found with the entire 80-foot interval perforated. That indicated low flow efficiency for the

perforations. The decreasing initial static bottomhole pressure prior to each test suggests that this sand member is not large. 
In January 1990 the uppermost sand member in the zone of interest $(20,220$ to 20,260 feet) was perforated and tested in a 7-day flow test during which the brine produced from this interval was commingled with that from the lower sand. No free gas was found, although the commingled gas-to-brine ratio of 32 to $33 \mathrm{SCF} / \mathrm{STB}$ indicated the brine in the upper zone was also at or near saturation with natural gas. The brine and gas compositions of the commingled flow changed slightly compared to the lower zone alone, which suggests the upper zone was to some degree isolated from the lower zone. Bottomhole pressures were not measured and the reservoir characteristics of the upper zone were not determined. But substantially lower drawdown for the commingled zones suggests either higher permeability or lower skin for the shallower perforated interval.

Although production of free gas from the reservoir was not observed for either the upper or the lower sand members, this does not preclude the possibility of future free-gas production. One possible mechanism is downward coning of an offsetting gas cap, as was observed at the Koelemay "Well-of-Opportunity."

Hydrate formation in the wellhead and near surface tubing was a problem. To circumvent this problem, about 10 barrels of diesel were pumped into the well after each flow period to displace the brine in the wellbore down to a point where the temperature was high enough to prevent hydrate formation (above $75^{\circ} \mathrm{F}$ ). Calcium carbonate scale formation in the tubing was a potential problem but was avoided by conducting the flow tests only in pressure and flow-rate ranges where scale would not form in the well. The surface equipment was protected from scaling by injecting scale inhibitor into the surface flow lines.

Total production for the December 1989 through January 1990 instrumented testing of the well was 40,163 barrels of brine and 1,205,000 SCF of gas. Production was through a 5-inch liner from the perforations at 20,220-plus feet to the bottom of the packer set at 15,982 feet and then up through 3-1/2 inch tubing to the wellhead. Flow rates were chosen to avoid pressure and temperature regimes that would result in scale formation in the wellbore. The maximum sustained flow rate was 5000 barrels of brine per day for a few hours on January 6 . The highest wellhead temperature achieved during the flow tests was $268^{\circ} \mathrm{F}$ during that same time. The lowest flowing wellhead pressure was 4390 psia on December 22, 1989. 


\section{TABLE OF CONTENTS}

Page

1.0. INTRODUCTION 1

1.1. Conditions for Hydrate Formation 6

1.2. Sequence of Test Activities $\quad 7$

2.0. FEBRUARY 1989 INITIAL CLEANUP FLOW FOR THE DEPTH INTERVAL FROM 20,670 TO 20,690 FEET 10

2.1. Brine Analyses 12

2.2. Hydrocarbon Analyses 13

2.3. Potential for Problems Due to Scale and Corrosion 14

3.0. PREPARATIONS FOR TESTING OF THE DEPTH INTERVAL FROM 20,670 TO 20,690 FEET

3.1. Possible Hydrate Problems and Measurement of Bottomhole Pressure

3.2. November 21, 1989, Cleanup Flow to Tanks $\quad 21$

3.3. Disposal Well Completion 23

3.4. Surface Hardware Installation $\quad 24$

4.0. THE 36-HOUR FLOW TEST OF THE 20,670 TO 20,690-FOOT INTERVAL

4.1. Bottomhole Pressures 26

$\begin{array}{lr}\text { 4.2. Production Well Performance } & 28\end{array}$

4.3. Disposal Well Performance 28

4.4. Surface Facility Performance 31

4.5. Scale and Corrosion 33

4.6. Filters $\quad 33$

4.7. Gas and Brine Analyses $\quad 34$

4.8. Equipment Modification and Measurement of Flow Rates 34

5.0. PERFORATION AND CLEANUP FLOWS OF THE 20,602 TO 20,690-FOOT INTERVAL

5.1. Perforation 
TABLE OF CONTENTS, Cont.

Page

5.2. Cleanup Flow $\quad 35$

5.3. Disposal Well 37

5.4. Effect of the Additional Production Well Perforations 38

5.5. Liquid Hydrocarbon Production, Scale and Corrosion Treatment 38

$\begin{array}{ll}\text { 5.6. Filters } & 38\end{array}$

5.7. Discussion of Sampling and Analysis 39

6.0. DECEMBER 1989 4-1/2 DAY FLOW TEST OF THE 20,602 TO
20,690-FOOT INTERVAL

6.1. Bottomhole Pressures 40

6.2. Production Well Performance 41

6.3. Disposal Well Performance 43

6.4. Surface Facility Performance 48

6.5. Gas/Brine Ratio 49

6.6. Liquid Hydrocarbon Production 50

6.7. Scale and Corrosion 50

6.8. Filters 51

6.9. Discussion of Onsite Sampling and Analysis 52

7.0. RESERVOIR ENGINEERING ANALYSIS OF THE 20,602 TO
20,690-FOOT INTERVAL

7.1. Pretest Estimated Flow Rates and Pressures 52

7.2. S-Cubed Analysis of the 20,602 to 20,690-Foot Zone 55

7.3. Changing Static Bottomhole Pressure 56

8.0. JANUARY 1990 FLOW TEST OF THE 20,220 TO 20,260-FOOT INTERVAL 56

8.1. Perforation of the 20,220 to 20,260 -Foot Interval 69

8.2. Production Well Performance 69

8.3. Disposal Well Performance $\quad 70$

vi 
8.4. Surface Facility Performance

8.5. Gas/Brine Ratio

8.6. Liquid Hydrocarbon Production

8.7. Scale and Corrosion 75

8.8. Filters

8.9. Gas and Brine Analyses

9.0. SAMPLING AND ANALYSIS

9.1. Results of Brine Analyses

9.2. Results of Hydrocarbon Analyses

82

10.0. CONCLUSIONS

99

11.0. RECOMMENDATIONS

100

12.0. REFERENCES CITED

101

APPENDIX A: Brine Sampling and Analysis Methodology

A-1

APPENDIX B: Hydrocarbon Sampling, Analysis Procedures, and Results

B-1

vii 


\section{LIST OF EXHIBITS}

Exhibit No.

Page

1.0-1 Location of the Willis Hulin Well 2

1.0-2 Structure Map for the Sand of Interest 3

1.0-3 Log of the 20,000 to 20,700-Foot Zone of the Hulin Well 4

1.0-4 Schematic Diagram of Well Completion, January 1990

1.1-1 Conditions for Hydrate Formation 6

$\begin{array}{lll}1.2-1 & \text { Sequence of Events } & 8\end{array}$

1.2-2 Summary of Daily Production of Brine and Gas 9

2.0-1 Wellhead Pressure During Cleanup Flow 11

2.1-1 Brine Analysis: 2/8/89 Wellhead Cleanup Sample 13

2.2-1 Hydrocarbon Analyses: 2/8/89 Wellhead Cleanup Sample $\quad 15$

2.3.1-1 Approximations to Wellhead Pressure and Temperature 17

2.3.1-2 Wellhead Saturation Index as a Function of Brine Rate 17

3.1-1 Down-Hole Panex Gauge Measurements on 11/20/89 21

3.2-1 Wellhead Pressures on 11/21/89 22

3.2-2 Flow Rates for Well Cleanup 23

3.3-1 Disposal Well Temperatures 24

3.4-1 Surface Facilities for Production Testing $\quad 25$

3.4-2 Computer-Based Data Acquisition and Analysis System 27

4.1-1 Recorded Bottomhole Pressure for 12/5/89 Through 12/11/89 29

$\begin{array}{lll}\text { 4.2-1 Plot of Wellhead Pressure and Temperature for 12/2/89 } & 30\end{array}$

4.2-2 Daily Brine and Gas Production During Cleanup Flows 31

4.4-1 Plot of Brine Flow Rate and Corrosion Rate for 12/2/89 $\quad 32$

4.5-1 Analysis of Corrosion Coupons After 1-Day Flow Test 33

5.2-1 Daily Brine and Gas Production During Cleanup Flows 37

ix 


\section{LIST OF EXHIBITS, Cont.}

Exhibit No.

Page

5.7-1 Analysis of Gas Samples Taken on 12/11/89 40

6.1-1 Recorded Bottomhole Pressure for 12/17/89 Through 12/28/89 42

6.2-1 Summary of Brine and Gas Production for December 1989 Flow Test

6.2-2 Wellhead Pressure and Temperature for 12/16/89

Through $12 / 22 / 89$

6.2-3 Brine Flow Rate and Corrosion Rate for 12/16/89

Through 12/22/89

6.2-4 Gas Flow Rate and Gas/Brine Ratio for 12/16/89 Through 12/22/89

6.2-5 Disposal Wellhead Pressure and Filter Differential Pressure for 12/16/89 Through 12/22/89

6.7-1 Analysis of Corrosion Coupons After 4-Day Flow Test 51

6.9-1 Onsite Analysis of Brine Sample on 12/20/89 52

7.1-1 Estimated Flowing Pressure Loss 54

7.1-2 Pretest Estimated Reservoir Permeability as a Function of Composite Skin Factor

7.1-3 Pretest Estimated Flowing Wellhead Pressure for a

Given Flow Rate

7.2-1 S-Cubed Preliminary Analysis of the 20,000 to 20,700-Foot Zone

7.3-1 1/2/90 Pressure Gauge Calibration Cross-Check 56

7.3-2 Comparison of Bottomhole Pressures 56

8.0-1 Plot of Wellhead Pressure and Temperature for 12/30/89

Through $1 / 5 / 90$

8.0-2 Plot of Wellhead Pressure and Temperature for 1/6/89

Through $1 / 12 / 90$

8.0-3 Plot of Brine Flow Rate and Corrosion Rate for 12/30/89 Through $1 / 5 / 90$

8.0-4 Plot of Brine Flow Rate and Corrosion Rate for 1/6/89 Through $1 / 12 / 90$ 
LIST OF EXHIBITS, Cont.

Exhibit No.

Page

8.0-5 Plot of Gas Flow Rate for 12/30/89 Through 1/5/90 62

8.0-6 Plot of Gas Flow Rate for 1/6/89 Through 1/12/90 63

8.0-7 Plot of Disposal Well Wellhead Pressure and Filter

Differential Pressure for 12/30/89 Through 1/5/90

64

8.0-8 Plot of Disposal Well Wellhead Pressure and Filter

Differential Pressure for 1/6/89 Through 1/12/90 65

8.0-9 Plot of Gas/Brine Ratio for 12/30/89 Through 1/5/90 66

8.0-10 Plot of Gas/Brine Ratio for 1/6/90 Through 1/12/90 67

8.0-11 Summary of Brine and Gas Production for January 1990 Flow Test

68

8.7-1 Analysis of Corrosion Coupons for Final Flow Test 76

$\begin{array}{lll}\text { 9.1.1-1 Brine Analyses } & 78\end{array}$

9.1.1-2 Brine Analyses Performed Onsite 78

9.1.2-1 Carboxylic Acids in the Brine $\quad 79$

9.1.2-2 Radium Activity in the Brine, Minimum Values 80

$\begin{array}{ll}\text { 9.1.3-1 } & \begin{array}{l}\text { Differences Between December } 1989 \text { and January } 1990 \\ \text { Brine Analyses }\end{array}\end{array}$

9.2.1-1 Hydrocarbon Analyses, Including Oil 83

9.2.1-2 Typical Geopressured-Geothermal Well Gas Analyses 85

9.2.1-3 Analyses of Hulin Liquid Hydrocarbons 86

9.2.1-4 Chromatograms for Condensate and Diesel 87

9.2.2-1 Large Separator Gas Analysis, IGT $\quad 89$

9.2.2-2 Properties of Deep and Commingled Gas 91

9.2.2-3 Radioisotope Activity and Isotopic Analyses of the Gas 91

9.2.3-1 Gas Samples Analyzed by Both IGT and SPL : 93

9.2.4-1 Total Gas Calculation for Separator Pressure of 405 psia 95

9.2.4-2 Total Gas Calculation for Separator Pressure of 735 psia 95

$\mathbf{x i}$ 


\section{LIST OF EXHIBITS, Cont.}

Exhibit No

9.2.4-3 Total Gas Calculation for Separator Pressure of 737 psia

9.2.4-4 Total Gas Calculation for Separator Pressure of 295 psia

9.2.4-5 Gas Flashed From Separator Brine Versus Pressure

9.2.4-6 Gas Bled From the Disposal Wellhead

A-1 Analytical Methods Used A-4

A-2 BEG Brine Analysis Report Cover Page A-5

A-3 BEG Sample Analysis Data A-6

A-4 BEG Reference Material Data A-7

A-5 BEG Replicate Analysis Data A-8

A-6 Hulin Brine Alkalinity A-9

B-1 Large Separator Gas Analyses, IGT B-4

B-2 Large Separator Gas Analyses, SPL B-5

B-3 Small Separator Gas Analyses, SPL B-6

B-4 Gas Flashed From Separator Brine

B-5 Gas Bled From the Disposal Wellhead B-8 


\section{FLOW TESTS OF THE WILLIS HULIN WELL}

\subsection{INTRODUCTION}

In the Hulin well test, the Institute of Gas Technology (IGT) was responsible for conducting the flow tests under the direction of Eaton Operating Company (EOC) and obtaining the associated gas and brine data. EOC maintained control of all activities related to the production and disposal wells, including the bottomhole pressure (BHP) measurements. The EOC field personnel also policed the area and maintained the brine filters and the flare. IGT directed the well-testing company and had control over the surface separation equipment between the production and disposal well as approved by EOC.

The Willis Hulin No. 1 Well, located in Vermilion Parish, Louisiana, was drilled by Superior Oil Company. It was completed as a gas well producing from the interval 21,059 to 21,094 feet in 1981. Production ceased because of mechanical problems in 1983. In 1984, the U.S. Department of Energy (DOE) accepted the offer of the well as a "Well of Opportunity."

The zone tested during the tests described herein is a section approximately 600 feet thick in the interval between 20,100 and 20,700 feet. This geologic section is comprised mostly of layers of clean sand with occasional intervening shale layers or lenses. Exhibit 1.0-1 shows the location of the well on a United States Geological Survey map. The well is in the Lower Planulina section of the Tigre Lagoon Field at a depth of about 15,400 feet. Exhibit 1.0-2 is a structure map of the top of the sand of interest from seismic data interpretation by Louisiana State University 9 personnel as a part of the DOE program. Exhibit 1.0-3 shows a log of the zone of interest and the perforated intervals. The geology, reservoir, and well parameters are summarized by Eaton. ${ }^{1}$

The well had been cleaned out by EOC during the winter of 1988-1989 to a depth of 20,720 feet. The flow for the tests discussed herein was up the 5-inch production liner to a packer set at 15,988 feet and then through $3-1 / 2$ inch tubing to the surface. A schematic diagram of the well completion is presented in Exhibit 1.0-4. The bottom 20 feet (20,670 to 20,690 feet) of the massive sandstone was perforated with four shots per foot using a 2-1/8 inch Ultrajet throughtubing perforator on January 30, 1989.

The wellhead originally used by Superior is still on the well. It has a working-pressure rating of $20,000 \mathrm{psi}$. The inside diameter is only 1-13/16 inches. Prior experience at the Gladys McCall and Pleasant Bayou wells had indicated rapidly increasing severity of corrosion of mild steel for brine velocities in excess of 10 feet per second. This velocity would exist for a brine rate of only 3000 barrels per day (BPD) through the wellhead. 


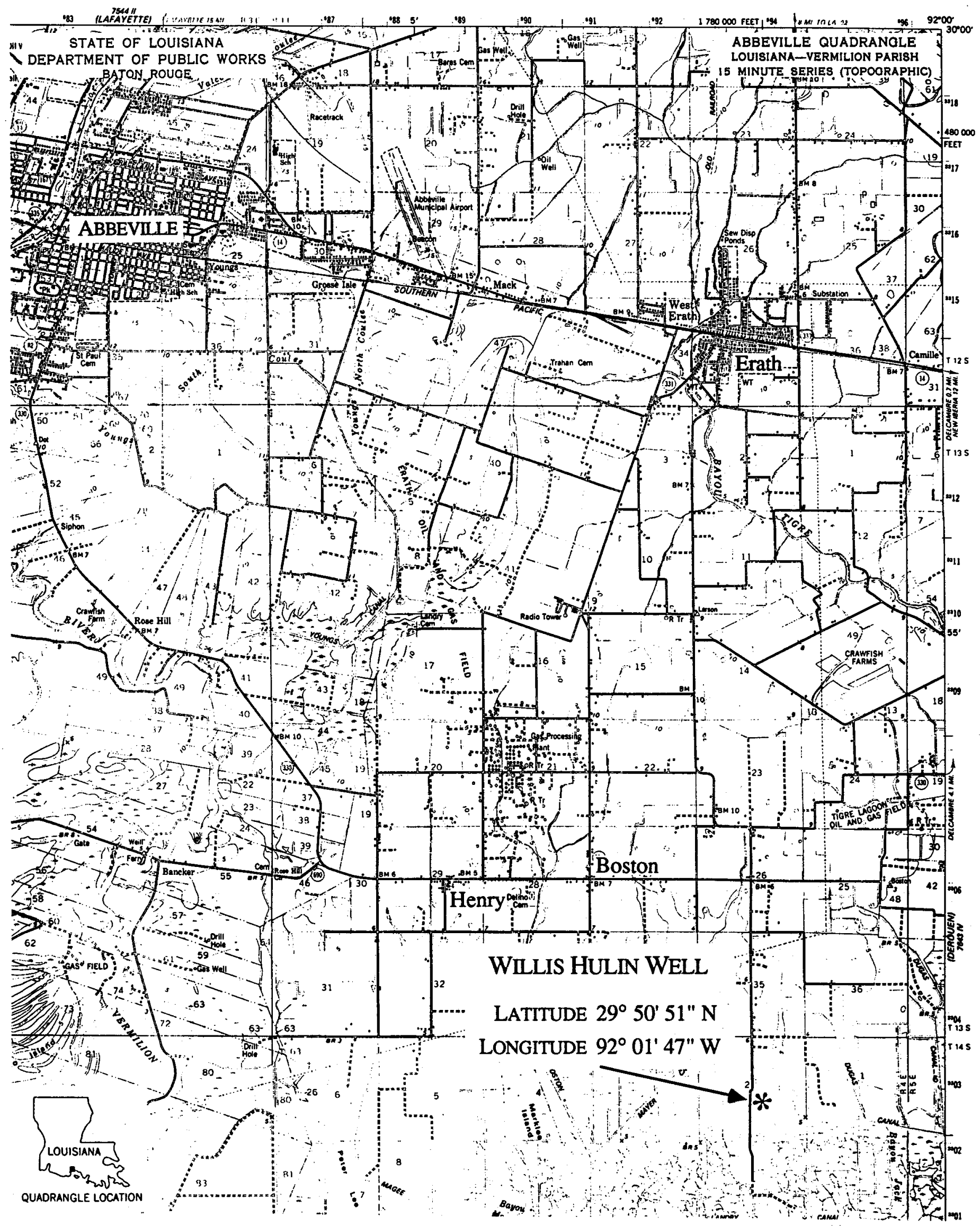

Exhibit 1.0-1. LOCATION OF THE WILLIS HULIN WELL

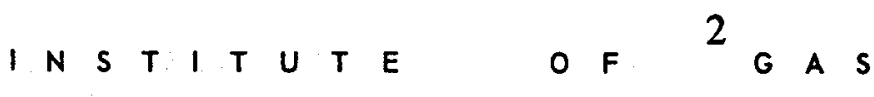


FLOW TESTS OF THE WILLIS HULIN WELL

FINAL REPORT JANUARY 1992

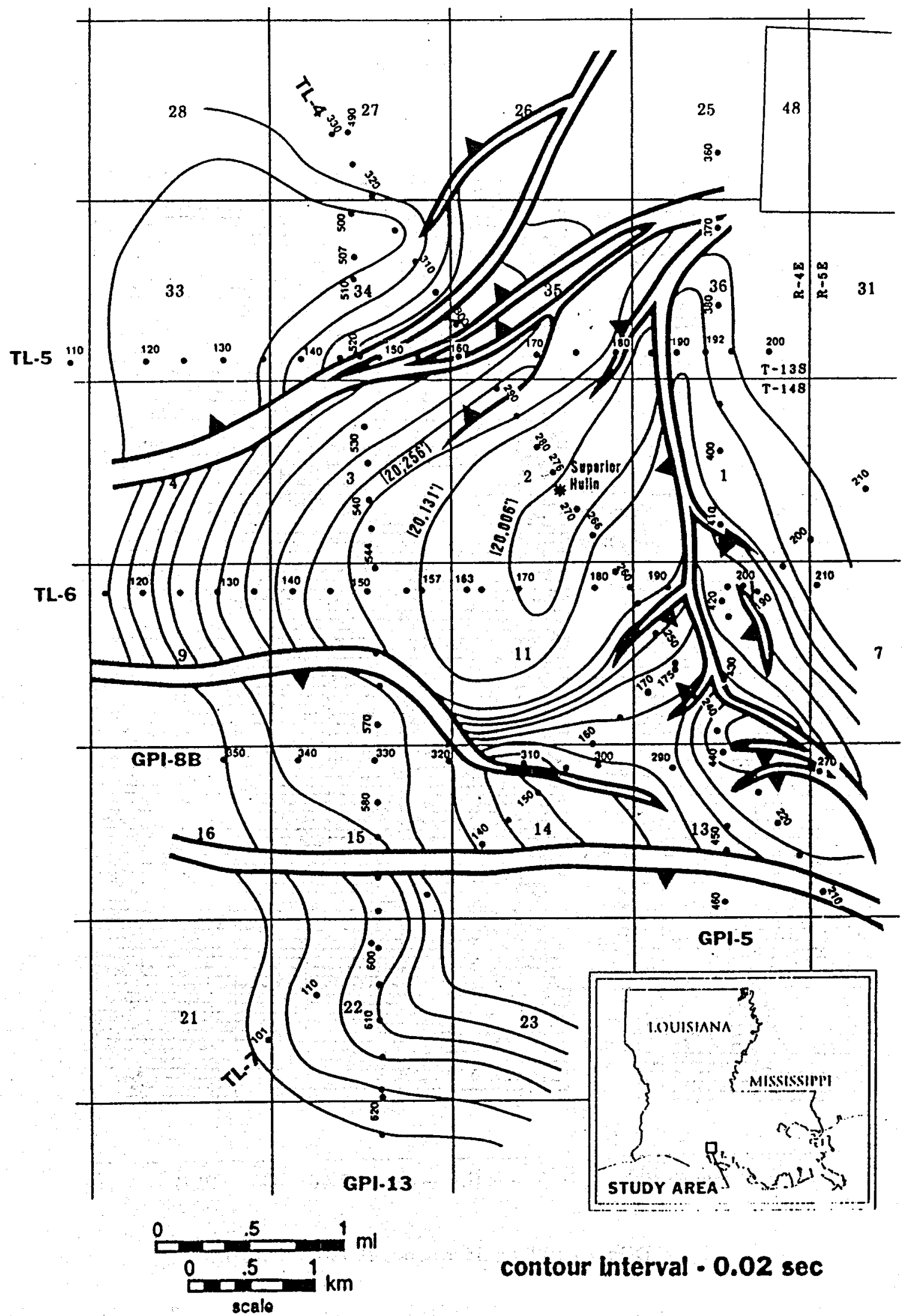

Exhibit 1.0-2. STRUCTURE MAP FOR THE SAND OF INTEREST 
Superior 1-Hulin

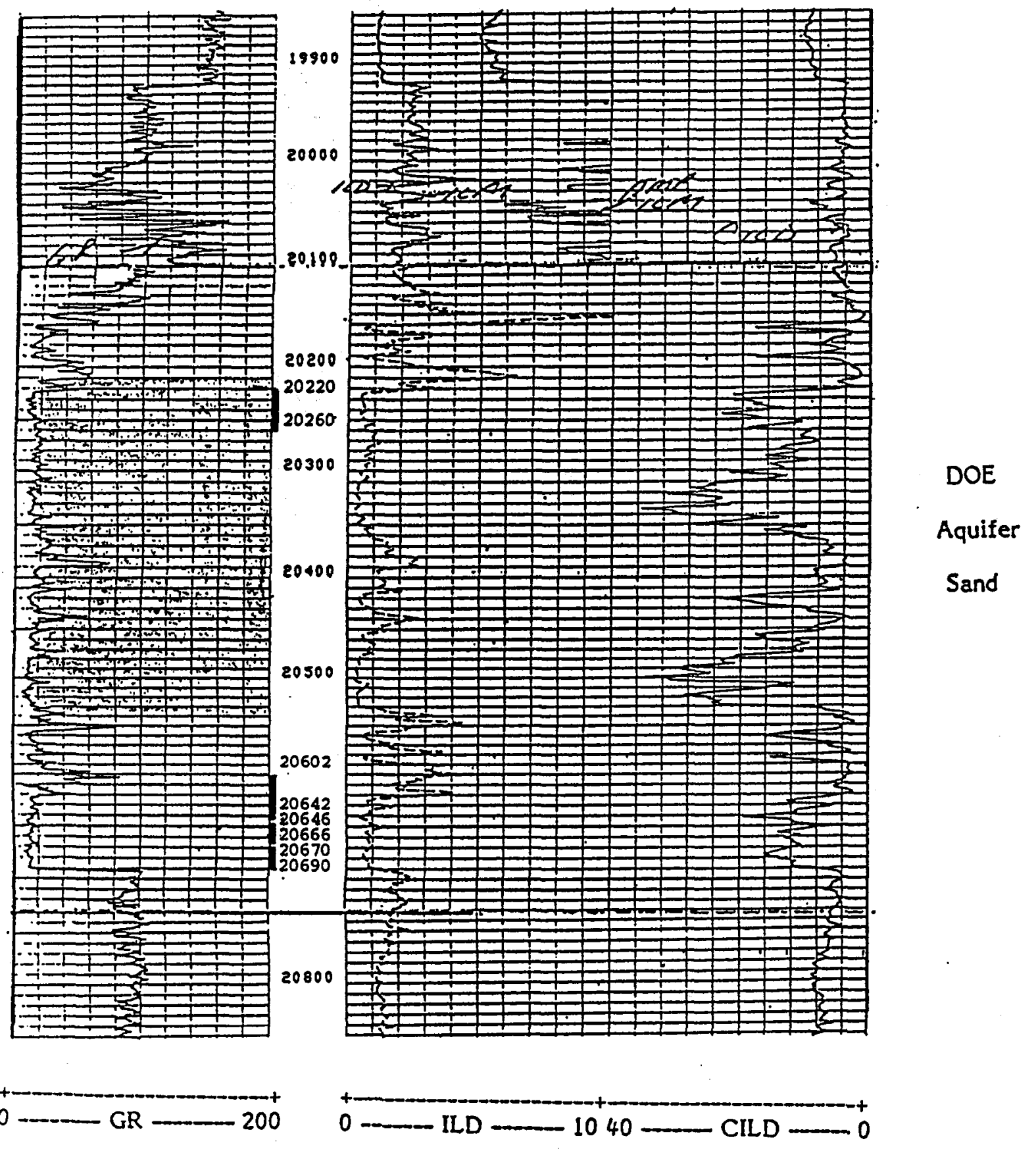

DOE 20,100' aquifer sand, 1" ISF/SONIC Log

Exhibit 1.0-3. LOG OF THE 20,000 TO 20,700-FOOT ZONE OF THE HULIN WELL 


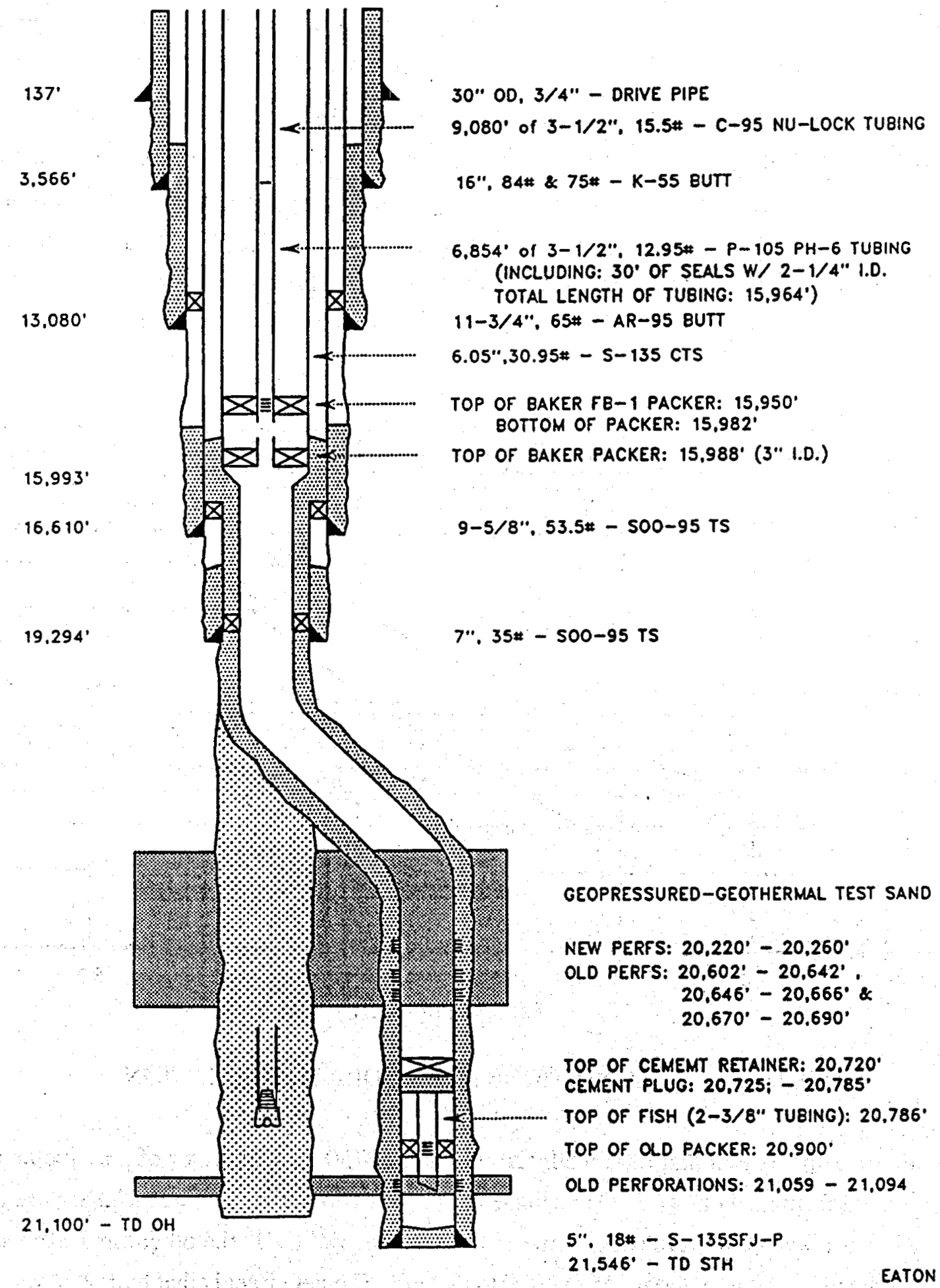

Exhibit 1.0-4. SCHEMATIC DIAGRAM OF WELL COMPLETION, JANUARY 1990 


\subsection{Conditions for Hydrate Formation}

Before perforating, it was recognized that hydrate formation could be a severe problem in the Hulin wellhead. Hydrate formation would result in blockage of the tubing or seizing of a wireline.

A gas hydrate is a compound of methane and water that freezes into an ice-like structure at temperatures well above $32^{\circ} \mathrm{F}$ if pressure is in excess of about $400 \mathrm{psi}$. The temperature at which the hydrate forms increases with increasing pressure. To help understand this potential problem at Hulin, Exhibit 1.1-1 was prepared from the graphs in Chapter 5 of The Handbook of Natural Gas Engineering. ${ }^{3}$ This exhibit shows the hydrate-formation points for pure methane in pure water and the effects of salt in the water and higher hydrocarbons in the gas, as applicable to the Hulin situation.

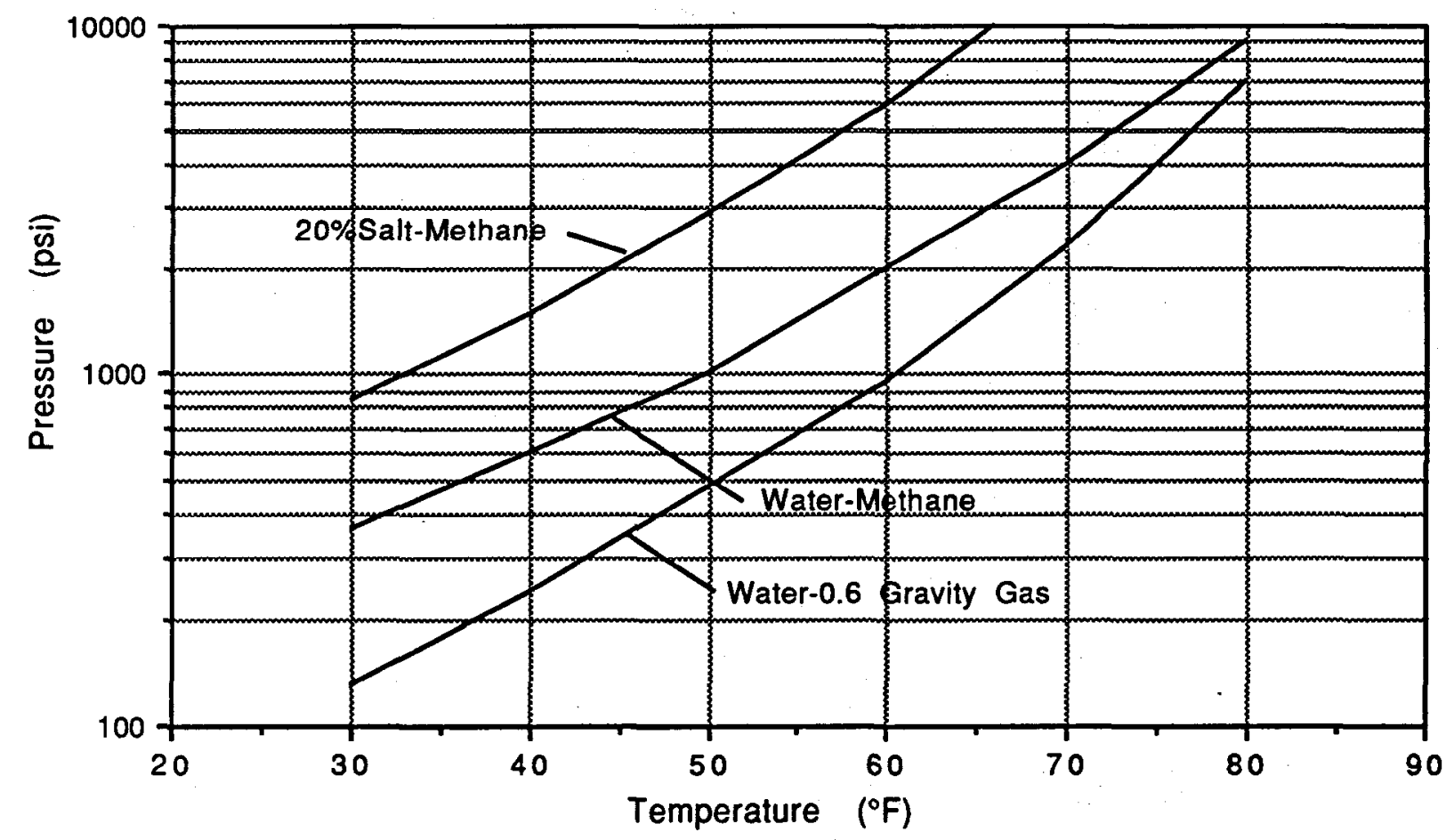

Exhibit 1.1-1. CONDITIONS FOR HYDRATE FORMATION

Note from the exhibit that for a wellhead pressure of $7500 \mathrm{psi}$, hydrates of pure methane in pure water will form at about $78^{\circ} \mathrm{F}$. The ethane and other hydrocarbons in the gas that raise the gas gravity will shift the equilibrium curve some $3^{\circ}$ to $5^{\circ} \mathrm{F}$ to the right. On the other hand, $20 \%$ salt in the brine will shift the curve about $15^{\circ}$ to $18^{\circ} \mathrm{F}$ to the left. The net effect is that hydrates were expected to form when the temperature in the wellhead or tubing near the surface dropped below a 
value somewhere in the range of $60^{\circ}$ to $78^{\circ} \mathrm{F}$, depending on the particular salinity of the brine and composition of the gas in the wellbore.

A temperature $\log$ that had been run on January 15,1989 , indicated a temperature of $70^{\circ} \mathrm{F}$ at 870 feet and $80^{\circ} \mathrm{F}$ at 1840 feet. There may well be a span of several hundred feet from the ground surface where hydrates can form at the shut-in wellbore pressure. In winter, hydrate-forming conditions are expected at the surface. But in summer, the first few tens of feet may have a temperature too high for hydrates. Nevertheless, a hydrate plug might still form at a depth of several hundred feet. If there is a gas cap on top of the brine in the upper portion of the wellbore, water might possibly evaporate and reflux in the tubing such that hydrates of pure water and gas will form rather than hydrates of brine and gas. The hydrates of pure water and methane will form at higher temperatures.

The temperature for onset of hydrate formation may be suppressed by up to about $20^{\circ} \mathrm{F}$ with an injection of an antifreeze such as methanol or glycol, which will mix with the brine. Even greater protection can be provided by displacing the water to a greater depth with a light oil such as diesel, which will float on the brine.

\subsection{Sequence of Test Activities}

Flow testing of the Hulin well was initiated in February 1989 with the cleanup of the first zone to be tested by flowing about 800 barrels to tanks. IGT field activity at this time consisted of manual logging of data and collecting samples for laboratory analysis. Also at this time, requests for bids were sent to five well-testing companies for proposals to provide rental test equipment for the short-term flow test. The IGT activity initiated in February 1989 was abruptly curtailed in March, however, because of DOE/EOC budgetary constraints. Field work was resumed in the fall when the new fiscal year monies allowed continuation of the work.

Resumption of field activity in November 1989 started with measurement of shut-in bottomhole pressure, a second cleanup flow of 1000 barrels to tanks, and completion of the disposal well. Production facilities and flow instrumentation were then installed, and instrumented production testing was performed in several steps during December 1989 and January 1990. The overall sequence of events from the first perforations through the end of production testing is summarized in Exhibit 1.2-1.

Production between midnights for each calender day in which there was instrumented production is summarized in Exhibit 1.2-2. A total of 40,163 barrels of brine and 1.205 million SCF of gas was produced through the test facilities in December 1989 and January 1990. 
January 30,1989 : Perforated the interval 20,670 to 20,690 feet with four shots per foot using a $2-1 / 8$ inch Ultrajet through-tubing gun.

February $8 \& 9$, 1989: Cleaned the $17.2 \mathrm{lb} / \mathrm{gal}$ drilling mud from the well by lifting with water pumped through coiled tubing and then flowing about 800 barrels to tanks. (The volume of the well is about 200 barrels.)

November 20, 1989: Measured bottomhole pressure and temperature values of 17,308 psia and $337.9^{\circ} \mathrm{F}$ at 20,600 feet.

November 21, 1989: Flowed 1000 barrels to tanks for additional cleanup of the well before flowing to the production equipment.

November 21 \& 22, 1989: Perforated the disposal well from 6530 to 6590 feet with four shots per foot and 90 degree phasing using a 3-3/8 inch Ultrapac casing gun. Treated the disposal well with 150 barrels of $15 \% \mathrm{HCl}$ to improve injectivity.

December 5, 1998: Ran the bottomhole pressure sensor into the well to stabilize before recording draw-down data. The pressure and temperature at 20,600 feet were measured to be 17,298 psia and $338: 2^{\circ} \mathrm{F}$.

December 6-8, 1989: Produced the well for 36.2 hours with bottomhole pressure being measured.

December 8-10,1989: Recorded 50 hours of bottomhole pressure buildup and then pulled the bottomhole pressure 'sensor from the well.

December $11 \& 12,1989$ : The depth intervals of 20,602 to 20,642 feet and 20,646 to 20,666 feet were perforated with four shots per foot using a magnetically decentralized 1-9/16 inch Schlumburger HD-HMX through-tubing gun carrying 3.2-gram charges.

December $13 \& 14,1989$ : Cleaned up of the new perforations by flowing through the production equipment. Substantial problems were caused by produced debris.

December 17, 1989: The bottomhole pressure sensor was run to 20,525 feet. Extrapolating to 20,600 feet gave values of 17,193 psia and $337.5^{\circ} \mathrm{F}$.

December 17-22, 1989: Produced at a rate of about 2000 BPD for 12 hours and then 4000 BPD for almost 4 days.

December 22-27, 1989: Recorded buildup pressure with the bottomhole pressure sensor until starting out of the well at 06:45 on December 27.

January 2, 1990: Measured bottomhole pressure at 20,525 feet. Extrapolating to 20,600 feet gave a value of 17,126 psia.

January 3, 1990: Perforated the interval from 20,220 to 20,260 feet with four shots per foot using a magnetically decentralized 1-9/16 inch Schlumburger through-tubing gun carrying 3.2-gram Hyperdome charges.

January 4-11, 1990: With the exception of being shut in the night of January 8-9, the well was produced at various rates in the range of 2000 to 5000 BPD. Production from all of the perforations was commingled and bottomhole pressure was not measured.

January 11, 1990: The well was shut in due to freezing in the dark and in the fog at 05:00. Data collection ended when the wellhead valves to the pressure sensors were closed at 07:00. 


\section{Exhibit 1.2-2. SUMMARY OF DAILY PRODUCTION OF BRINE AND GAS}

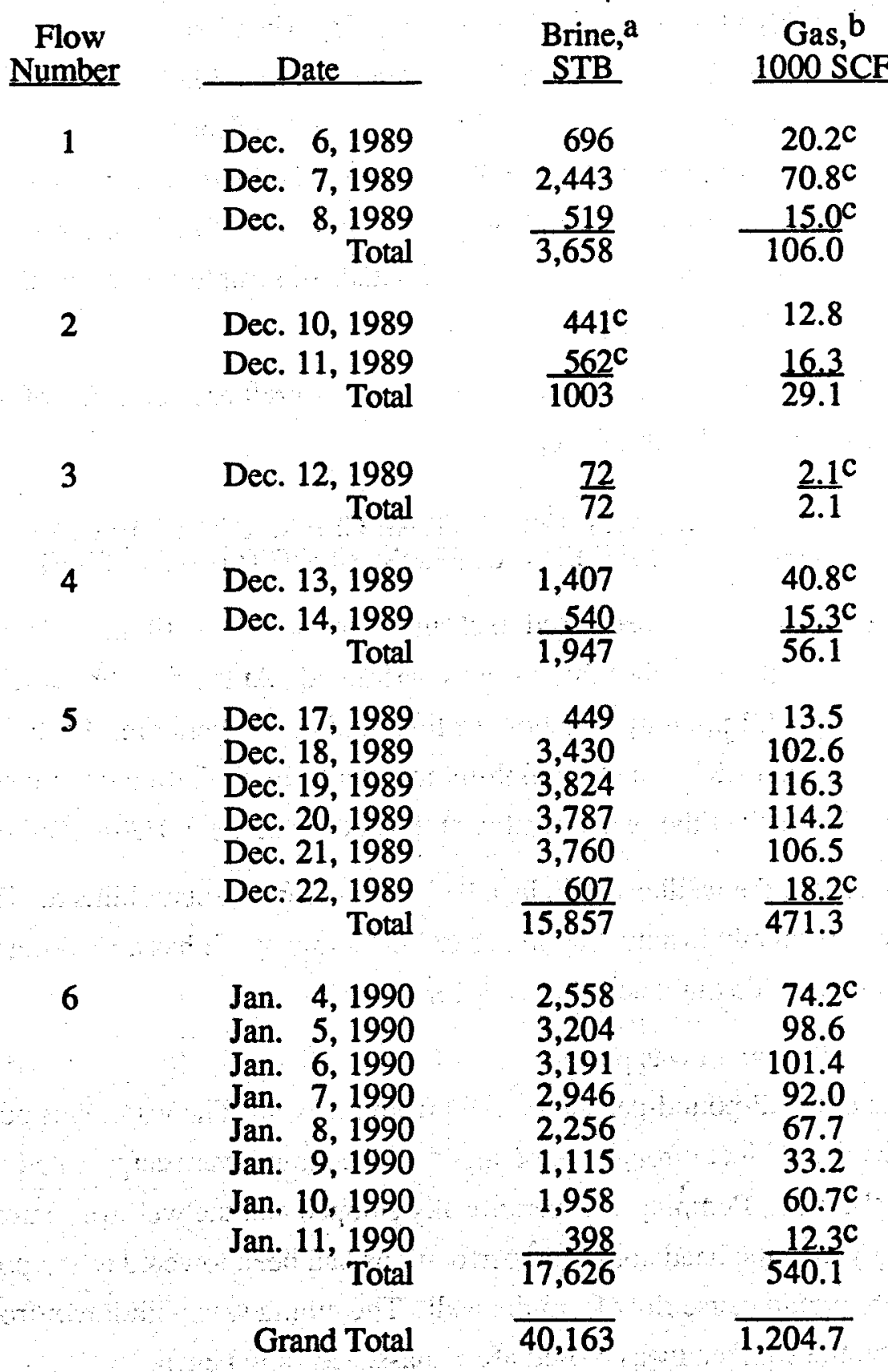

a STB = Stock tank barrel. The volume that the brine would occupy at $60^{\circ} \mathrm{F}$ and 1 atmosphere pressure.

b Gas volume at $60^{\circ} \mathrm{F}$ and 15.025 psia. Tabulated values include a calculated estimate of gas remaining in solution in brine leaving the separator.

c Adjusted value to correct for incomplete or inaccurate data. 
Sections 2 through 4 of this report cover the initial cleanup of the first perforations in February 1989, preparation for testing, and the 36-hour flow test through perforations in the depth interval of 20,670 to 20,690 feet early in December 1989. Then Sections 5 through 7 provide details of perforation, cleanup, and testing for the depth interval 20,602 to 20,690 feet. Section 8 then covers commingling production from the top of the sand of interest $(20,220$ to 20,260 feet) with flow from the deeper perforations, and Section 9 covers the results from analyses of brine and hydrocarbon samples. Sections 10 and 11 of the report provide IGT's conclusions from the work and recommendations for future work. Additional details of sample collection and analysis procedures are provided in Appendixes A and B.

To place the IGT report in better perspective to the overall project, some of the results obtained by others are included in this report.

\subsection{FEBRUARY 1989 INITIAL CLEANUP FLOW FOR}

THE DEPTH INTERVAL FROM 20,670 TO 20,690 FEET

While the drill rig that had been used to clean out the well was still in place, the deepest 20 feet of the 600 -foot-thick sand of interest was perforated. At the time, the reservoir pressure was overbalanced by 17.2-pound-per-gallon drilling mud in the wellbore. Four shots per foot were fired using a 2-1/8 inch Ultrajet through-tubing gun. The limitation on gun size was the 2-1/4 inch inside diameter of the seal assembly at the bottom of the 3-1/2 inch tubing.

After perforating, the wellhead was installed and the rig was demobilized. This is the same wellhead that was originally installed by Superior Oil Company. It has a working-pressure rating of 20,000 psi and an inside diameter of only 1-13/16 inches.

The initial well cleanup was performed on February 8 and 9, 1989. It was done by pumping water to displace the 17.2-pound-per-gallon mud from the well. The water was pumped to a maximum depth of 6500 feet through coiled tubing. The tubing was reciprocated as the mud was circulated from the well. Pumping was periodically stopped and the well was carefully observed to see whether the hydrostatic head above the perforations had been lowered to the point where reservoir pressure would cause flow from the well. The tubing was withdrawn from the well and the swab valve on the wellhead was closed after unassisted flow began.

As the mud unloaded from the wellbore to tanks, the rate was controlled with a rented choke manifold that had two chokes plus a bypass in parallel. It had a working pressure rating of 20,000 psi and was equipped with appropriate valves for switching from one choke to the other.

An annotated wellhead tubing pressure record for the cleanup operation is plotted in Exhibit 2.0-1. Note that the scale of the plot changes by a factor of 100 at 20 hours on the plot. 

$\lambda$
$\begin{array}{llllllll}0 & 7 & O & N & H & 2 & 3 & 1\end{array}$
$S \forall 9$
$\pm 0$
$\exists \perp \cap \perp|1 S N|$

TUBING PRESSURE (pale)

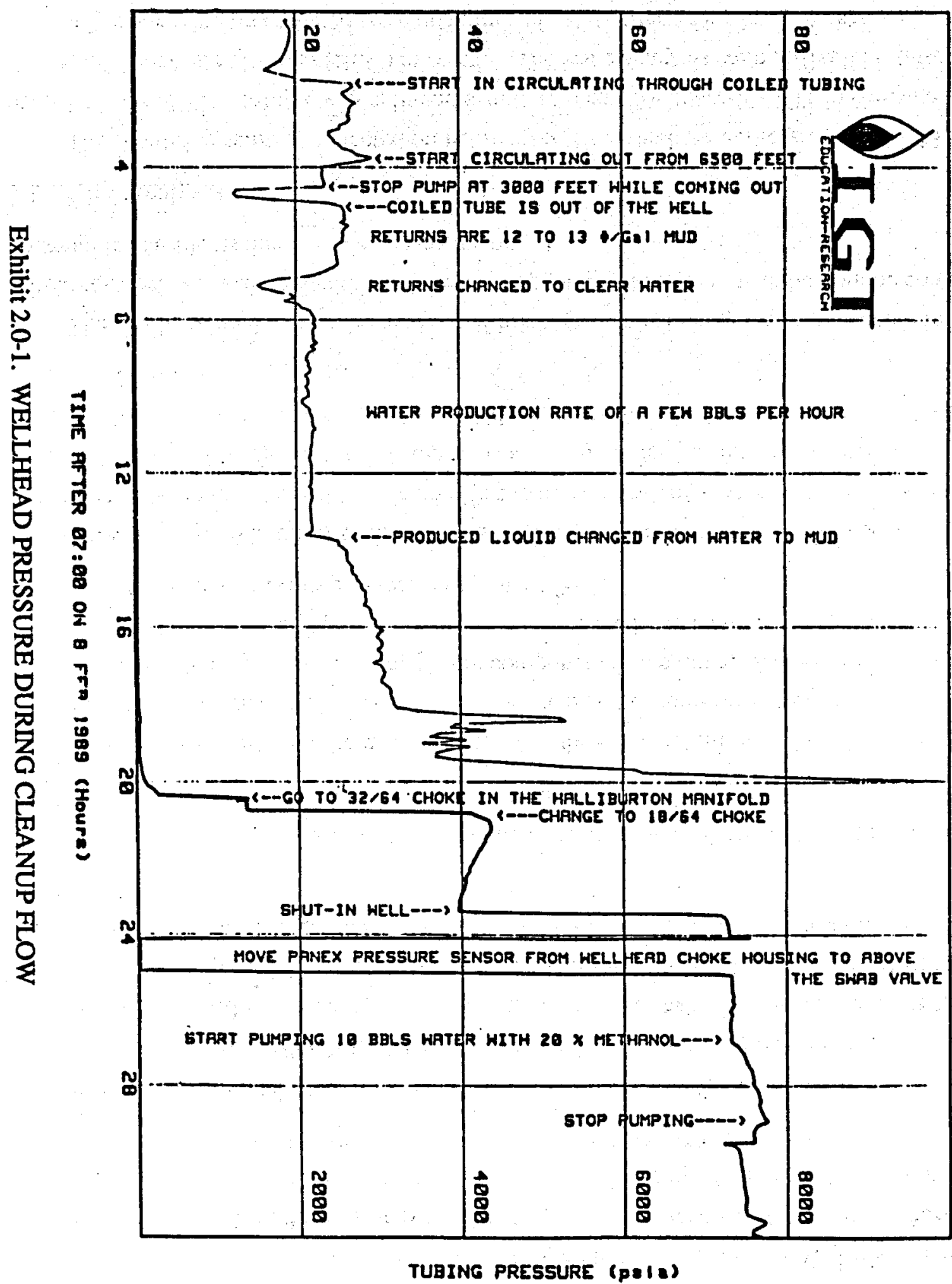


This corresponds to the time of the unloading of mud and the onset of controlled flow rate with the choke manifold. Monitoring of the rate of rise of liquid level in the tanks provided estimates of brine production rate for choke settings of 32/64" and 18/64" after the heavy mud had been produced from the wellbore. The estimated brine rate and measured tubing pressures for each of these choke settings were 10,000 BPD at 1350 psia and 4000 BPD at 4200 psia.

IGT collected three brine samples of 1 liter each while the well was flowing on the 18/64" choke at a rate of about 4000 BPD. The brine was cooled at wellhead pressure in a coil of stainless steel tubing immersed in a bucket of ice water. It then flowed through a needle valve into a sample bottle that was being flushed with carbon dioxide. This provided samples that stayed clear without precipitation. The specific gravity of the brine was 1.132 , corresponding to a salinity of roughly 200,000 ppm.

A Draeger (length-of-stain) tube measurement of hydrogen sulfide in the head space of the frac tank receiving the brine indicated a concentration of less than $5 \mathrm{ppm}$.

An hour and a half after the well was shut in at the choke manifold, a sample of gas that had been liberated from brine in the wellbore was collected at the wellhead at a pressure of 7300 psi. The minimum working-pressure rating of any component of the tubing and valve arrangement for sample collection was 11,500 psi. The sample was collected into a previously evacuated $750-\mathrm{ml}$ sample vessel with a working-pressure rating of $12,000 \mathrm{psi}$.

Between 3 and 6 hours after the well was shut in, 10 barrels of a mixture of $20 \%$ methanol in water was pumped into the wellbore in an effort to avoid problems due to hydrate formation. After the pumping, it was recognized that a communication failure had resulted in the methanol being mixed with fresh water. As a result, it provided less protection against hydrates than the salinity of the produced brine.

The results of analyses of the samples of brine, gas, and condensate are presented in the subsections below. The implications of the cleanup data will be examined there in the context of potential for problems due to scale and corrosion.

\subsection{Brine Analyses}

The first brine sample, collected on February 9, 1989, had a specific gravity of 1.132 measured onsite. The sample was split and sent to two labs for analysis: IGT in Chicago and the Bureau of Economic Geology (BEG) in Austin. The brine analyses were difficult because the originally clear brine precipitated large quantities of solids after a few days. As shown in Exhibit 2.1-1, both analyses found large quantities of dissolved solids and a high concentration of calcium. Although the two analyses were similar, there was variation between the two laboratories 
EXHIBIT 2.1-1. BRINE ANALYSIS: 2/9/89 WELLHEAD CLEANUP SAMPLE

\begin{tabular}{lrr} 
Laboratory & IGT & BEG \\
Component & $\mathrm{mg} / \mathrm{L}$ & $\mathrm{mg} \mathcal{L}$ \\
\hline Acetic Acid, by GC/MS & 51 & - \\
Alkalinity, as $\mathrm{CaCO}_{3}$ & 690 & 32 \\
Alkalinity, as $\mathrm{HCO}_{3}$ & 842 & - \\
Barium & 110 & 180 \\
Bromide & -- & 76 \\
Calcium & 19,400 & 16,830 \\
Cadmium & -- & 0.5 \\
Chloride & 115,000 & 115,400 \\
Fluoride & - & 2.1 \\
Iodide & $<20$ & 12 \\
Iron & 410 & 415 \\
Lithium & 67 & 29 \\
Magnesium & 1,000 & 892 \\
Manganese & 62 & 56 \\
Potassium & 720 & 420 \\
Silica, as SiO2 & 96 & 150 \\
Strontium & 880 & 1,020 \\
Sodium & 48.800 & 52.220 \\
Total Dissolved Solids & 194,000 & 201,600 \\
Specific Gravity @ $60^{\circ} \mathrm{F}$ & 1.134 & 1.134
\end{tabular}

for individual elements that could be traced to precipitation problems. After a few weeks on the shelf, the samples had the appearance of a very thin mud. This led to sampling and analytical procedural changes that successfully prevented precipitation problems in sample analysis during the subsequent flow tests.

\subsection{Hydrocarbon Analyses}

The quantity of gas that bubbled to the wellhead after shutting in the well was consistent with the amount that would be expected if the brine in the wellbore contained between 20 and 50 cubic feet of gas per barrel of brine. A gas sample was collected on February 9 after the well was shut in 
by bleeding a sample of this gas into a previously cleaned and evacuated high-pressure Ruska cylinder. The wellhead pressure was near 7300 psig when the sample was collected.

Gas and a very light oil or condensate were observed leaking from a seal on the Ruska cylinder the following morning. This leak resulted in the need to accelerate the analytical process. IGT and Chromaspec personnel flashed the sample during the morning of February 9, collecting both a gas and a condensate fraction. The sample pressure was over 5000 psig prior to flashing the sample from the Ruska cylinder, indicating that very little of the sample had been lost. There were about 10 barrels of condensate per million cubic feet of gas, and the dew-point pressure was estimated to be below $3000 \mathrm{psig}$. A portion of the gas and a portion of the condensate were sent to IGT. Results of the gas and condensate analyses are tabulated in Exhibit 2.2-1 below.

There was over $4 \%$ carbon dioxide in the gas sampled from the wellhead, which indicated that at lower separator pressures the carbon dioxide content could exceed $15 \%$. The hydrocarbon distribution had a strange characteristic. Normal dry gases usually contain a small quantity of ethane and an even smaller quantity of heavier components, following a declining logarithmic distribution. This gas had this typical dry gas distribution through heptanes (C7). The trend then reversed and the quantity of these heavy hydrocarbons began increasing, reaching a peak between $\mathrm{C} 10$ and $\mathrm{C} 17$ hydrocarbons. These heavy hydrocarbons also comprised the liquids that were condensing from the gas phase.

The Hulin condensate was considerably different from the Pleasant Bayou condensate. The Hulin condensate was composed almost exclusively of $\mathrm{C} 11$ to $\mathrm{C} 16$ alkanes and contained less than $5 \%$ by weight of ring-type compounds such as benzene, naphthalene, and their derivatives. By comparison, the Pleasant Bayou condensate averaged about $70 \%$ ring-type compounds. Aromatic compounds are much more soluble in water than are the comparable alkanes. The Pleasant Bayou condensate is dissolved in the brine at reservoir conditions. The Hulin well condensate, on the other hand, probably existed in a gas phase at reservoir temperature and pressure.

This Hulin distribution of hydrocarbons shows a conspicuous lack of $\mathrm{C} 4$ to $\mathrm{C} 9$ hydrocarbons and the C18-plus hydrocarbons. This type of distribution could be obtained by spiking a dry gas with diesel oil. This hypothesis was reached independently by both IGT and Core Lab personnel. Black Magic and other diesel drilling fluids were believed to be left in the hole when the well was sidetracked. This may be the source of the observed condensate, although the data were not conclusive.

\subsection{Potential for Problems Due to Scale and Corrosion}

The data obtained in conjunction with the cleanup flow provided a basis for evaluation of the potential for problems due to scale and corrosion. In order to minimize costs, this was approached 
FLOW TESTS OF THE WILLIS HULIN WELL

FINAL REPORT JANUARY 1992

Exhibit 2.2-1. HYDROCARBON ANALYSES: 2/8/89 WELLHEAD CLEANUP SAMPLE ${ }^{a}$

\begin{tabular}{|c|c|c|c|}
\hline $\begin{array}{l}\text { Laboratory } \\
\text { Component }\end{array}$ & $\begin{array}{r}\text { Chromaspec } \\
\text { Hulin Gas }\end{array}$ & $\begin{array}{r}\text { IGT-Chicago } \\
\text { Hulin Gas }\end{array}$ & $\begin{array}{r}\text { IGT-Chicago } \\
\text { Hulin Oil }\end{array}$ \\
\hline Helium & - & 0.003 & \\
\hline Hydrogen & 0.11 & 0.13 & - \\
\hline Nitrogen & 0.33 & 0.24 & - \\
\hline Carbon Dioxide & 4.31 & 4.12 & \\
\hline Methane & 93.09 & 93.20 & Trc \\
\hline Ethane & 2.04 & 2.03 & $\operatorname{Trc}$ \\
\hline Propane & 0.11 & 0.12 & $\operatorname{Trc}$ \\
\hline iso-Butane & 0.01 & 0.008 & Trc \\
\hline n-Butane & 0.01 & 0.007 & Trc \\
\hline iso-Pentane & $\operatorname{Trc}^{\mathrm{b}}$ & 0.003 & 0.01 \\
\hline$n$-Pentane & $\operatorname{Trc}$ & 0.001 & \\
\hline neo-Pentane & 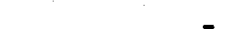 & 0.0001 & \\
\hline Hexanes & $\operatorname{Trc}$ & 0.002 & 0.01 \\
\hline Heptanes & $\operatorname{Trc}$ & 0.002 & 0.03 \\
\hline Octanes (C8) & Trc & 0.002 & 0.08 \\
\hline Nonanes & Trc & 0.003 & 0.32 \\
\hline Decanes (C10) & Trc & 0.009 & 1.88 \\
\hline Undecanes & & 0.024 & 8.92 \\
\hline Dodecanes (C12) & & 0.025 & 17.50 \\
\hline Tridecanes & & 0.025 & 21.24 \\
\hline Tetradecanes (C14) & & 0.014 & 17.07 \\
\hline Pentadecanes & & 0.013 & 12.40 \\
\hline Hexadecanes (16) & & 0.006 & 7.22 \\
\hline Heptadecanes & & 0.004 & 4.48 \\
\hline Octadecanes (C18) & & 0.003 & 2.48 \\
\hline Nonadecanes & & 0.002 & 1.00 \\
\hline Eicosanes $(\mathrm{C} 20)$ & & 0.001 & 0.38 \\
\hline Heneicosanes & & 0.001 & 0.15 \\
\hline Docosanes (C22) & & 0.001 & 0.06 \\
\hline Tricosanest & & 0.001 & 0.05 \\
\hline Benzene & & 0.013 & 0.10 \\
\hline Toluene & & 0.004 & 0.27 \\
\hline C2 Benzenes & & 0.003 & 0.10 \\
\hline C3 Benzenes & & 0.006 & 0.81 \\
\hline Naphthalenes & & 0.004 & 0.06 \\
\hline C1 Naphthalenes & & 0.007 & 0.23 \\
\hline C2 Naphthalenes & & 0.004 & 2.27 \\
\hline C3 Naphthalenes & & $<0.001$ & 0.84 \\
\hline
\end{tabular}

a Gas analyses are in mole percent. Condensate analysis is in weight percent.

b $\operatorname{Trc}=$ Trace, or less than $0.01 \%$. 
from the perspective of defining constraints upon flow testing so that inhibitors would not be needed upstream of the choke. Chemical treatment for corrosion and scale would be performed only after the produced fluids had passed through the wellhead.

\subsubsection{Scale}

A preliminary examination of the scaling tendency was performed by using the Oddo and Tomson Saturation Index. ${ }^{5}$ In the absence of an inhibitor, scale formation is generally expected to start at a value of about 1.0 to 1.4 for the saturation index (SI). Scale inhibitors cease to be effective for values of SI above about 2.3. To minimize possible systematic errors from application of the scale index on a well having reservoir temperature and pressure higher than the range for which it has been validated, the $\Delta$ SI nomographs for the effects of changes in pressure and temperature were used. These nomographs assume that the produced brine is in equilibrium with calcium carbonate in the reservoir.

The observed wellhead pressure of 7300 psi was used to estimate a value of 16,800 psi for the reservoir pressure. A value of $340^{\circ} \mathrm{F}$ was used for reservoir temperature on the basis that the value of $336^{\circ} \mathrm{F}$ measured in January 1989 was probably still depressed due to mud circulation. Brine-rate dependent values for flowing wellhead pressure were estimated by using runs of a single-phase tank model simulator that includes flowing friction to approximate shut-in and flowing values estimated for the cleanup flow (7300 psi at zero flow rate, $4200 \mathrm{psi}$ at a rate of about 4800 barrels per day). A high value for the skin factor (about 10) was essential to obtain a credible match to the data. Estimates of the equilibrium wellhead temperature as a function of flow rate were provided by Dr. Riney of S-Cubed on the basis of runs of the S-Cubed "WELBOR" model. 8 Plots of these approximations to the flowing pressure and temperature are shown below in Exhibit 2.3.1-1 and the values for the carbonate saturation index from the nomographs are shown in Exhibit 2.3.1-2.

These results indicated that scale formation in the wellhead would become a problem for a brine rate above a value somewhere in the range of 4000 to 6000 barrels per day. But it was recognized that a period of days would be required to reach the equilibrium temperature used in the calculations.

Temperature sensitivity of the saturation index was examined using the equation published by Matty et al. 6 and the values for chemical composition that were measured in conjunction with the end of the February 1989 cleanup flow. These were 1) total dissolved solids, $200,000 \mathrm{mg} / \mathrm{L}$; 2) calcium, $19,000 \mathrm{mg} / \mathrm{L}$; 3) carbon dioxide content of gas, 4.4\%; and 4) alkalinity, $660 \mathrm{mg}$ $\mathrm{HCO}_{3} / \mathrm{L}$. Calculated values for the saturation index were about 0.8 higher than deduced using the $\Delta$ SI nomographs. The high values are assumed to result from a systematic error because the 


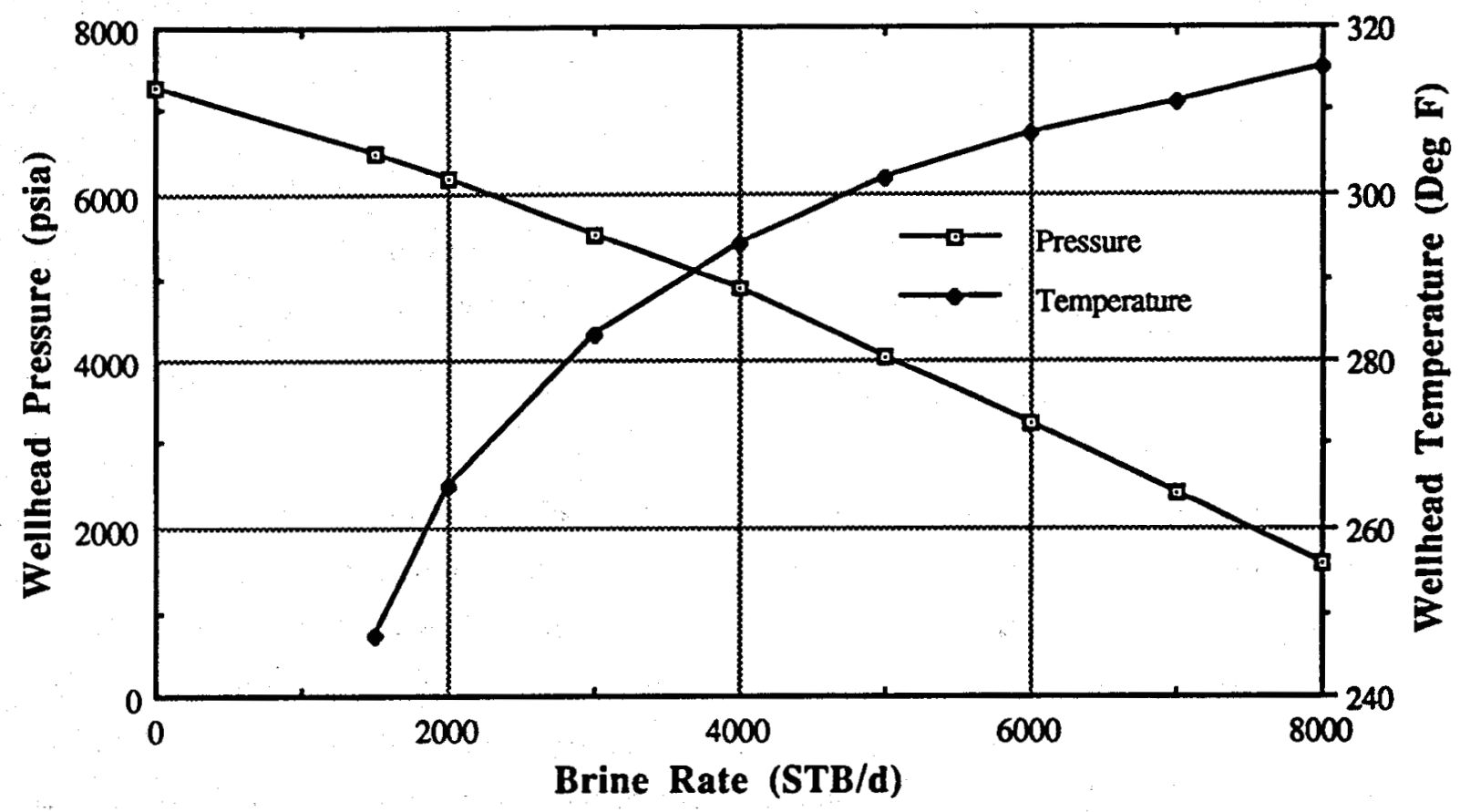

EXHIBIT 2.3.1-1. APPROXIMATIONS TO WELLHEAD PRESSURE AND TEMPERATURE

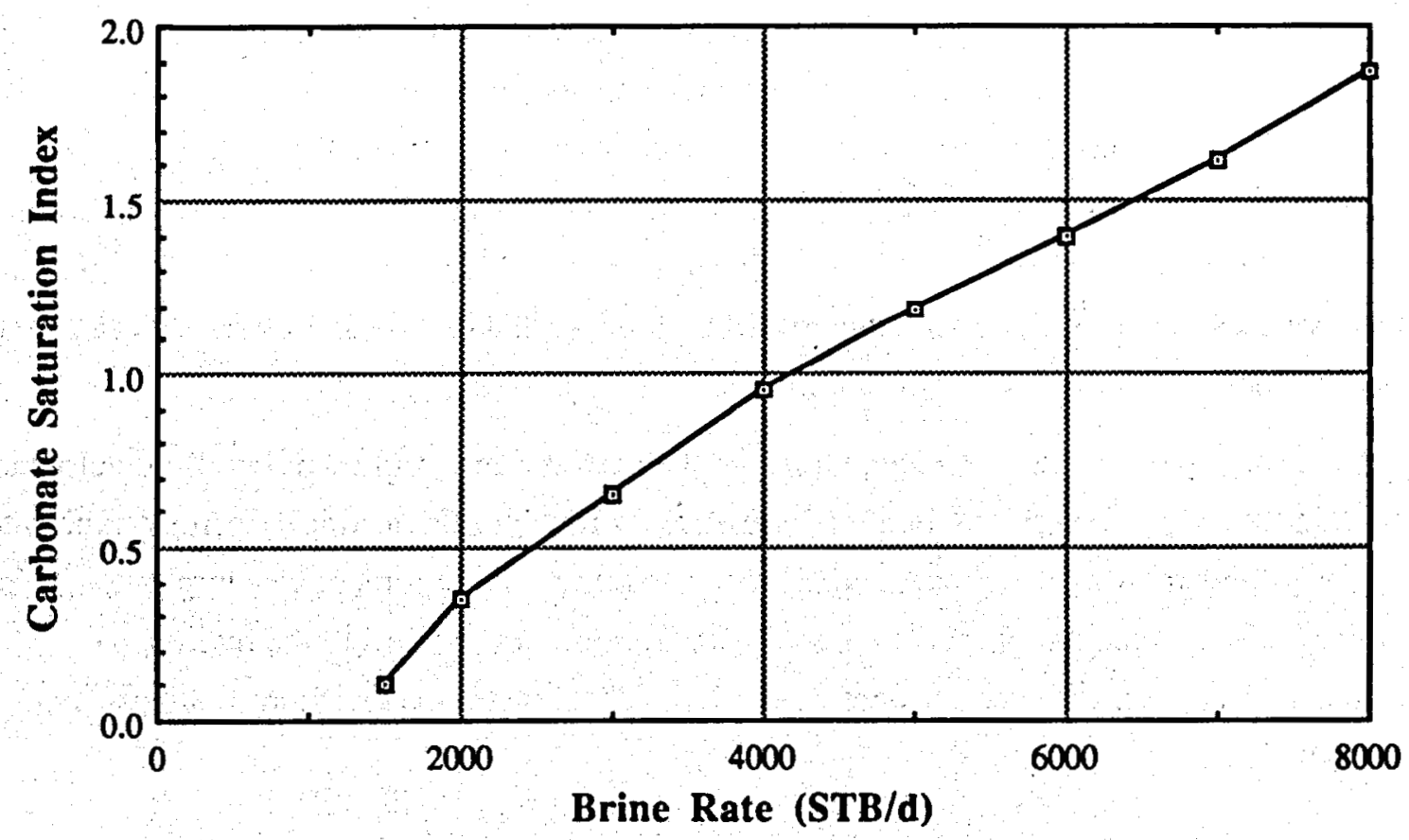

Exhibit 2.3.1-2. WELLHEAD SATURATION INDEX AS A FUNCTION OF BRINE RATE 
calculated value for reservoir pressure and temperature is about 1.0 rather than zero. Nevertheless, the calculation provides the useful estimate that the saturation index increases about 0.13 for each $10^{\circ} \mathrm{F}$ increase in temperature.

In practice, the rates during the subsequent flow tests were chosen such that there should be no scaling in the producing well. Scale inhibitor was injected into the flow line just upstream of the wellhead choke. No scale deposition on piping was observed during the test. But it is possible that that calcite precipitation was the reason for increasing injection pressure on the disposal well.

\subsubsection{Corrosion}

Corrosion in the wellbore tubulars was a also significant concern. The first gas and brine samples from the February 1989 cleanup flow contained 0.11 mole percent hydrogen gas and $410 \mathrm{mg} / \mathrm{L}$ iron, respectively. Hydrogen gas is a by-product of the corrosion of iron. Iron in the brine is also a by-product of corrosion, although some iron is naturally present in the brine. Finally, the high partial pressure of carbon dioxide at wellhead conditions also suggested corrosion could be a problem. The rule of thumb is that a carbon dioxide partial pressure greater than 5 psia could result in corrosion. The partial pressure of carbon dioxide at the wellhead after the February 1989 cleanup flow was 300 psia. These early warning signs suggested that corrosion could be severe.

IGT experience at the Gladys McCall well had shown that brine rates in excess of 10 feet per second resulted in greatly accelerated corrosion rates in carbon steel piping. The flow velocity for gas-free brine in the tubing is 10 feet per second at a brine rate of 5680 barrels per day. The velocity of 10 feet per second is reached in the 1-13/16 inch-inside-diameter wellhead components at a brine rate of only 3000 barrels per day. Because the steels used to fabricate both the tubing and the wellhead have greater resistance to carbon dioxide that carbon steel, exceeding 10 feet per second by modest amounts was not of concern.

In reality, the low flow efficiency through the perforations resulted in low flow velocities during the test and lower-than-anticipated pressure for much of the testing. Corrosion inhibitor was injected upstream of the choke, and corrosion-monitoring equipment was in place at several locations in the surface facilities. The iron concentration in the brine and the hydrogen concentration in the produced gas were monitored. There were no corrosion problems during these short tests. 


\subsection{PREPARATIONS FOR TESTING OF THE DEPTH INTERVAL FROM 20,670 TO 20,690 FEET}

As discussed earlier, this depth interval was perforated at the end of January 1989, and the 17.2-pound-per-gallon drilling mud was flowed from the well to tanks on February 8 and 9, 1989. The well was then shut in because of budgetary constraints after pumping 10 barrels of a mixture of $20 \%$ methanol in fresh water into the wellhead. This volume displaced the top of produced brine down to a depth of about 1500 feet.

During August 1989, attempts to measure bottomhole pressure were not successful. Actions taken at the time and the subsequent success in measuring bottomhole pressure in November 1989 are described under the first subheading below. Actions taken to complete the disposal well are discussed under the next subheading.

\subsection{Possible Hydrate Problems and Measurement of Bottomhole Pressure}

An attempt to measure bottomhole pressure on August 17,1989, was not successful because the tool would not go down the tubing. Definitive data on the role of hydrates do not exist. But, as discussed earlier, hydrate-forming conditions may well have existed to a depth in excess of 1000 feet. A chronological log of relevant activities through August follows:

2/10/89: Injected 10 barrels of fresh water containing $20 \%$ methanol after the cleanup flow of 809 barrels of mud and formation brine at rates up to 10,000 BPD.

8/17/89: An attempt to run a BHP encountered an obstruction in the wellbore at a depth of 268 feet. Two drums (110 gallons) of methanol were injected while reciprocating the wireline tools on top of the obstruction. The BHP system would not pass the obstruction.

8/21/89: A 0.92-inch slick line carrying a 1-11/16 inch-diameter bar was run to 16,000 feet.

8/22/89: No down-hole work was done because the BHP computer failed.

8/23/89: The following data were recorded while tripping in with the BHP tool.

\begin{tabular}{|c|c|c|}
\hline $\begin{array}{l}\text { Depth, } \\
\text { feet }\end{array}$ & $\begin{array}{l}\text { Pressure, } \\
\text { psi }\end{array}$ & $\begin{array}{c}\text { Temperature, } \\
{ }_{\mathrm{OF}}\end{array}$ \\
\hline 45 & 7486 & 81.2 \\
\hline 85 & 7501 & 81.4 \\
\hline 119 & 7529 & 80.8 \\
\hline 155 & 7557 & 79.2 \\
\hline 194 & 7579 & 77.4 \\
\hline 234 & 7599 & 75.9 \\
\hline 255 & 7689 & 74.8 \\
\hline 260 & 7685 & 73.9 \\
\hline
\end{tabular}


Note that these data give a calculated pressure gradient of $0.925 \mathrm{psi} / \mathrm{ft}$ in the wellbore between 45 and 260 feet. One possible reason for this high gradient is that a deeper solid plug of hydrates existed in the well so that the shallower pressures were low because of fluid loss from above the plug while rigging the wireline lubricator. Also, the volume occupied by wireline entering the wellbore would cause the deeper pressures to be higher if a hydrate plug existed below the greatest depth of wireline penetration.

Five (5) drums (275 gallons or 6.55 barrels) of methanol were injected while working the wireline. But the deepest wireline tool penetration was 285 feet. The capacity of the 15.5-pound-per-foot, 3.5 -inch tubing is $0.00659 \mathrm{barrel} / \mathrm{ft}$. Thus, this amount of methanol was enough to fill 994 feet of tubing.

8/24/89: The wellhead pressure and temperature were 7577 psia and $80.2^{\circ} \mathrm{F}$. The Cooke wireline again tagged up at 285 feet.

An 18-foot-long slick line assembly consisting of 1-1/2 inch bars with a 1.60 -inch-gauge ring went to 400 feet with no problem. In contrast, the Cooke assembly that would not go below 285 feet was 60 feet long with a diameter of 1-11/16 inches and contained two knuckle joints.

Injection of triethylene glycol was started but ended abruptly after 80 gallons because the injection pressure suddenly went up to more than 10,000 psi.

No problems were encountered when a surface-reading Panex bottomhole pressure gauge was used to measure bottomhole pressure on November 20, 1989. A 48-foot-long assembly containing two knuckle joints was run into the well. Stops were made at 500-foot intervals down to 2000 feet to get stabilized temperature data relevant to hydrate formation in the wellbore. Then the gauge was run to an indicated depth of 20,670 feet (depth of the shallowest perforation) without stopping. The gauge was in a viscous mud-like fluid and pulled free at an indicated depth of 20,640 feet. This viscous material is presumed to be partially congealed residual drilling mud. Inability to push this material into the formation may be the reason that triethylene glycol injection had to be terminated when injection pressure became excessive on August 24, 1989.

The deepest stabilized pressure, 17,308 psia, was recorded with the Panex sensor at a depth of 20,600 feet. Stabilized pressures were then recorded with the Panex sensor at additional depths of $20,000,19,000,18,000,17,000,15,000$ feet, and in the lubricator, on the way out of the well. In chronological order, the recorded stabilized pressures and temperatures are given in Exhibit 3.1-1.

The variations in pressure gradient in the first 2000 feet are due to different fluids that had been pumped into the well in August to combat hydrate formation. Assuming plug displacement and no mixing, from the top down those fluids would be 290 feet of triethylene glycol, 1400 feet of methanol, and 1500 feet of an $80 \% / 20 \%$ fresh water-methanol mixture. Below 3200 feet the fluid in the wellbore should be produced brine. 
Exhibit 3.1-1. DOWN-HOLE PANEX GAUGE MEASUREMENTS ON 11/20/89

$\begin{array}{rcccc}\begin{array}{c}\text { Depth, } \\ \mathrm{ft}\end{array} & \begin{array}{c}\text { Pressure, } \\ \text { psia }\end{array} & \begin{array}{c}\text { P Gradient, } \\ \text { psi/ft }\end{array} & \begin{array}{c}\text { Temperature, } \\ \text { of }\end{array} & \begin{array}{c}\text { T Gradient, } \\ \text { oF/100ft }\end{array} \\ 26 & 7,632 & & 61.5 & \\ 500 & 7,841 & 0.442 & 70.7 & 0.32 \\ 1,000 & 8,035 & 0.389 & 76.1 & 1.08 \\ 1,500 & 8,219 & 0.368 & 81.7 & 1.12 \\ 2,000 & 8,439 & 0.439 & 86.4 & 0.94 \\ 20,600 & 17,308 & 0.477 & 337.9 & 1.35 \\ 20,000 & 17,013 & 0.492 & 333.5 & 0.73 \\ 19,000 & 16,519 & 0.494 & 321.0 & 1.25 \\ 18,000 & 16,060 & 0.459 & 306.6 & 1.44 \\ 17,000 & 15,590 & 0.470 & 291.6 & 1.50 \\ 15,000 & 14,653 & 0.469 & 263.1 & 1.43\end{array}$

\subsection{November 21. 1989. Cleanup Flow to Tanks}

The 30 feet of viscous mud-like fluid shallower than the top of the 20-foot perforated interval made another cleanup flow to tanks necessary before production to a separator or to the disposal well. This cleanup took place on November 21, 1989, the day after the BHP measurement. A total of slightly less than 1000 barrels of brine was produced to two (2) frac tanks.

Wellhead pressures are shown in Exhibit 3.2-1. During the first 6 minutes of flow, the choke was opened stepwise to 10/64", 12/64", 14/64", and then 22/64" (choke setting in equivalent bean size) in an attempt to break loose the mud over the perforations and get it moving uphole. At a choke opening of 22/64", the flowing wellhead pressure was $1800 \mathrm{psi}$ for a drawdown of almost $6000 \mathrm{psi}$. After a couple of minutes, the choke opening was reduced in two steps to $18 / 64$ " and the flowing wellhead pressure came to about 3200 psi.

After producing 230 barrels to a 500 -barrel tank, the choke opening was increased to $24 / 64$ " to finish filling the tank. When flow was switched to the second 500-barrel tank, the choke opening was increased to $36 / 64 "$. It was left at that setting until the second tank filled. The choke openings, associated average rates, and flowing wellhead pressures are given in Exhibit 3.2-2.

Prior to bottoms up, the produced liquid was free of foam or surface scum. At bottoms up, a surface scum became apparent. After the two tanks filled, they had about a quarter- to a half-inch layer of floating debris. There was noticeably more on the first tank. The debris was primarily an 


\begin{tabular}{|c|c|c|}
\hline $\begin{array}{l}\text { Choke } \\
\text { Opening }\end{array}$ & $\begin{array}{c}\text { Brine Rate, } \\
\text { STB/d }\end{array}$ & $\begin{array}{c}\text { Pressure, } \\
\text { psi }\end{array}$ \\
\hline $\begin{array}{l}18 / 64^{\prime \prime} \\
24 / 64^{\prime \prime} \\
36 / 64^{\prime \prime}\end{array}$ & $\begin{array}{l}3925 \\
4750 \\
6000\end{array}$ & $\begin{array}{r}3100 \\
1850 \\
735\end{array}$ \\
\hline
\end{tabular}

oil-wet solid that broke down to floating oil and sediment at the bottom of sample bottles after the samples had been at room temperature for a couple of days.

After the cleanup flow, 10 barrels of diesel fuel were pumped into the wellbore to displace the top of brine to below 1500 feet. At this depth, temperature had been found to be above maximum for hydrate formation in the wellbore $\left(80^{\circ} \mathrm{F}\right)$. The amount of diesel injected was large compared to the quantity of condensate recovered in subsequent production tests. The result is large uncertainty in the amount of condensate produced from the formation.

The decision was made to inject 10 barrels of diesel oil into the top of the wellbore before hydrates could form after each flow period. Once the well was under production and the well temperature was raised above $80^{\circ} \mathrm{F}$, hydrates were not expected to form. When the well was shut in long enough to cool off, action was needed to prevent hydrate formation from plugging the well. The diesel pumping was generally held off until 3 hours after the well had been shut in to minimize interference with pressure-buildup tests.

\subsection{Disposal Well Completion}

The disposal well had been drilled with 9-5/8 inch, 43.50-pound-per-foot N-80 SFJP casing cemented to a depth of 6687 feet in February 1989. Drilled-out depth to the top of cement inside the casing was 6644 feet and 5-1/2 inch, 17.00-pound-per-foot $\mathrm{N}-80$ Hydril FJ tubing was run to a Brown-Hughes 2B permanent packer set at a depth of 5450 feet. Depths are from a Rig Kelly Bushing (RKB) height of 27.0 feet above the tubing hanger, 29.0 feet above ground level, and 32.0 feet above mean sea level (MSL).

A Class II Well disposal well integrity test was performed on the new disposal well on November 20, 1989, by pressuring-up on the 5-1/2 X 9-5/8 inch annulus to $300 \mathrm{psi}$. The pressure was held for 1 hour with no leak-off and the test was judged to be satisfactory.

On November 21, 1989, a combination cement bond/collar locator log was run from 6644 to 5450 feet in the disposal well. A temperature log was run from the surface to 6644 feet. Recorded temperatures at 500-foot depth increments are shown in Exhibit 3.3-1. 


\begin{tabular}{|c|c|c|c|}
\hline $\begin{array}{c}\text { Depth, } \\
\mathrm{ft}\end{array}$ & $\begin{array}{c}\text { Temperature, } \\
{ }^{\circ} \mathrm{F} \\
\end{array}$ & $\begin{array}{l}\text { Depth, } \\
\mathrm{ft}\end{array}$ & $\begin{array}{c}\text { Temperature, } \\
{ }^{\circ} \mathrm{F} \\
\end{array}$ \\
\hline 500 & 72 & 4000 & 112 \\
\hline 1000 & 77 & 4500 & 118 \\
\hline 1500 & 83 & 5000 & 124 \\
\hline 2000 & 88 & 5500 & 131 \\
\hline 2500 & 93 & 6000 & 137 \\
\hline 3000 & 99 & 6500 & 145 \\
\hline 3500 & 105 & & \\
\hline
\end{tabular}

Then the well was perforated from 6530 to 6590 feet with four shots per foot and 90 degree phasing using three runs with Schlumburger 3-3/8 inch Ultrapac casing guns and 22-gram charges.

After perforating, an attempt to inject filtered produced brine resulted in rapid pressure buildup to 1400 psi with about a barrel of fluid. The pressure would then drop to $300 \mathrm{psi}$ in about 5 minutes with the pump off. There was little communication between the wellbore and the disposal formation.

The next morning, November 22, 1989, 150 barrels of $15 \% \mathrm{HCl}$ were pumped into the formation. The maximum pressure while displacing the acid down the tubing at a pump rate of 4 barrels per minute (BPM) was 2600 psi. After the acid reached the perforations, the pressure broke back to $400 \mathrm{psi}$ at a pump rate of $7 \mathrm{BPM}$. The acid was followed with 400 barrels of produced brine from the second of the two frac tanks filled on the previous day. A pressure of 1000 psi was held on the 5-1/2 $\times 9-5 / 8$ inch annulus during the acid treatment and subsequent injection.

When the injection was stopped, the disposal tubing went on vacuum. Thirteen days later, on December 5, the brine level in the disposal well was found to be at a depth of 497 feet ( 476 feet below the top of the wellhead).

\subsection{Surface Hardware Installation}

The surface facilities for flow testing were installed during the last week of November 1989. The surface facilities for production testing, as configured after addition of metering following the first flow test, are shown schematically in Exhibit 3.4-1. The choke manifold, separators, tanks, and piping were provided and operated by Lafayette Well Testing, Inc., (LWT) under subcontract to IGT. The gas cooler, filter skid, and flare stack were DOE-owned hardware moved from the Gladys McCall location. 


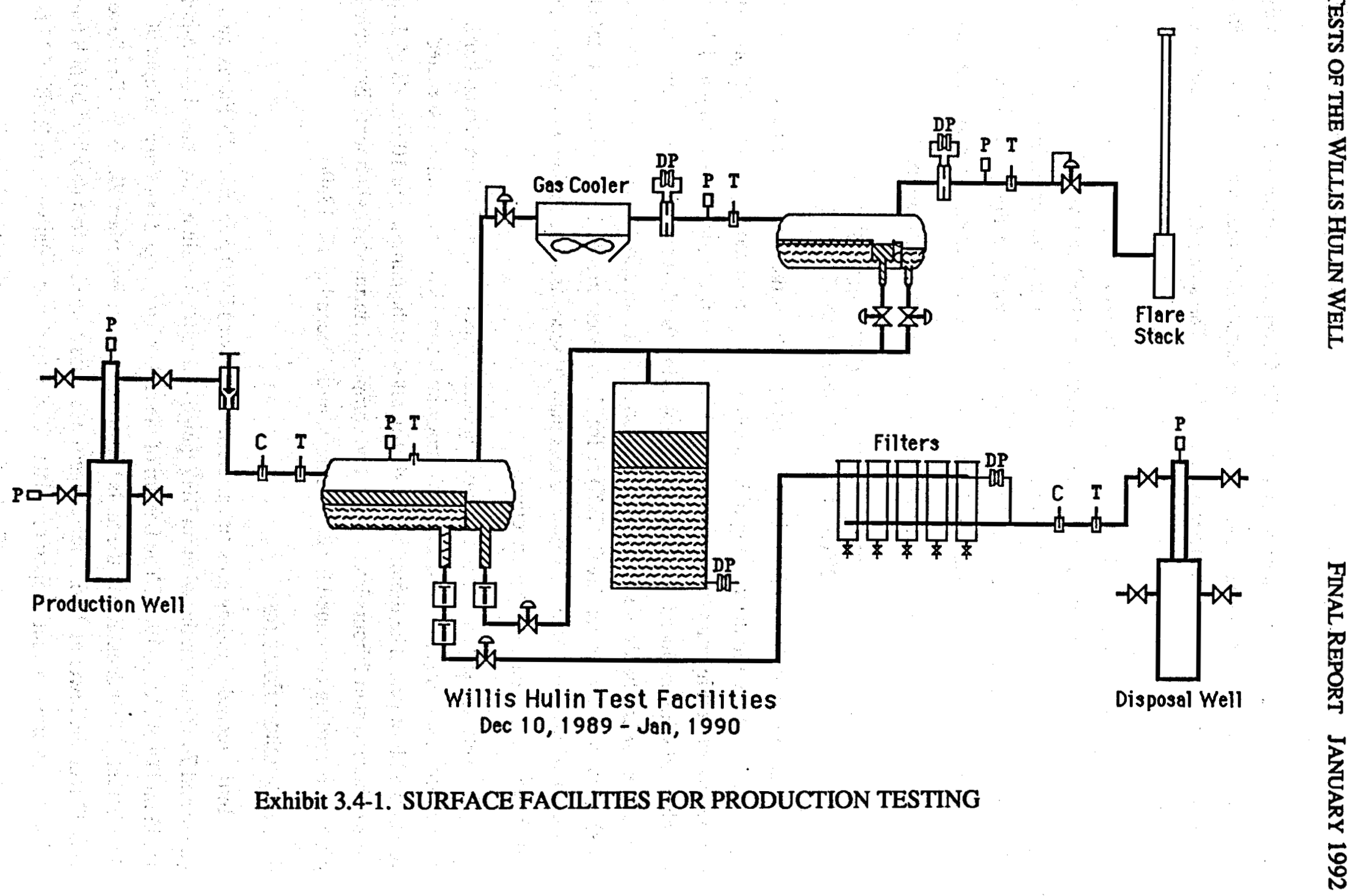


The data acquisition system consisted of a DOE computer system used previously by IGT at the Gladys McCall well supplemented by new transmitters and other components. A block diagram of the data system is shown in Exhibit 3.4-2. The computer-based system was backed up by conventional circular chart recorders and turbine-meter indicators operated by LWT and EOC.

After assembly in accordance with details of the previously approved design and Safety Analysis Report, the surface facilities were inspected by DOE representatives. The most significant change made prior to DOE approval to operate the facility was changing the straight run of 3-inch pipe between the separator and filter skid to a " $Z$ " configuration. This removed any question about whether thermal expansion could result in excessive stress at any point in the system.

DOE approval to start test operations was received mid-afternoon on December 5, 1989.

\subsection{THE 36-HOUR FLOW TEST OF THE 20,670 TO 20,690-FOOT INTERVAL}

After receiving DOE approval to start test operations, the bottomhole pressure sensor was run and set at 20,600 feet in the evening of December 5. The next morning, the diesel previously injected to prevent hydrate problems was slowly flowed off the top of the tubing and the separator was charged with produced brine. Then, after waiting for the bottomhole pressure to recover and after some surface hardware problems were corrected, production was started at a rate of about 2400 stock tank barrels per day (STB/d) at 16:51 on December 6, 1989. Flow was started by opening the choke to $12 / 64$ " in a time of less than 30 seconds. The setting was not changed until the choke was closed to stop production.

The well was shut in for buildup testing 36.23 hours later, at 5:05 on December 8. Total production during this flow test was 3658 stock tank barrels of brine and an estimated $106,000 \mathrm{SCF}$ of gas. The timing of the shut-in allowed the pumping of 10 barrels of diesel into the wellbore to start 3 hours later and still be completed during daylight hours. Bottomhole pressure recording continued for 2 more days, until December 10, 1989.

\subsection{Bottomhole Pressures}

Initial recorded tubing pressure at the wellhead was 7460 psia on IGT's Panex quartz-crystal gauge and 7465 psia on the wireline BHP gauge before the wireline was started down-hole at 15:45 on December 5, 1989. The bottom of the sinker bars tagged bottom at a depth of 20,673 feet, 3 feet deeper than the tools that were run on November 20, 1989. The Panex sensor was 42 feet shallower at 20,631 feet. The sensor was moved up to a depth of 20,600 feet for the recording of pressure and temperature data. These depths are relative to an RKB of 26 feet above the tubing hanger (29 feet above ground level and 32 feet above mean sea level). 


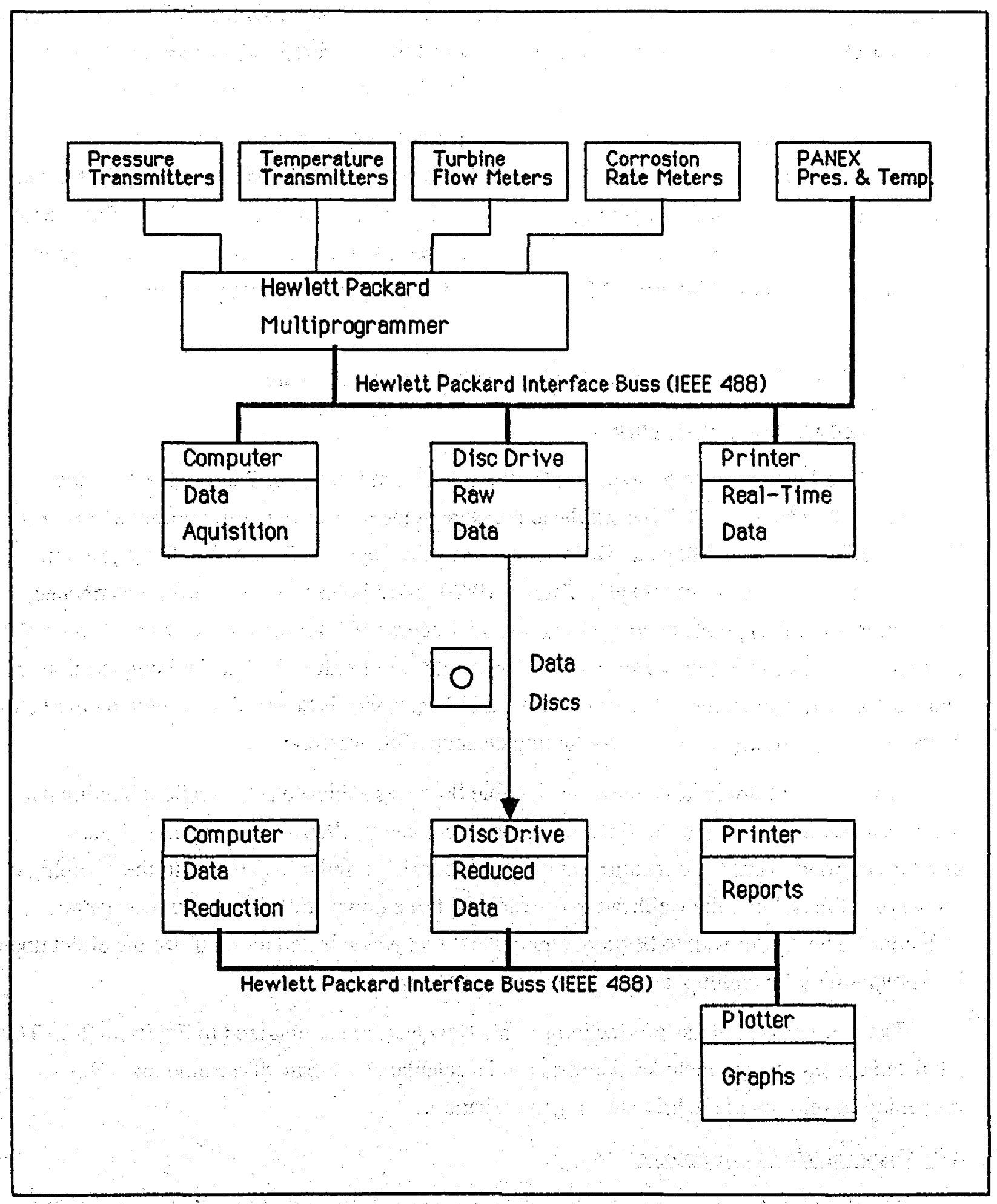

Exhibit 3.4-2. COMPUTER-BASED DATA ACQUISITION AND ANALYSIS SYSTEM 
The stabilized bottomhole pressure and temperature were $17,298 \mathrm{psia}$ and $338.2^{\circ} \mathrm{F}$, respectively. In contrast, measured bottomhole values were $17,308 \mathrm{psia}$ and $337.9^{\circ} \mathrm{F}$ at the same depth before producing 1000 barrels to tanks on November 21,1989 . The bottomhole pressure was 17,297 psia the next morning before flowing the diesel from the tubing to a tank.

Wellhead pressure leveled out at 7332 psia, and bottomhole pressure leveled out at 17,294 psia after removing the diesel. After an aborted start at 12:20 on December 6, 1990, the draw-down test was started by opening the choke to $12 / 64$ " at 16:51 that same day. The lowest measured bottomhole pressure during this flow test was $14,760 \mathrm{psia}$, and the lowest recorded wellhead pressure was 5030 psia. After 50 hours of buildup, bottomhole pressure was 17,210 psia.

Exhibit 4.1-1 shows the 5 days of recorded bottomhole pressure.

\subsection{Production Well Performance}

Wellhead pressure and temperature for the week from December 2 through 8 are shown in Exhibit 4.2-1. The initial flowing wellhead pressure at the start of the 36-hour draw-down test on December 5 was about 5600 psia. But after an hour and a half the flowing wellhead pressure suddenly increased by about 400 psi. Then at 19:20, 2-1/2 hours after the choke was opened, flowing pressure dropped back to about 5600 psi. Recorded bottomhole pressure made a similar excursion. The result is that the early draw-down data are of reduced value for interpretation to deduce reservoir parameters. The cause of the erratic behavior is believed to be partial obstruction of the choke by drilling mud from continuing cleanup of the perforations.

After a day of production, reasonably stable flow was achieved and excellent buildup data were obtained following the shut-in at 05:06 on December 8, 1989. The ramp in wellhead pressure between 3 and 6 hours after shut-in (Exhibits 4.1-1 and 4.2-1) is due to the pumping of 10 barrels of diesel into the wellhead to displace the brine down 1500 feet to prevent hydrate formation. The 3-hour wait to begin pumping the diesel was selected to minimize the effect upon interpretation of the buildup data from the bottomhole pressure sensor.

The daily brine and gas production for this flow test are summarized in Exhibit 4.2-2. This tabulated gas production includes flared gas and a calculated estimate of the amount of gas remaining in solution in the brine leaving the separator.

\subsection{Disposal Well Performance}

The fluid level in the disposal well was initially found to be at 497 feet below the RKB for the well. At the start of production at a brine rate of about $2400 \mathrm{BPD}$, disposal wellhead pressure 


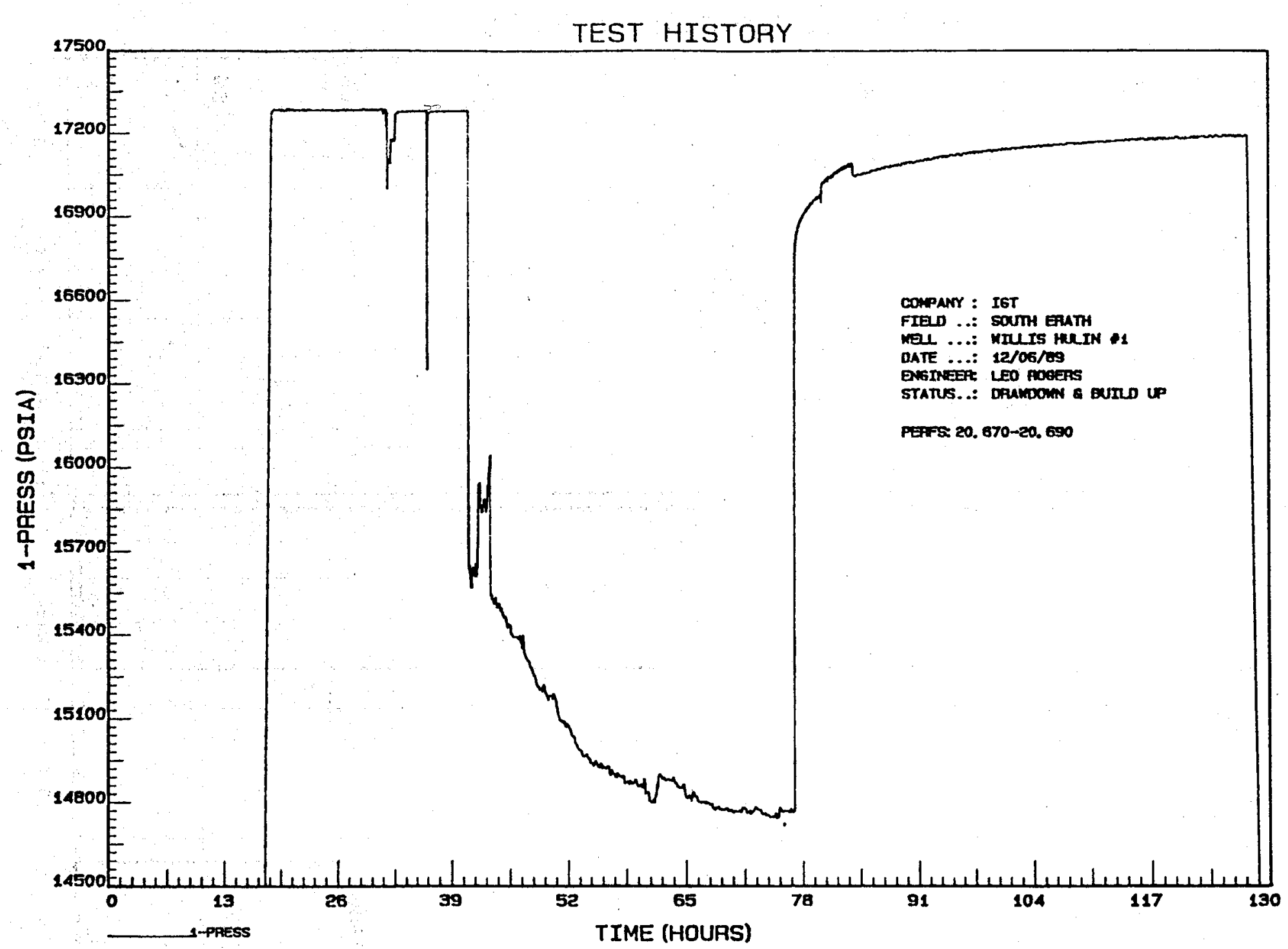

Exhibit 4.1-1. RECORDED BOTTOMHOLE PRESSURE FOR 12/5/89 THROUGH 12/11/89 


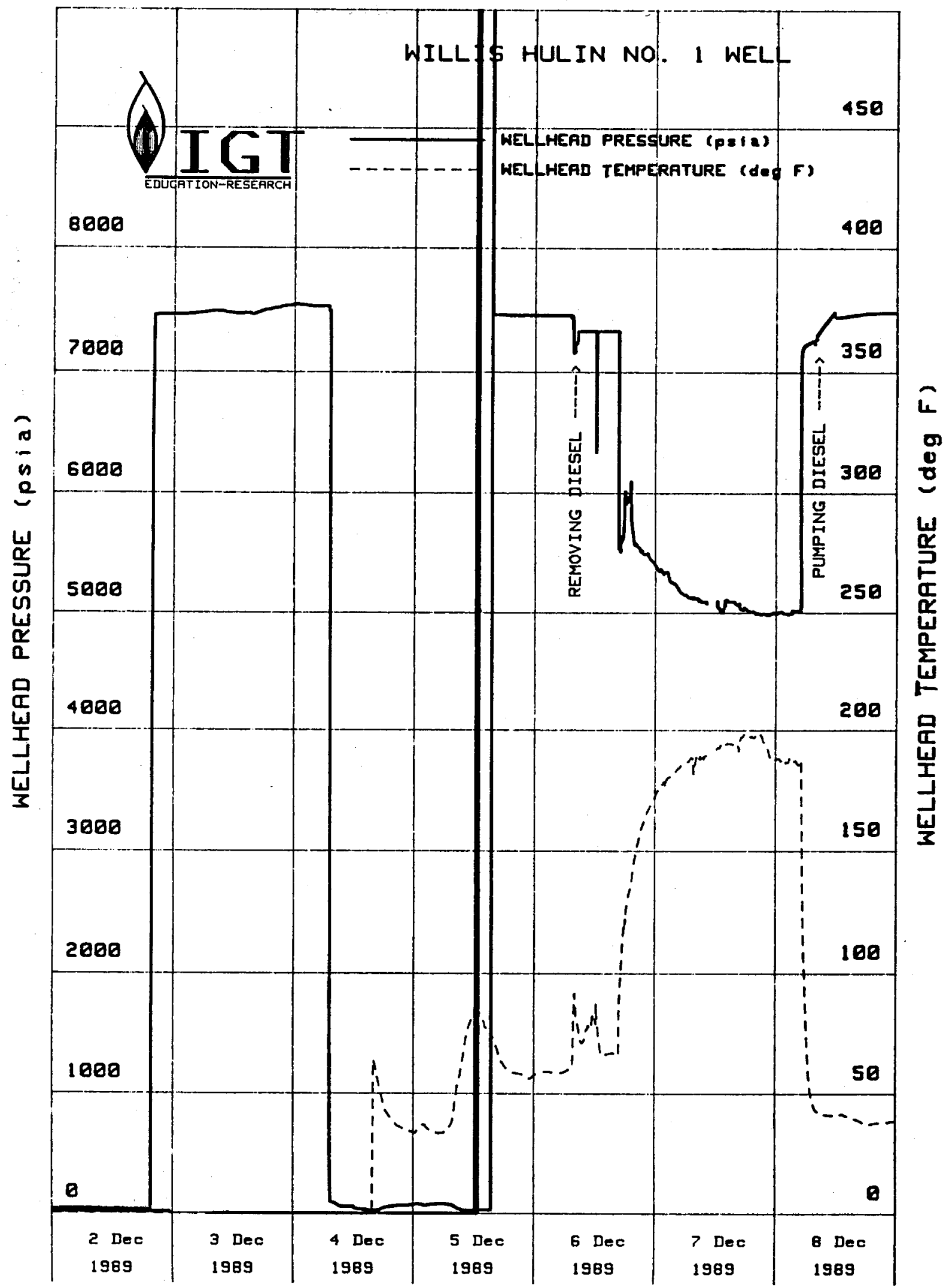

Exhibit 4.2-1. PLOT OF WELLHEAD PRESSURE AND TEMPER ATURE FOR 12/2/89 THROUGH 12/8/89 


\section{Exhibit 4.2-2. DAILY BRINE AND GAS PRODUCTION \\ DURING CLEANUP FLOWS}

\begin{tabular}{crc} 
Date & $\begin{array}{r}\text { Brine, } \\
\text { STB }\end{array}$ & $\begin{array}{c}\text { Gas, } \\
1000 \text { SCF }\end{array}$ \\
\cline { 1 - 3 } Dec 6, 1989 & 696 & 20.2 \\
Dec 7, 1989 & 2443 & 70.8 \\
Dec 8, 1989 & 519 & 15.0
\end{tabular}

immediately went from vacuum to about $50 \mathrm{psi}$. This corresponds to a bottomhole value about $250 \mathrm{psi}$ greater than static disposal sand reservoir pressure. Thus the injectivity is roughly $10 \mathrm{STB} / \mathrm{d} / \mathrm{psi}$. For comparison, the injectivity of the Pleasant Bayou disposal well is a little above $40 \mathrm{STB} / \mathrm{d} / \mathrm{psi}$.

During the 36 hours of production, the disposal well injection pressure increased from about 50 to about 100 psia. Much, if not all, of the increase was due to decreasing density of the brine in the wellbore as the disposal wellhead temperature increased to about $175^{\circ} \mathrm{F}$ at the end of production.

\subsection{Surface Facility Performance}

The surface facilities operated well in the context of lack of leaks and separation of fluid phases. On the other hand, metering of both gas and brine production encountered problems that precluded getting good-quality data. The problem with brine-rate measurement was plugging of the single turbine meter with produced debris. Hammering on the meter and surging the flow through the meter by opening and closing the block and bypass valves restored the signal each time the turbine stopped. But it was not possible to say whether accuracy characteristic of a clean and properly operating turbine meter was achieved. Exhibit 4.4-1 shows the time dependence of recorded brine flow rate.

The measured gas rates were less than half the expected value and changed when the orificeplate size was changed. The problem was found to be bypassing of the plate in the single Daniel Senior orifice meter. The problem was at least in part due to rust accumulation during the several months of delay between the time that bids were first solicited for the hardware and the time of the actual start of the field experiment. The errors in recorded gas-rate data were so large the data would be seriously misleading and were therefore not reported. Liquid hydrocarbon production, if any, was too small to be detected in the background of diesel that had been used to prevent hydrates while the production well was shut-in. 


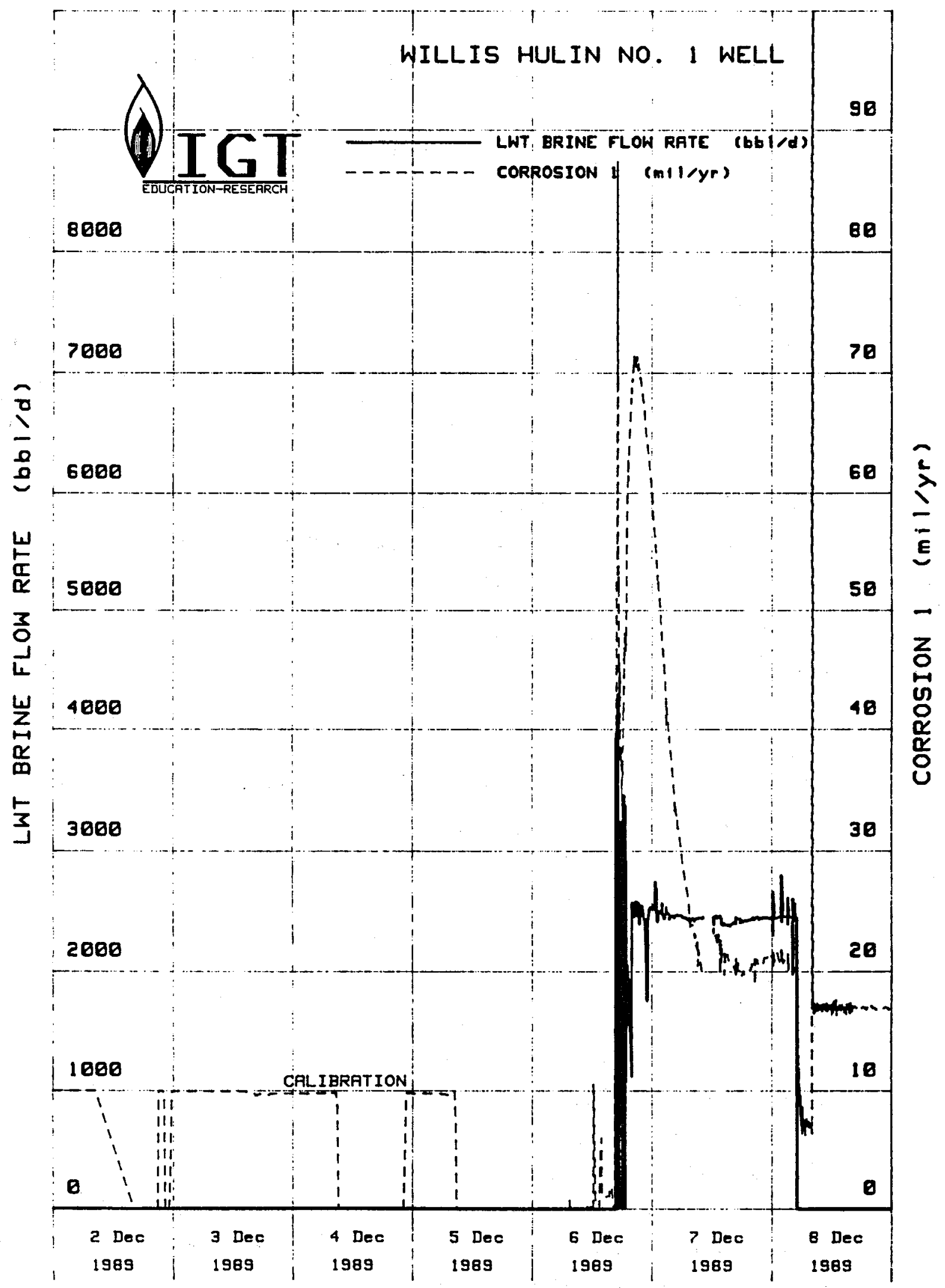

Exhibit 4.4-1. PLOT OF BRINE FLOW RATE AND CORROSION RATE FOR 12/2/89 THROUGH 12/8/89 


\subsection{Scale and Corrosion}

Neither corrosion inhibitor nor scale inhibitor were injected during this first instrumented flow test. But both C-1018 corrosion coupons and Petrolite M-6010 corrosion-rate-monitoring probes were installed upstream and downstream of the separator. The output of corrosion rate from the Petrolite system was recorded on the digital data system, and is given in Exhibit 4.4-1. The upstream probe showed a corrosion rate that declined from a peak of about 60 mils per year to a level of about 20 mils per year for the last half of the 36 -hour flow test. The electronic control for the downstream probe failed.

Coupons were in the lines both before and after the separator. The corrosion rates determined from the coupons were less than 5 mils per year. The coupon analyses were performed by Coastal Fluid Technologies, Inc., who supplied the coupons as well as scale- and corrosioncontrol chemicals. These analyses are presented in Exhibit 4.5-1. The coupons had a large buildup of calcite. The presence of calcite was anticipated because no inhibitor was injected during this short flow test. The coupon before the separator had a large buildup of acid-insoluble material and of iron compounds.

\section{Exhibit 4.5-1. ANALYSIS OF CORROSION COUPONS AFTER 1-DAY FLOW TEST}

\section{Upstream Coupons Downstream Coupons}

Corrosion Rate, mils/yr

Deposits, $\mathrm{g} / \mathrm{sq}$ in./yr

Hydrocarbons

Water-Soluble Salts

Calcium Carbonate

Iron Compounds

Acid-Insoluble
1.5

5.0

0.06

0.14

0.45

1.14

1.20

4.41
0.03

1.23

0.02

0.16

\subsection{Filters}

Two pots of 10-micron cotton filters were on-line for the duration of the 36-hour test. Pressure drop across them increased monotonically from less than 1 to $6.5 \mathrm{psi}$, indicating filter loading. When the elements were removed on December 9 , they were found to be coated with a black material that did not feel oily. No sand grains were apparent. 


\subsection{Gas and Brine Analyses}

Three brine samples were collected from the sight glass of the large separator and two sets of length-of-stain tube gas analyses for carbon dioxide and hydrogen sulfide were made during the 36-hour flow. The results of onsite and laboratory analyses of all brine and gas samples are presented in Sections 9 of this report.

\subsection{Equipment Modification and Measurement of Flow Rates}

During the buildup phase following the 36-hour flow on December 6 through 8, 1989, major changes were made in the surface hardware to achieve greater reliability in measuring flow rates. A second turbine meter was installed in series with the first turbine for brine-rate measurement. The rusty Daniel Senior orifice meter for gas-rate measurement was replaced with two Simplextype orifice runs. One of these was between the cooler and the small separator and the second was after the small separator, as shown in Exhibit 3.4-1.

After the bottomhole pressure sensor had been removed from the well on December 10, 1989 , the choke was opened to the same 12/64" that had been used for the 36-hour flow test on December 6 through 8 . Overnight, the flowing wellhead pressure stabilized at about 5100 psia and within $100 \mathrm{psi}$ of the same value as the prior flow. This provided a reasonable level of confidence that the prior flow rate was being duplicated.

The well was shut in at 06:00 on December 11, after 12 hours of production at a rate of about 2000 STB/d. Consistency had been achieved between the readings of the series brine turbines and between the series gas-rate meters. The gas/brine ratio was found to be 28 SCF/STB. Ten barrels of diesel oil were pumped into the wellhead after the overnight flow.

\subsection{PERFORATION AND CLEANUP FLOWS}

OF THE 20,602 TO 20,690-FOOT INTERVAL

The deepest 70 feet of the 600 -foot-thick sand of interest is a uniform sand that is separated from the majority of the sand by potentially significant shale breaks. The 36-hour flow test, the subsequent buildup test of the 20,670 to 20,690-foot interval, and 12-hour flow test to validate rate measurements involved the deepest 20 feet of the 70-foot-thick uniform sand. Testing of the 20-foot perforated interval showed a substantial drawdown in bottomhole pressure for modest production rates.

After pumping 10 barrels of diesel to prevent hydrate formation on December 11, perforation of the rest of the thickness of the uniform sand and the lower 20 feet of shale breaks was begun. 
Details of perforating, including a small flow in an attempt to get a gun into the well, cleanup of the perforations, and a 4-1/2 day flow test with bottomhole pressure data are provided under subheadings below.

\subsection{Perforation}

The additional perforations were shot using a magnetically decentralized 1-9/16 inch Schlumburger HD-HMX through-tubing gun carrying 3.2-gram, shaped charges. The decentralizing magnet was at the top of the gun, and the gun swelled to a maximum diameter of $1-11 / 16$ (1.688) inches when fired. This small perforation gun was required because the gun had to pass through the wellhead that had a minimum interior diameter of $1-13 / 16(1.813)$ inches. The smallest diameter in the wellbore was 20 feet or so of seals in the tubing string that had an interior diameter of 2-1/4 inches.

After the 10 barrels of diesel had been pumped into the wellbore on December 11 , four perforating charges per foot with zero degree phasing were fired in the depth interval from 20,646 to 20,666 feet on the ISF log. An open circuit developed in the wireline during the trip out of the well and the second gun had to wait for the arrival of a second wireline truck. When the other truck was rigged up, four perforating charges per foot were fired in the depth interval from 20,622 to 20,642 feet.

Attempts to get a third, similar gun down-hole were aborted when the 1.72-inch-diameter sinker bars would not pass the master valves. The diesel was slowly bled off the wellhead and then the well was produced until the wellhead temperature was high enough so that hydrates could not exist in the wellbore. After flowing at low rate for about a half hour to remove the 10 barrels of diesel, the well was flowed for a little over half an hour using choke openings of 16/64" and $12 / 64^{\prime \prime}$. The peak wellhead temperature was $130^{\circ} \mathrm{F}$. Brine rate averaged about $4000 \mathrm{STB} / \mathrm{d}$ and the total produced volume was about 120 barrels or about two-thirds of the volume of the wellbore. The gun still did not go down-hole. The problem was found to be a bent decentralizing magnet. After fixing the bent magnet problem, the third gun then failed to fire on two trips down hole. A new gun was run and successfully fired four shots per foot in the interval 20,602 to 20,622 feet late in the evening of December 12.

\subsection{Cleanup Flow}

Cleanup flow of the new perforations through the surface test equipment began mid-morning on December 13 with the choke being opened stepwise to a maximum of $18 / 64$ " and then cut back to $12 / 64^{\prime \prime}$. In less than 20 minutes and only one-third of the way towards bottoms up, both of the turbine meters were sticking and the dump valve was plugging so badly that mud was carried over through the gas line to the small separator. Filter differential pressure built up so fast that the 
elements in one pot were collapsed by the high differential pressure. These surprises were triggered by the short flow on December 12 when the perforating gun would not go in the wellhead. This short flow had filled two-thirds of the well volume with debris-laden fluid (mostly old drilling mud) from behind the new perforations made by the first two guns fired.

After observing bottoms up in the form of a slug of mud and black oil, produced brine rapidly cleared up. At 13:48, the well was shut in for cleaning of the turbine meters and the separator dump valve, as well as changing the filters and other maintenance made mandatory by the debris produced from behind the new perforations. Diesel was not pumped because the well would be shut-in for less than 3 hours and would not cool enough for hydrates to form.

Cleanup flow was resumed at 15:45 with proper operation of the surface control and metering hardware. During the next hour, choke openings of 16/64", 10/64", 12/64", 14/64", $12 / 64 "$, and 10/64" were used. Intermittent stoppage of turbine meters was overcome by rapidly switching ball valves to surge the flow. The debris that had passed by the collapsed filters caused a large jump in injection pressure when it reached the disposal sand 2 hours later. The rate decreases at the end of the hour were required to keep disposal well injection pressure below the working-pressure rating of the filter pots.

From 17:20 to 19:20 on December 13, the production well was operated on a 9/64" choke and a brine rate of about $1400 \mathrm{STB} / \mathrm{d}$, or 1 barrel per minute. Disposal well injection pressure kept climbing, from 315 to 400 psia during a 2-hour period at that low flow rate. A pump truck was called out and 50 barrels of inhibited $15 \% \mathrm{HCl}$ was pumped into the disposal well at a rate of just under 1 barrel per minute, so total flow down the disposal well was 2 barrels per minute. Once the acid was in the wellbore, the production rate was increased to about 2 barrels per minute. The disposal well volume is 207 barrels, so the acid did not reach the perforations until 100 minutes after pumping had been started. The injection pressure broke back from 620 to 240 psia as the acid passed through the perforations.

The production well choke opening was increased to $16 / 64$ " and then to $18 / 64$ " as the acid went through the disposal perforations, and injection pressure broke back in two steps starting at 21:20. The 18/64" choke setting gave a brine rate of 4800 STB/d. At 22:20 the choke was opened to 24/64" and the brine rate went up to $6000 \mathrm{STB} / \mathrm{d}$. A small amount of additional debris surfaced at bottoms up after this rate increase, but not enough to cause operational problems. After producing two well volumes ( 400 barrels) at the high rate, the choke opening was reduced to $12 / 64 "$ at midnight and the well flowed another $2-1 / 2$ well volumes at a rate of about $2400 \mathrm{STB} / \mathrm{d}$. The produced gas/brine ratio averaged about $31.5 \mathrm{SCF} / \mathrm{STB}$. This is above the value of $30.5 \mathrm{SCF} /$ STB measured on December 10 and 11 before the additional perforations were shot. 
The well was then shut in to wait for the reservoir pressure to stabilize before running the wireline bottomhole pressure sensor prior to another draw-down test. Ten barrels of diesel were pumped to ensure that hydrates would not form during the shut-in period.

The daily brine and gas production for the flows after the 36-hour drawdown through 20 feet of perforations at the base of the sands of interest are summarized in Exhibit 5.2-1.

\section{Exhibit 5.2-1. DAILY BRINE AND GAS PRODUCTION DURING CLEANUP FLOWS}

\begin{tabular}{crc} 
Date & $\begin{array}{c}\text { Brine, } \\
\text { STB }\end{array}$ & $\begin{array}{c}\text { Gas, } \\
1000 \text { SCF }\end{array}$ \\
\cline { 3 - 3 } Dec. 10, 1989 & 441 & 12.8 \\
Dec. 11, 1989 & 562 & 16.3 \\
Dec. 12, 1989 & 72 & 2.1 \\
Dec. 13, 1989 & 1407 & 40.8 \\
Dec. 14, 1989 & 540 & 15.3
\end{tabular}

This tabulated gas production includes flared gas and a calculated estimate of the amount of gas remaining in solution in the brine leaving the separator.

\subsection{Disposal Well}

A substantial but unmeasured quantity of fluid that had the appearance of old drilling mud, as well as other debris, was injected into the disposal well past the collapsed filters on December 13, 1989. Assuming a gradient of $0.47 \mathrm{psi} / \mathrm{ft}$ above the fluid level of 476 feet below the wellhead pressure transmitter (measured on December 5, 1989, before heating with injection), the injectivity of the well declined from about 8.7 to $2.8 \mathrm{STB} / \mathrm{d} / \mathrm{psi}$.

During the evening of December 13,50 barrels of inhibited $15 \% \mathrm{HCl}$ were pumped into the disposal well. The production well was on-line at a rate of about $1 \mathrm{BPM}(1400 \mathrm{STB} / \mathrm{d})$ during the acid injection. The acid pump rate was adjusted to stay below the 750 psi emergency shutdown (ESD) pilot setting at the filter skid. The 50 barrels of acid were pumped into the disposal wellbore in an hour and pumping was completed before the first of the acid reached the disposal perforations.

As soon as the injection pressure broke back, indicating acid through the perforations, the production rate was increased to cause the acid to go to as many perforations as possible. After the last of the acid entered the disposal formation, the injection pressure went to a minimum of 200 psi and then climbed back to $330 \mathrm{psi}$ at a rate of $6000 \mathrm{STB} / \mathrm{d}$. The production rate was reduced to $2400 \mathrm{STB} / \mathrm{d}$ and the injection pressure leveled out at about $60 \mathrm{psia}$ at this rate. This corresponds to 
an injectivity of $8.3 \mathrm{STB} / \mathrm{d} / \mathrm{psi}$. The disposal well injectivity, which had been damaged by drilling mud and debris that passed through the collapsed filters, was almost completely restored by the acid treatment.

IGT experience on several disposal wells has found that injectivity values range from 8 to over $100 \mathrm{STB} / \mathrm{d} / \mathrm{psi}$. For instance, the injectivity of the Pleasant Bayou disposal well is over $40 \mathrm{STB} / \mathrm{d} / \mathrm{psi}$. The $8 \mathrm{STB} / \mathrm{d} / \mathrm{psi}$ is on the low end of these wells -- so low that substantial improvements must be made if high-rate brine production is planned. For instance, at a separator pressure of 1200 psia -- near the maximum operating pressure of typical separators -- the maximum injection pressure available at the disposal well would be about 1100 psia. At that pressure, with an injectivity of $8.3 \mathrm{STB} / \mathrm{d} / \mathrm{psi}$ and with the static fluid level 476 feet below the ground level, the maximum brine injection rate would be $11,000 \mathrm{STB} / \mathrm{d}$.

\subsection{Effect of the Additional Production Well Perforations}

The readings from wellhead Panex quartz-crystal gauge with 10 barrels of diesel oil in the tubing indicate little, if any, change in pressure due to the additional 60 feet of perforations. Recorded tubing pressure at the wellhead Panex quartz-crystal gauge was 7468 psia on December 10 (before any additional perforations), 7451 psia after shooting two perforating guns and before producing the diesel on December 12, and 7460 psia before the start of flow on December 13. The minor differences may well be due to 1) small differences in the amount of diesel in the wellbore, or 2) the temperature sensitivity of the Panex transducer, or 3) small differences in the wellbore temperature and therefore the density of the brine in the wellbore.

The wellhead pressure drawdown for production of $2400 \mathrm{STB} / \mathrm{d}$ after shooting the additional 60 feet of perforations was about 900 psi less than for the same rate with only the original 20 feet of perforations. But the rapid bounce back of pressure after the shut-in on December 14 was still in excess of 1000 psi and suggested a high value for the skin factor due to poor perforation efficiency.

\subsection{Liquid Hydrocarbon Production. Scale and Corrosion Treatment}

Liquid hydrocarbon production, if any, was too small to be detected in the background of diesel that had been used to prevent hydrates while the production well was shut in. Neither corrosion inhibitor nor scale inhibitor were injected during the cleanup flows. Also, the corrosion coupons and the Petrolite M-6010 corrosion-rate-monitoring probes were not installed.

\subsection{Filters}

A single pot of 10-micron cotton filters was on-line for the overnight flow on December 10 and 11. Pressure drop increased monotonically to $5.5 \mathrm{psi}$, indicating filter loading. When the 
elements were removed on December 11, they were found to be coated with a black material that did not feel oily. No sand grains were apparent and there was a noticeable diesel odor. The solids are believed to be residue from old drilling mud.

There was one pot of 10-micron filter elements in use during the short flow on December 12. There was no trend in pressure drop and no indication of filter loading. This is to be expected since the well was shut in before bottoms up was reached.

The flow on December 13 was started through a single pot of 10 -micron filter elements. In less than 20 minutes, pressure drop across these element exceeded the 20-psi full-scale range of the differential-pressure transmitter. A second pot loaded with 10-micron elements was put on-line in parallel with the first and the indicated pressure drop went down to $1.3 \mathrm{psi}$. That evening, before going to $6000 \mathrm{STB} / \mathrm{d}$, a third pot, containing 50-micron elements, was put on-line in parallel with the other two pots. The differential-pressure transmitter had ceased to operate properly, but monitoring of upstream and downstream pressure gauges indicated that pressure drop was kept below the 20-psi rating of the filter elements.

The filters were changed in the three pots after the well was shut in on December 14. The 10-micron elements in the pot that had experienced pressure drop in excess of 20 psi were found to have collapsed on their mounting posts and are believed to have passed unfiltered brine for virtually all of the December 13 and 14 cleanup production. The loading on these elements was black with a greasy feel and a slight smell of diesel. No granular material with a grain size similar to sand was apparent.

In contrast, the loading on the 50-micron elements, which were only on-line for the latter portion of the cleanup flow, was grey and had a strong oil smell. The second pot of 10-micron elements had a loading that was between these extremes. Formation sand grains could not be found on any of the elements from the three filter pots. The small amount of granular material found was judged to be cement rather than formation material.

\subsection{Discussion of Sampling and Analysis}

A gas sample was collected shortly before the end of production on the moming of December 11, 1989. Separator pressure was $305 \mathrm{psia}$ and the brine temperature was $190^{\circ} \mathrm{F}$. Results from the analysis of this sample by Southern Petroleum Laboratories, Inc., (SPL) are given in Exhibit 5.7-1.

The very low content of butanes and pentanes is consistent with results from the analysis of the high-pressure sample collected after the first cleanup flow in February 1989. 


\section{Exhibit 5.7-1. ANALYSIS OF GAS SAMPLES TAKEN ON 12/11/89}

\begin{tabular}{lr} 
Component & mol \% \\
\hline Nitrogen & 0.13 \\
Carbon Dioxide & 17.90 \\
Methane & 79.76 \\
Ethane & 1.98 \\
Propane & 0.18 \\
iso-butane & 0.01 \\
$n$-butane & 0.01 \\
iso-pentane & Nil \\
$n$-Pentane & Nil \\
Hexanes & Nil \\
Heptanes+ & 0.03 \\
Specific Gravity & 0.741 \\
Heating Value, & \\
Btu/SCF (Dry) & 869
\end{tabular}

\subsection{DECEMBER 1989 4-1/2 DAY FLOW TEST OF THE 20,602 TO 20,690-FOOT INTERVAL}

For this test the well was produced for 4-1/2 days with bottomhole pressure measurement and then shut in for recording of buildup data. The pretest plan called for $1 / 2$ day each of production at rates of 2000 and $4000 \mathrm{STB} / \mathrm{d}$ to be followed by 4 days at $6000 \mathrm{STB} / \mathrm{d}$. But the $6000 \mathrm{STB} / \mathrm{d}$ step was canceled when it was recognized that it would have resulted in scale formation in the well tubing. The well was flowed for $1 / 2$ day at $2000 \mathrm{STB} / \mathrm{d}$ and was then flowed at just under $4000 \mathrm{STB} / \mathrm{d}$ for 4 days.

\subsection{Bottomhole Pressures}

The wireline Panex sensor was placed in the lubricator the morning of December 17, 1989. After pressure-testing the lubricator assembly, the well was opened up. The Panex gauge was lowered into the wellhead, where it read 7464 psia. The IGT wellhead pressure Panex read 7467 psia and the IGT deadweight tester measured 7472 psia. These were all in excellent agreement. The Panex gauge was run to a maximum depth of 20,600 feet and then pulled back to 20,525 feet. This was to move the bottom of the sinker bars ( 42 feet below the sensor) to above the shallowest perforation (20,602 feet). Bottom was not tagged. These depths are relative to an RKB of 26 feet above the tubing hanger (29 feet above ground level and 32 feet above mean sea level). The stabilized bottomhole pressure and temperature were $17,157 \mathrm{psia}$ and $336.4^{\circ} \mathrm{F}$, respectively. Using the gradients of $0.48 \mathrm{psi} / \mathrm{ft}$ and $1.5^{\circ} \mathrm{F} / 100 \mathrm{ft}$, equivalent values at 20,600 feet 
are 17,193 psia and $337.5^{\circ} \mathrm{F}$. In contrast, measured values at 20,600 feet were 17,308 psia and $337.9^{\circ} \mathrm{F}$ before producing 1000 barrels to tanks on November 21,1989 , and 17,283 psia and $338.2^{\circ} \mathrm{F}$ before the start of production on December $6,1989$.

The recorded bottomhole pressure for the draw-down and buildup test is shown in Exhibit 6.1-1. The lowest bottomhole pressure achieved during this flow test was 14,450 psia at 20,525 feet RKB $(14,486$ psia at a 20,600 -foot depth).

\subsection{Production Well Performance}

After flowing the diesel from the well, the shut-in wellhead pressure leveled out at $7286 \mathrm{psia}$ and bottomhole pressure leveled out at 17,161 psia (17,197 psia adjusted to 20,600 feet). These surface and bottomhole values are less than after flowing out the diesel on December 6 by 46 and 82 psi, respectively.

Exhibit 6.2.1 summarizes the daily brine and gas production for the 6 days during which the well flowed. Production data are from midnight to midnight. Exhibits 6.2-2 through 6.2-5 show the pressures, flow rates, and other data obtained during the test.

The gas production tabulated above is flared gas and a calculated estimate of the amount of gas remaining in solution in the brine leaving the separator.

The first planned rate of 2000 STB/d was achieved with a choke opening of 11/64". The next morning, the rate leveled out a little below $4000 \mathrm{STB} / \mathrm{d}$ after increasing the choke opening to 16.5/64". The large instantaneous pressure changes that occurred when choke settings were changed suggest poor flow efficiency of the perforations. But the absence of differential-pressure buildup across the filters indicated little continuing cleanup of perforations. The ramp in wellhead pressure between 3 and 6 hours after shut-in on December 22 (Exhibits 6.1-1 and 6.2-2) is due to the pumping of 10 barrels of diesel into the wellhead to displace the brine down 1500 feet to avoid hydrate formation.

Oddo and Tomson developed a saturation index to predict when scale would form in oil field brines, and easy-to-use nomographs for the effects of changes in individual parameters that control scaling have been published. 6 The only scale-related parameters whose values change between the reservoir and the wellhead are temperature and pressure.

After 11 hours at a flow rate of $4000 \mathrm{STB} / \mathrm{d}$, the wellhead pressure was $4640 \mathrm{psia}$ and the wellhead temperature was climbing through $244^{\circ} \mathrm{F}$. For these values, the change in the component of the saturation index due to pressure is +1.5 and the change in the component due to temperature is -1.1 for a sum of +0.4 for $\Delta$ SI. Experience has shown that calcite does not form in scale-free piping at $\Delta S I$ values below 1.0 . The 0.4 value was well below this level and there was no danger 


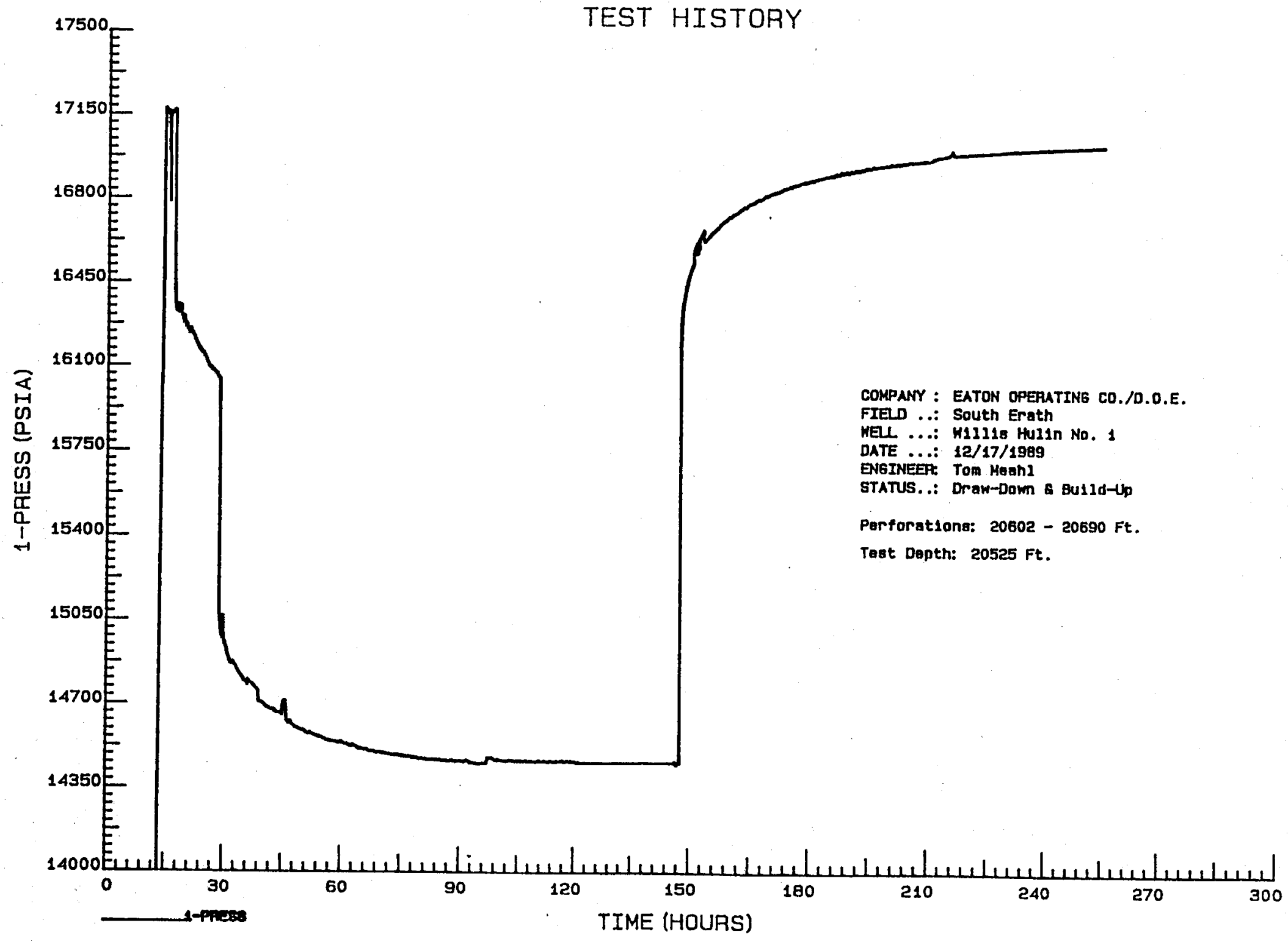




\section{Exhibit 6.2-1. 'SUMMARY OF BRINE AND GAS PRODUCTION FOR DECEMBER 1989 FLOW TEST}

\begin{tabular}{|c|c|c|}
\hline Date & $\begin{array}{l}\text { Brine, } \\
\text { STB }\end{array}$ & $\begin{array}{c}\text { Gas, } \\
1000 \text { SCE }\end{array}$ \\
\hline Dec. 17,1989 & 449 & 13.5 \\
\hline Dec. 18,1989 & 3340 & 102.6 \\
\hline Dec. 19,1989 & 3824 & 116.3 \\
\hline Dec. 20,1989 & 3787 & 114.2 \\
\hline Dec. 21,1989 & 3760 & 106.5 \\
\hline Dec. 22,1989 & 607 & 18.2 \\
\hline
\end{tabular}

of scale formation in the tubing. On the other hand, if the brine rate had been increased to $6000 \mathrm{STB} / \mathrm{d}$, wellhead pressure and temperature would have been expected to level out at values of about $3000 \mathrm{psi}$ and $300^{\circ} \mathrm{F}$, respectively. The resultant value for $\Delta S I$ would have been about +1.2 . This value is into the transition region from nonscaling to scaling. Therefore, the planned rate increase to $6000 \mathrm{STB} / \mathrm{d}$ was not executed because of an unacceptably high possibility of scale formation in the wellhead.

\subsection{Disposal Well Performance}

Output of the disposal well tubing-pressure transmitter increased from 15 to 32 psia during the 12 hours of injection at about $2000 \mathrm{STB} / \mathrm{d}$. But a half hour after the brine rate was increased to about $3800 \mathrm{STB} / \mathrm{d}$, the output of the transmitter went through a minimum of 22 psia. After an hour and a half, it was back up to 32 psia and increasing steadily. The initial rise and fall is not understood. But the lack of a sudden change at the time of the rate increase is strong evidence that the tubing was in fact on vacuum and the injectivity of the disposal well was substantially above the value of $8.3 \mathrm{STB} / \mathrm{d} / \mathrm{psi}$ when the previous flow test was terminated the morning of December $14,1989$.

The injection pressure at a brine rate of about $3800 \mathrm{STB} / \mathrm{d}$ increased from 26 to $200 \mathrm{psia}$ over 3 days. This corresponded to the injectivity dropping back to about $9.0 \mathrm{STB} / \mathrm{d} / \mathrm{psi}$. The injection pressure broke back about $10 \mathrm{psi}$ when oil was manually dumped from the large separator. But this was caused by a temporary decline in the flow rates while the oil was being dumped. The injection pressure then built back up during the last night of operation. 


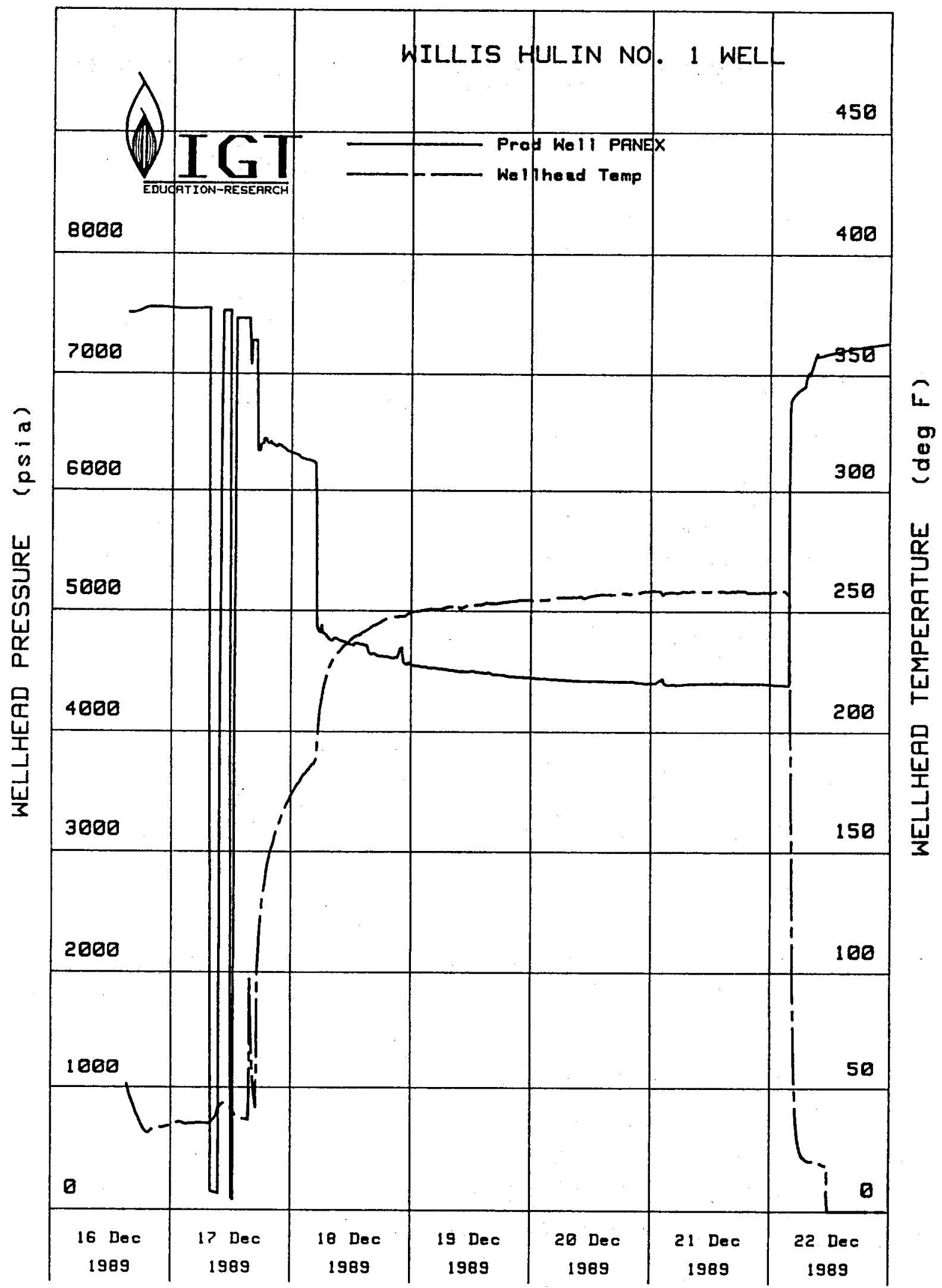

Exhibit 6.2-2. WELLHEAD PRESSURE AND TEMPERATURE FOR 12/16/89 THROUGH 12/22/89 


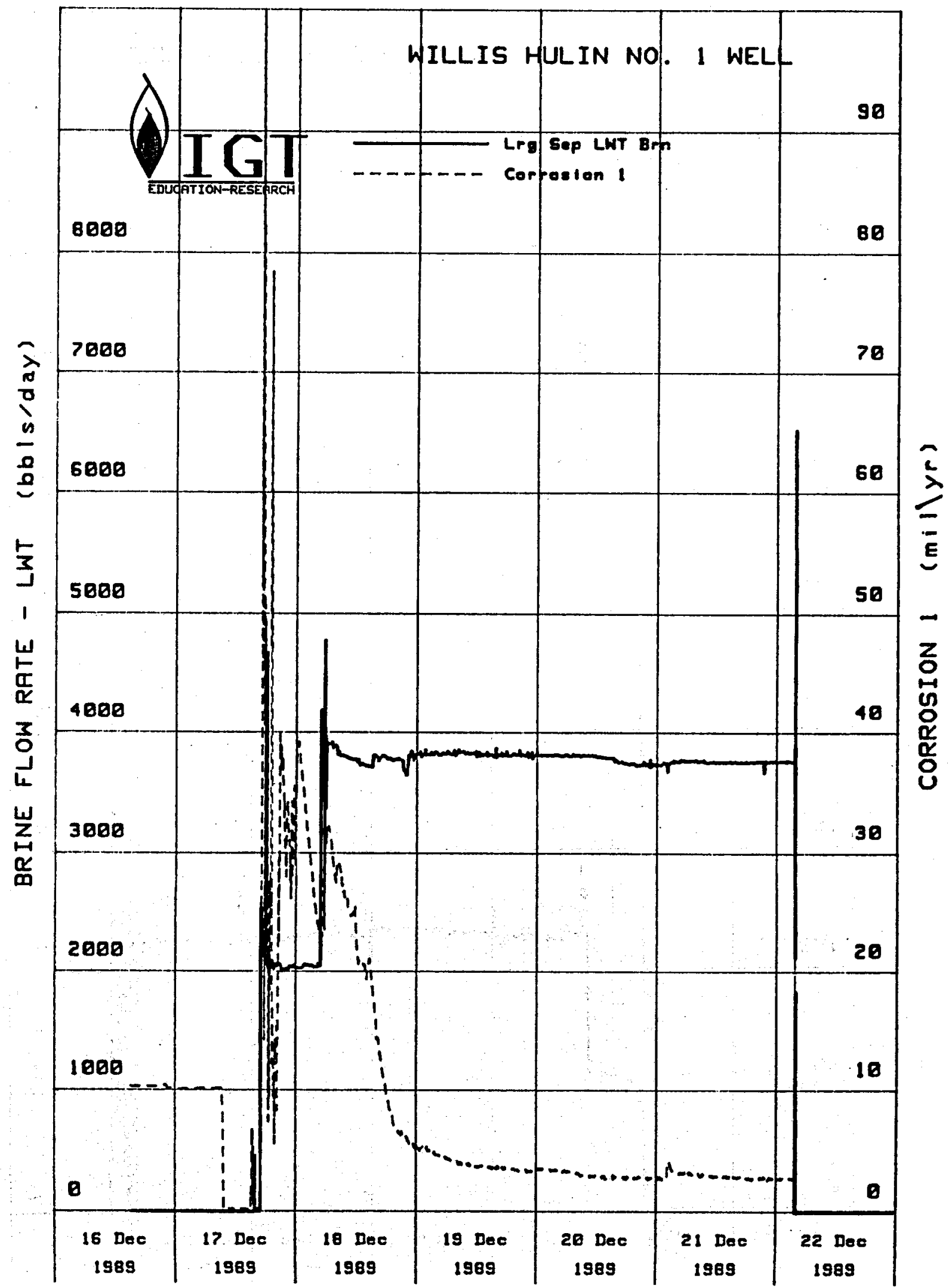

Exhibit 6.2-3. BRINE FLOW RATE AND CORROSION RATE FOR 12/16/89 THROUGH 12/22/89 


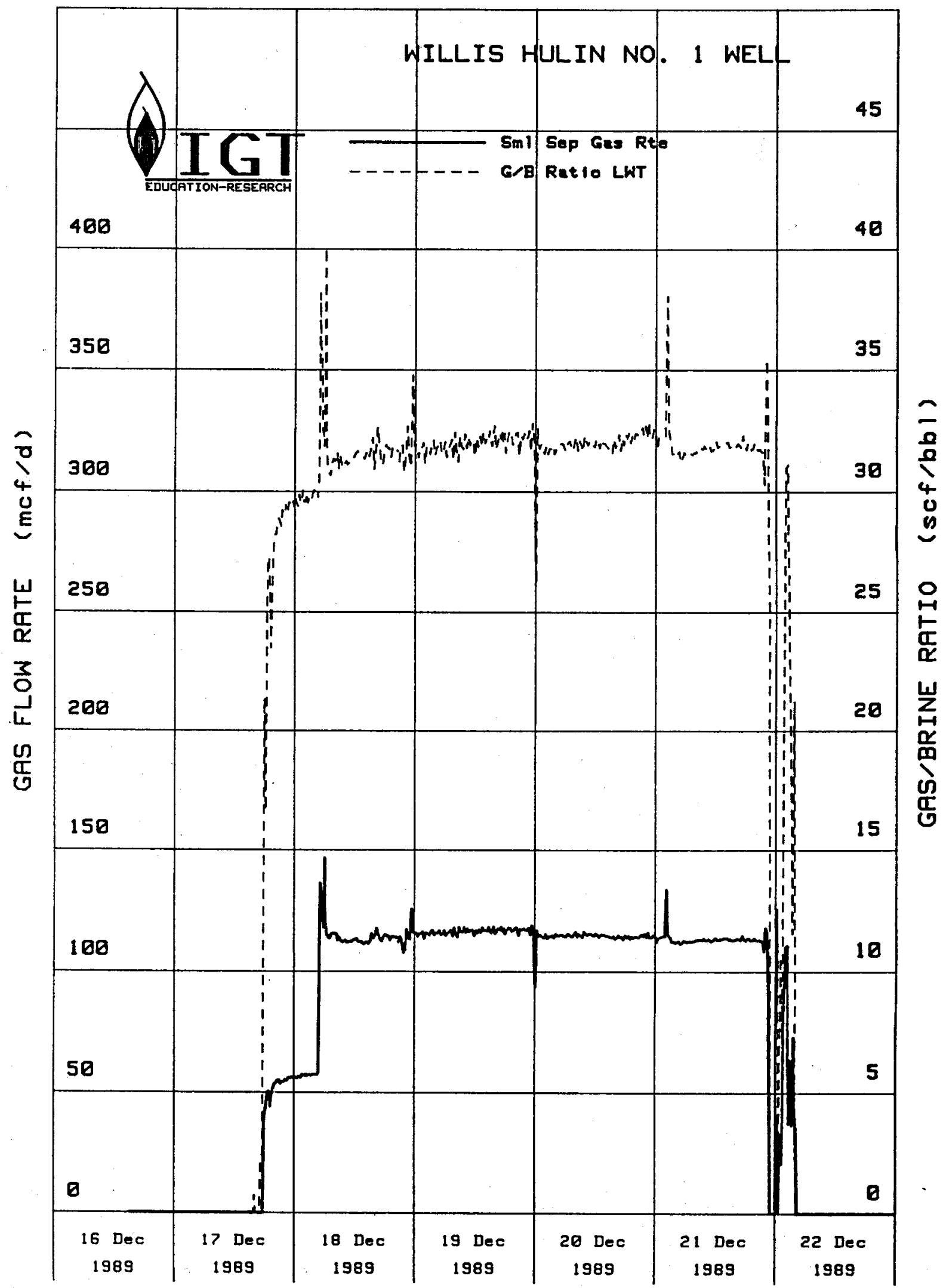

Exhibit 6.2-4. GAS FLOW RATE AND GAS/BRINE RATIO FOR 12/16/89 THROUGH 12/22/89 


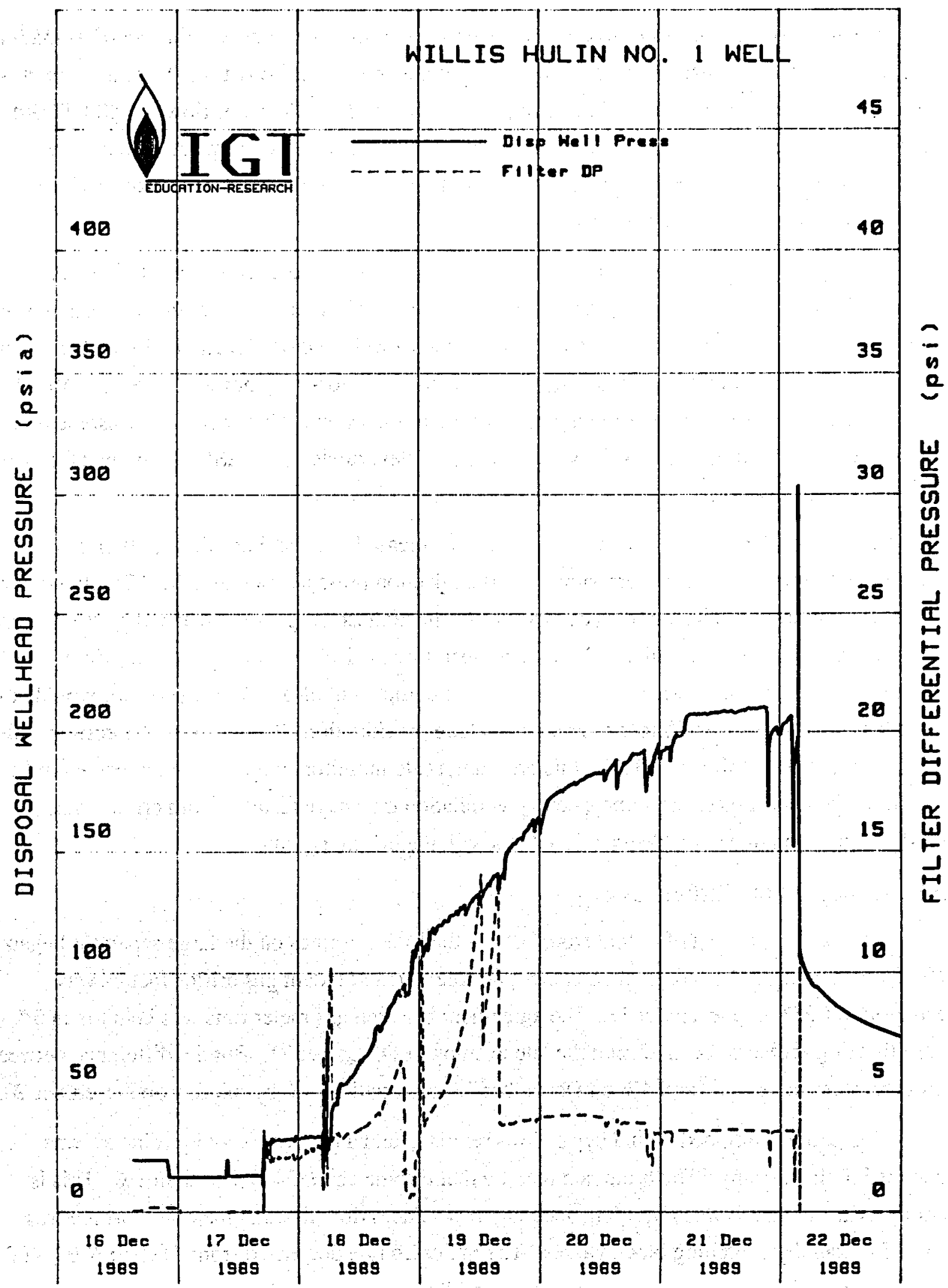

Exhibit 6.2-5. DISPOSAL WELLHEAD PRESSURE AND FILTER DIFFERENTIAL PRESSURE FOR 12/16/89 THROUGH 12/22/89 
The pressure buildup and subsequent reduced injectivity over time is evidence of formation plugging. The rate of change was declining toward the end of the 4-day test. The injection pressure had increased $174 \mathrm{psi}$, from 26 to 200 psia, during the first 3 days of flow at $3800 \mathrm{STB} / \mathrm{d}$. During the last day of flow the injection pressure increased only about 15 psia. There were 10-micron filters on-line for most of this test, and these fine filters should have protected the disposal formation from particulates in the brine.

One hypothesis to explain what may be responsible for the reduced injectivity is scale particles forming in the brine after the filters. The calcite $\Delta S I$ value at a disposal well changes with pressure and temperature. The $\Delta$ SI value at the disposal wellhead on December 18, early after the rate increase, was about 2.3. Tomson et al. stated that inhibitors may not work above a $\Delta$ SI of 2.3. The $\Delta S I$ kept decreasing as the injection pressure increased. This was offset to some degree by the increase in temperature as the well heated up. Nevertheless, the $\Delta$ SI fell below 2.0 toward the end of this flow test.

An explanation of why the injection pressure increased may be that calcite particles were forming in the brine at the low pressures. As the injection pressure climbed, the $\Delta \mathrm{SI}$ fell and the rate of formation of calcite particles decreased. At the highest temperature reached by the disposal brine during this test, $258^{\circ} \mathrm{F}$, the $\Delta S I$ due to temperature is -1.0 . Assuming that the $\Delta S I$ due to carbon dioxide removal at the separator is zero, the component of $\Delta$ SI due to pressure would have to be less than +3.3 for inhibitors to preclude calcite precipitation. The value of 3.3 corresponds to a pressure of about 150 psia. Below this pressure, scale inhibitors would not be expected to be effective. It is also noted that some calcite precipitation may have resulted from erratic scaleinhibitor injection due to mechanical problems with the injection pump.

\subsection{Surface Facility Performance}

Computer recording of output from both of the brine turbines on the large separator began at 19:30 on December 17, and good agreement between the redundant gas orifice meters was achieved at 09:00 on December 18. The agreement between gas meter runs was better than 3\% until freezing problems set in during the late evening of December 21. But the difference between brine turbines increased from $4 \%$ on December 18 to more than $8 \%$ by midday on December 20 .

The turbine equipped with a bypass was removed and a new calibrated turbine kit was installed in the housing. The brine rate read by that turbine changed by less than $1 \%$. This is strong evidence that it was providing accurate data. Then, flow through the other turbine was surged by rapidly switching block valves. The indicated rate decreased from 4145 to $3900 \mathrm{STB} / \mathrm{d}$ while the rebuilt turbine remained reading $3760 \mathrm{STB} / \mathrm{d}$. This second turbine was reading high. 
Turbine meters will read high when a foreign object, such as a rust flake, gets caught upstream of the turbine and causes the fluid to jet past the turbine blades at a higher velocity. The fact that the indicated rate was still significantly higher than the rebuilt turbine after being surged indicated that some debris still remained in the turbine. The redundancy of measuring brine rates provided the information necessary to determine the true flow rates.

The large separator was operated throughout most of the 4-1/2 day flow test with the control air to the oil leg of the separator shut off. IGT discovered after the flow test had ended that the reason for this was not because the oil box was empty, as was thought during the test, but because the oil box kept getting flooded with brine and was dumping brine to the oil tank. Operating without the oil dump 1) was not intended, 2) caused liquid oil in the large separator to be carried over with the water to the filter skid and disposal well, and 3) precluded measurement of the volume of oil leaving the large separator as a liquid.

\subsection{Gas/Brine Ratio}

Several potentially significant changes in gas/brine ratio (GWR) were observed. First, when the brine rate was increased on December 18, both a stepwise increase in gas/brine ratio, from about 29 to 31 SCF/STB, and a gas spike at bottoms up occurred. The separator pressure of 415 psia was not changed when the choke opening was increased from 11/64" to $16.5 / 64$ ", and therefore the calculated concentration of gas remaining in brine from the separator did not change. Thus, the stepwise increase of about 1 or 2 SCF/STB appears to be caused only by the increased reservoir drawdown. Also, the spike in gas/brine ratio at bottoms up may well indicate a small free-gas accumulation in the reservoir rock pores outside the perforations. Both of these observations suggest that the reservoir brine is fully saturated with natural gas. In contrast, at both Gladys McCall and Pleasant Bayou, the bubble-point pressure was initially thousands of psi below the original reservoir pressure.

The second potentially significant change in gas/brine ratio was the modest monotonic increase of about 1 SCF/STB between changes in operating conditions. Small, but real and consistent, changes in tubing pressure, brine rate, and gas rate were observed. The drop in GWR at the midnight between December 19 and 20 was caused by an increase of separator pressure from 415 to 483 psia in order to drive the increasing disposal well pressure. The spike at 02:15 on December 21 appears to be caused by changing reservoir conditions (perhaps a gas bubble from the opening of an additional perforation). The rate changes were seen by both of the redundant gas- and brine-rate meters. With the exception of GWR drops at these two times, which tended to level out the overall average GWR, the GWR tended to increase gradually under steady flow conditions. 


\subsection{Liquid Hydrocarbon Production}

The amount of liquid hydrocarbons that condensed from the gas stream leaving the large separator was large enough for proper operation of the oil leg of the small separator. During December 20, samples from the oil bucket in the separator contained both water and a straw yellow-colored condensate. That night, normal dumps had resulted in only the yellow condensate being present in the oil bucket. The API gravity was $40^{\circ}$. No accurate measurement was made, but the rate of condensate recovery by the small separator was estimated to be about 5 gallons per day.

At the brine rate of about $3800 \mathrm{STB} / \mathrm{d}$, this value gives a rough estimate of condensate recovery of about $30 \mathrm{ppmv}$ (parts per million by volume) in relation to brine production and 1 barrel per million standard cubic feet of gas production. This is about an order of magnitude greater than the amount that condenses due to cooling of the gas leaving the separators at Pleasant Bayou.

\subsection{Scale and Corrosion}

Injection of scale inhibitor and corrosion inhibitor began during the first few hours of production at 2000 STB/d. Both inhibitors were supplied by Coastal Fluid Technologies, Inc., of Abbeville, Louisiana. The corrosion inhibitor, Coastal 1036-C, is an alcohol-soluble proprietary blend that contains a quaternary alkyl amine roughly $40 \%$ by weight. It was injected at a rate of about 9 to 10 quarts/day into the choke manifold upstream of the choke. This provided a concentration in the range of 15 to $30 \mathrm{ppmv}$ in the brine. The scale inhibitor, Coastal 1035-SN, is a proprietary blend that contains $240 \mathrm{~g} / \mathrm{L}$ of ATMP (phosphonate). It was injected at a rate of 2 to 4 quarts/day at a point in the flow line upstream of the choke where the produced brine turned the corner in going from the wellhead to the choke manifold. Phosphonate concentration in the produced brine varied in the range of 0.5 to $3.0 \mathrm{mg} / \mathrm{L}$. There was difficulty in keeping the injection pumps functioning properly, and the injection rates were less uniform than desired.

C-1018 corrosion coupons and Petrolite M-6010 corrosion-rate-monitoring probes were installed both upstream and downstream of the separator. The output of corrosion rate from the Petrolite system is digitized, recorded on the digital data system, and is attached on then same plot as the brine rate. In contrast to the level of about 20 mils per year after an initial higher peak for the 36-hour flow without inhibitor, with inhibitor being injected, the upstream probe showed a corrosion rate that declined to only about 3 mils per year for the last 3 days of the 4-1/2 day test.

New corrosion and scale coupons were installed, and new probes were installed in the Petrolite electronic corrosion monitor on the December 17, just prior to the beginning of the flow. These coupons were not removed on the December 22, when the well was shut in, but remained in 
the lines until January 2. The flow line between the choke manifold and the large separator was opened for inspection on December 26, which exposed the upstream corrosion coupons to atmospheric conditions between December 26 and January 2. Nevertheless, corrosion rates are very low. The analyses reported by Coastal Fluids Technologies are presented in Exhibit 6.7-1.

\section{Exhibit 6.7-1. ANALYSIS OF CORROSION COUPONS AFTER 4-DAY FLOW TEST}

\section{Upstream Coupons Downstream Coupons}

\begin{tabular}{|c|c|c|}
\hline Corrosion Rate, mils/yr & 1.1 & 0.3 \\
\hline \multicolumn{3}{|l|}{ Deposits. $\mathrm{g} / \mathrm{sq}$ in./vr } \\
\hline Hydrocarbons & 0.68 & 0.06 \\
\hline Water-Soluble Salts & 0.20 & 0.02 \\
\hline Iron Compounds & 0.55 & 0.37 \\
\hline Acid-Soluble & 0.55 & 0.01 \\
\hline
\end{tabular}

\subsection{Filters}

One filter pot equipped with 10-micron filter elements was put on-line at the beginning of the flow on December 17. A second pot with 10-micron elements was put on-line when the flow rate was raised from 2000 to $4000 \mathrm{STB} / \mathrm{d}$ on the December 18 . The filter differential pressure was increasing in a manner that suggested solids loading. The first filter was then taken out of service and a third filter pot, with 50-micron elements, was put in service in its place. The 10-micron filter elements were removed from the first filter and found to be black and loaded with a material that resembled drilling mud. New 10-micron elements were placed in the first filter and it was put back on-line. The 50-micron filter was then taken off-line. When the pressure drop across the newly replaced filter was too low, it was taken back out of service and opened for inspection. A chunk of old scale (about an inch across) was found lodged under the end of the filter element such that fluid could bypass the filter. This problem was found and fixed in a few hours.

The filter differential pressure kept climbing rapidly. On the December 19, the differential pressure across the filter pots had increased to about $14 \mathrm{psi}$, so both of the filter pots containing 10-micron filter elements were removed from service and replaced with pots containing 50-micron elements. The 10 -micron elements removed were loaded. The 50-micron elements did not exhibit a pressure increase such as would be caused by filter loading. The solids that were being caught by 10-micron filters apparently passed through the 50 -micron filters.

As discussed in Section 6.3, the pressure and temperature conditions at the filter skid and disposal well were such that the saturation index was in excess of 2.0. It was suspected that scale may have been forming, causing both the filter loading and the disposal well pressure increase. 
Calculations further indicated that the scaling conditions would abate as the disposal well pressure climbed above $300 \mathrm{psi}$. Therefore the 50-micron filters were left on and the disposal well pressure was allowed to rise. The injection pressure kept rising through the test, although the rate of increase declined as the pressure climbed. The disposal well pressure never reached 300 psia during this 4-day flow. Definitive data do not exist on whether calcite was actually the primary source of disposal well plugging.

\subsection{Discussion of Onsite Sampling and Analysis}

Gas, brine, and condensate samples were collected on December 20, 1989, for analysis by IGT and the University of Texas Bureau of Economic Geology (BEG). The results of these analyses are presented in Sections 9.2, 9.5, and 9.6.

Results from the onsite analysis of a brine sample collected the afternoon of December 20 are given in Exhibit 6.9-1. The sulfate concentration in the brine is about $50 \%$ higher than measured for samples from the lower 20 feet of sand on December 6 and 7. The iron concentration was lower than the 280 to $320 \mathrm{mg} / \mathrm{L}$ found in the brine on December 6 and 7. Large reductions in the iron concentration is typical of what is usually observed as corrosion scale develops on newly installed tubulars. The alkalinity value was also significantly lower than the range of 456 to $380 \mathrm{mg} / \mathrm{L}$ observed on December 6 and 7 , raising the possibility that scale may be forming.

\section{Exhibit 6.9-1. ONSITE ANALYSIS OF BRINE SAMPLE ON 12/20/89

\begin{tabular}{lc} 
Component & Concentration in Brine. $\mathrm{mg} / \mathrm{L}$ \\
\cline { 2 - 2 } Iron & 255 \\
Sulfate & 46 \\
Alkalinity, as $\mathrm{CaCO}_{3}$ & 325
\end{tabular}

\subsection{RESERVOIR ENGINEERING ANALYSIS \\ OF THE 20,602 TO 20,690-FOOT INTERVAL}

\subsection{Pretest Estimated Flow Rates and Pressures}

A preliminary estimate of the expected flow capacity of the well was made from the initial flow data from the cleanup flow on February 8 and 9, 1989. IGT performed this analysis with the aid of a simplified numerical simulator that IGT developed (Aquaflo). This simulator assumes single-phase radial flow in the reservoir. It includes pressure drop through the perforations and production tubing friction. The calculations were based on predicted reservoir properties and the current well completion without regard to maximum rates to prevent scale and corrosion. The analysis procedure and projection were as follows: 
1. The static bottomhole pressure was estimated by adding the hydrostatic pressure to the wellhead pressure. Using a brine density of $68.8 \mathrm{lbs} / \mathrm{cu} \mathrm{ft}$ gives a hydrostatic pressure of $9555 \mathrm{psi}$. Adding this to the approximate wellhead pressure of $7245 \mathrm{psi}$ gave a bottomhole pressure of 16,800 psi. Subsequent measurements found this value to be low by just under 500 psi.

2. After the drilling mud was unloaded, the well produced about 400 barrels to a tank in about 2 hours. A flow rate of 4800 STB/d was therefore used for the analysis. As seen in Exhibit 2.0-1, the flowing pressure decreased from about 4300 to about 4000 psi during the flow period from 21:00 to 23:00 hours.

3. The flowing pressure drop up the tubing was calculated by the simulator, assuming normal surface roughness for new pipe. This is shown in Exhibit 7.1-1. Also shown in this exhibit is a similar calculation done by S-Cubed. 7 . The agreement between the IGT calculated friction pressure drop and the S-Cubed pressure drop is very good.

4. Because pressure drops due to flow through the perforations and the reservoir rock are both unknowns, the numerical simulator was run for a series of cases that trade off the reservoir permeability with the perforation losses while matching the $4800 \mathrm{STB} / \mathrm{d}$ flow rate. (In the simulator, skin effects and perforation effects are combined into a composite skin factor.) This curve is shown in Exhibit 7.1-2. For this calculation the reservoir thickness was assumed to be 80 feet, as estimated from the well logs. Because the perforations cover only 20 feet of the reservoir sand and are limited in size and number, there should be appreciable skin effect. For a composite skin factor of 10 , the calculated reservoir permeability would be in the range of 15 to $20 \mathrm{md}$.

5. The simulator was run at different flow rates to predict the initial flow that might be expected for the initial set of perforations in the proposed 90-day trial flow test. The resulting curve is shown in Exhibit 7.1-3. This calculation predicts a maximum initial flow rate of about 9000 STB/d for separator back pressure of about $1000 \mathrm{psi}$. This maximum rate would then decline with time, depending on the formation permeability. At 9000 STB/d the flow velocity through the $1-13 / 16$ inch valves in the wellhead is about $33 \mathrm{ft} / \mathrm{s}$, a high value in the context of probable erosion/corrosion.

6. To estimate the production from the 20,602 to 20,690 -foot zone if the entire zone were perforated, the simulator was run again using a composite skin factor of zero. The resulting flow rate is also shown in Exhibit 7.1-3. At a separator back pressure of 1000 psi the predicted maximum initial flow rate is $14,000 \mathrm{STB} / \mathrm{d}$. Again, this maximum rate will decline with time, depending on the formation permeability.

7. Also shown in Exhibit 7.1-3 is the scoping calculation by S-Cubed. S-Cubed used $17,850 \mathrm{psi}$ as the initial pressure, rather than $16,800 \mathrm{psi}$. The measured reservoir pressure was just over 500 psi below this estimate. There is a reasonable match between this analysis and that of S-Cubed.

8. These studies estimated maximum potential rates. To achieve the maximum rates, the wellhead will need to be replaced by one with larger valves. 


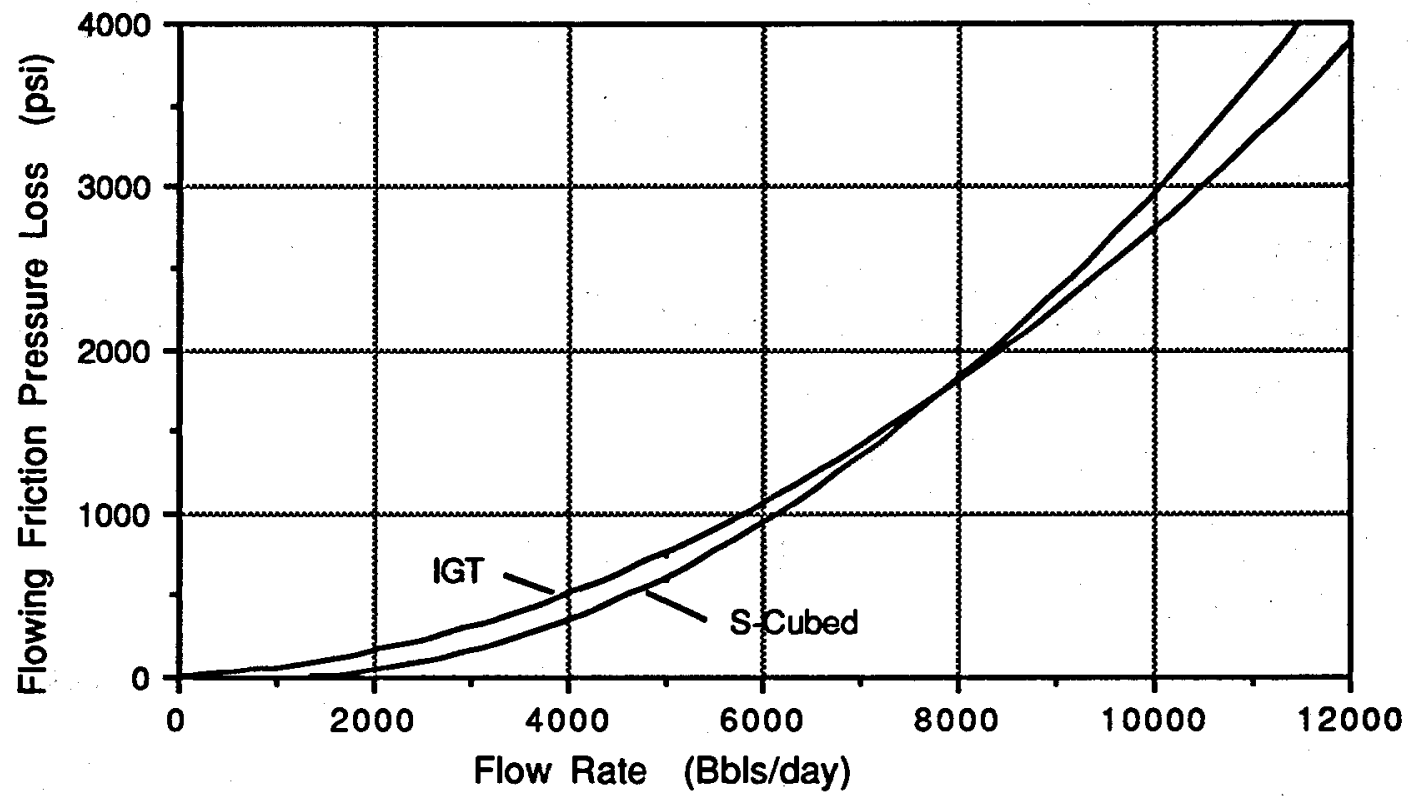

Exhibit 7.1-1. ESTIMATED FLOWING PRESSURE LOSS

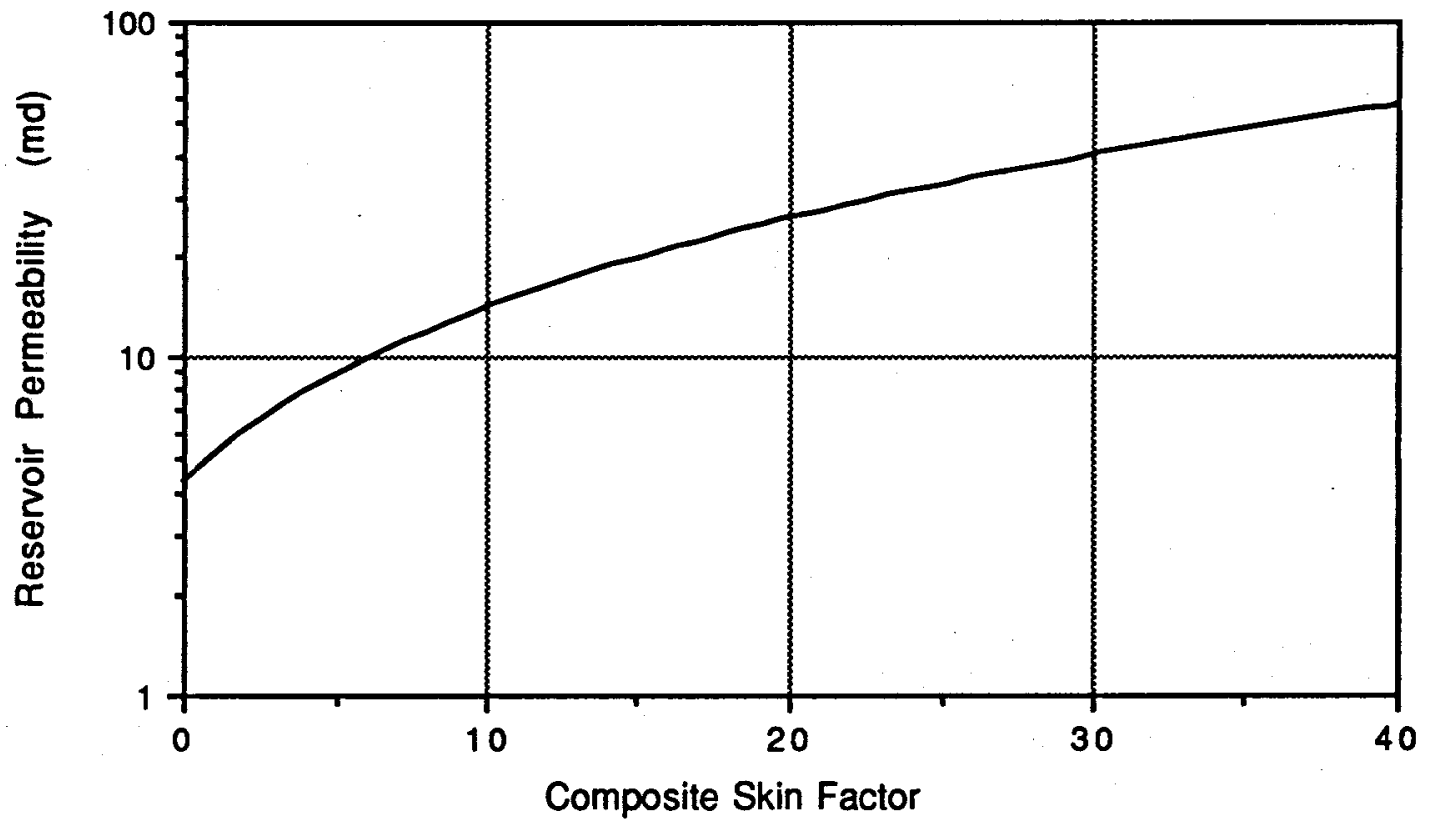

Exhibit 7.1-2. PRETEST ESTIMATED RESERVOIR PERMEABILITY AS A FUNCTION OF COMPOSITE SKIN FACTOR 


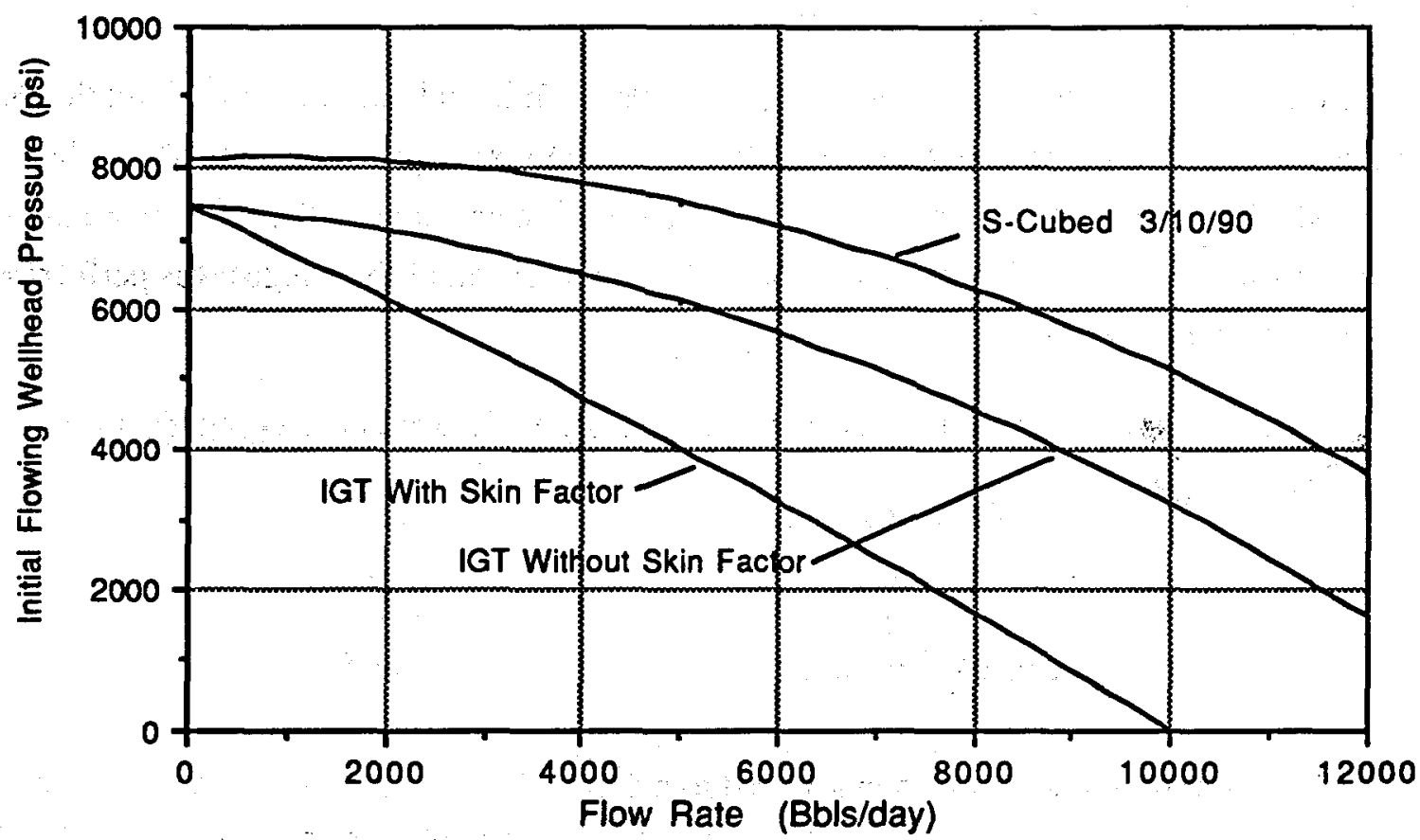

\section{Exhibit 7.1-3. PRETEST ESTIMATED FLOWING WELLHEAD PRESSURE FOR A GIVEN FLOW RATE}

\subsection{S-Cubed Analysis of the 20,602 to 20,690-Foot Zone}

The draw-down and buildup data from the 36-hour and 4-1/2 day December flow tests were immediately transmitted to S-Cubed for a reservoir engineering analysis. Preliminary interpretation, based mostly on the buildup data, is given in Exhibit 7.2-1. The pressure drop across the skin was roughly $1500 \mathrm{psi}$, or more than half the drawdown at the flow rate of $2400 \mathrm{STB} / \mathrm{d}$ used for the test from December 6 to 8 . This high skin for the first 20 feet of perforations may well be caused by very low perforation efficiency for the small charges that had to be used because only a small perforating gun would pass through the 2-1/4 inch inside diameter of the seal assembly. The gun used for the additional 60 feet of perforations before the 4-1/2 day test was even smaller because it had to pass through the 1-13/16 inch inside diameter of the wellhead.

Exhibit 7.2-1. S-CUBED PRELIMINARY ANALYSIS OF THE 20,602 TO 20,690-FOOT ZONE

36-Hour Test 4-1/2 Day Test

Transmissivity, md-ft

Permeability, md $(\mathrm{h}=78 \mathrm{ft})$

Skin Factor

Distance to Fault, $\mathrm{ft}$
1100

$100-130$
1450

20

11

$105-125$ 


\section{Changing Static Bottomhole Pressure}

On January 2 the Milton Cooke Company made a trip in and out of the hole with the Panex bottomhole pressure gauge to obtain a final pressure point for the pressure-buildup test that started at the end of the flow period on December 22. With the Cooke gauge in the lubricator and the sensor positioned at the tubing hanger, a calibration cross-check of the gauges was performed and is shown in Exhibit 7.3-1.

\section{Exhibit 7.3-1. 1/2/90 PRESSURE GAUGE CALIBRATION CROSS-CHECK

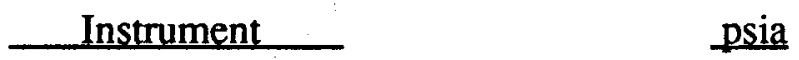 \\ Cooke PANEX 7471 \\ IGT PANEX 7479 \\ Dead Weight Tester 7482}

The bottomhole gauge was then lowered to a depth of 20,525 feet, where a stabilized pressure of $17,090 \mathrm{psia}$ was measured. Using a gradient of $0.48 \mathrm{psi} / \mathrm{ft}$, the pressure at 20,600 feet was calculated to be 17,126 psia. This compares to similar pressure measurements made before flowing to tanks on November 21,1989, and at the start of production on December 6, 1989, as shown in Exhibit 7.3-2.

\section{Exhibit 7.3-2. COMPARISON OF BOTTOMHOLE PRESSURES \\ Date Prior to Flow \\ $11 / 21 / 89$ \\ $12 / 06 / 89$ \\ $01 / 02 / 90$ \\ Bottomhole Pressure \\ at $20.600 \mathrm{ft}$. psia \\ 17,308 \\ 17,283 \\ 17,126}

The continued decrease of bottomhole pressure observed in Exhibit 7.3-2 suggests that the 20,602 to 20,690 -foot zone in the reservoir is of rather limited size.

\subsection{JANUARY 1990 FLOW TEST OF THE 20,220 TO 20,260-FOOT INTERVAL}

In January 1990, primary program emphasis shifted to determining whether there was free gas at the top of the massive sand of interest. The interval from 20,220 to 20,260 feet in the upper portion of the sand was perforated and flow-tested. The previously perforated zone 400 feet deeper, from 20,602 to 20,690 feet, was not isolated. The production from the lower perforated zone was commingled with production from the upper zone during the January 1990 flow tests. 
The strong management interest in whether hydrocarbon production was in excess of solubility in reservoir brine resulted in a number of directed changes in operating conditions and data collection. In addition, temperatures in the freezing or hydrate-forming range for gas piping and metering along with periodic production of rust flakes to the turbine meters caused complications in definitive rate measurements. Nevertheless, the data was good enough to show conclusively that the quantity of free-gas production, if any, was a trivial addition to the solution gas.

Plots of the pressures and rates for the January 1990 production are shown in Exhibits 8.0-1 through 8.0-10. A summary of the test activities follows and details are then presented under subheadings.

January 3: Perforated the depth interval from 20,220 to 20,260 feet.

January 4: 08:00 -- The diesel at the top of the wellbore was flowed through the separator to a tank in about a half hour. After a total of about 155 barrels had been produced to the oil tank and disposal well, the choke began plugging with solids from the new perforations. The separator was then bypassed and liquid was produced directly to a tank.

08:30 -- About 700 barrels were produced to tanks in an effort to clean up the new perforations. Maximum flow rate was estimated to be 11,000 barrels per day, and the last two well volumes were produced at a rate of about 8000 barrels per day.

15:40 -- Production was shut in for 3 hours for cleaning of debris from the brine turbines and repairing a gas leak near the inlet to the small separator.

18:30 -- Resumed production. After an hour at 4800 STB/d, the choke opening was reduced to level out at a brine rate of about $3200 \mathrm{STB} / \mathrm{d}$.

January 5: Steady production at a brine rate of about $3200 \mathrm{STB} / \mathrm{d}$ and with high-quality data. The gas/brine ratio increased from about 28 SCF/STB the evening of the January 4 to about 32 SCF/STB the night of the January 5.

10:00 - - The separator pressure had to be increased from 265 to 320 psia because of increasing disposal well injection pressure.

January 6: 03:40 -- Separator pressure was increased from 320 to 400 psia because of buildup of the disposal well injection pressure.

Collected data to define hydrocarbon loss to the disposal well involved varied operating conditions as set forth below.

11:30 - Increased separator pressure from 405 to 735 psia.

15:05 -- Increased brine rate from about 3200 to about 5000 STB/d. 


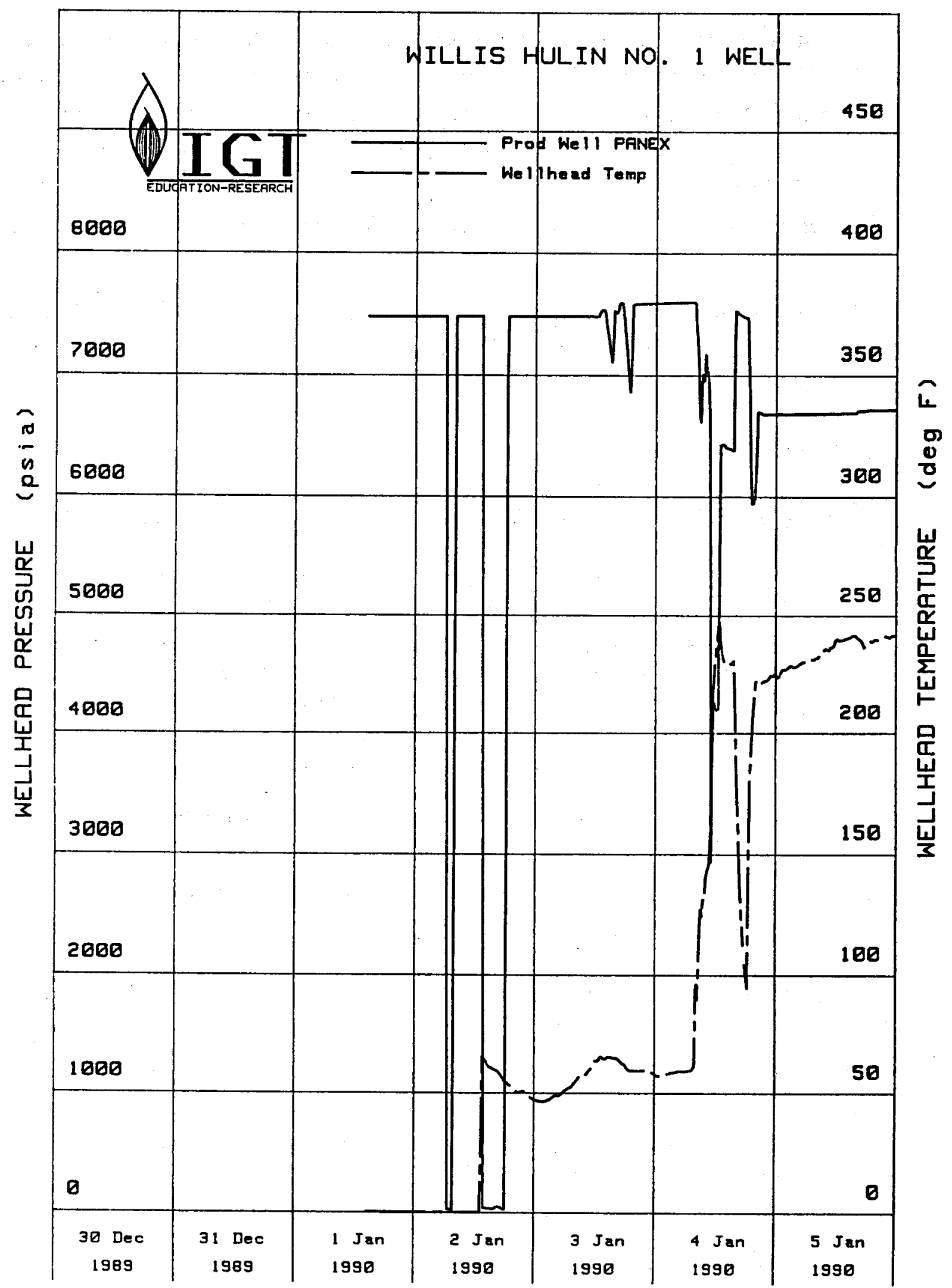

Exhibit 8.0-1. PLOT OF WELLHEAD PRESSURE AND TEMPERATURE FOR 12/30/89 THROUGH $1 / 5 / 90$ 


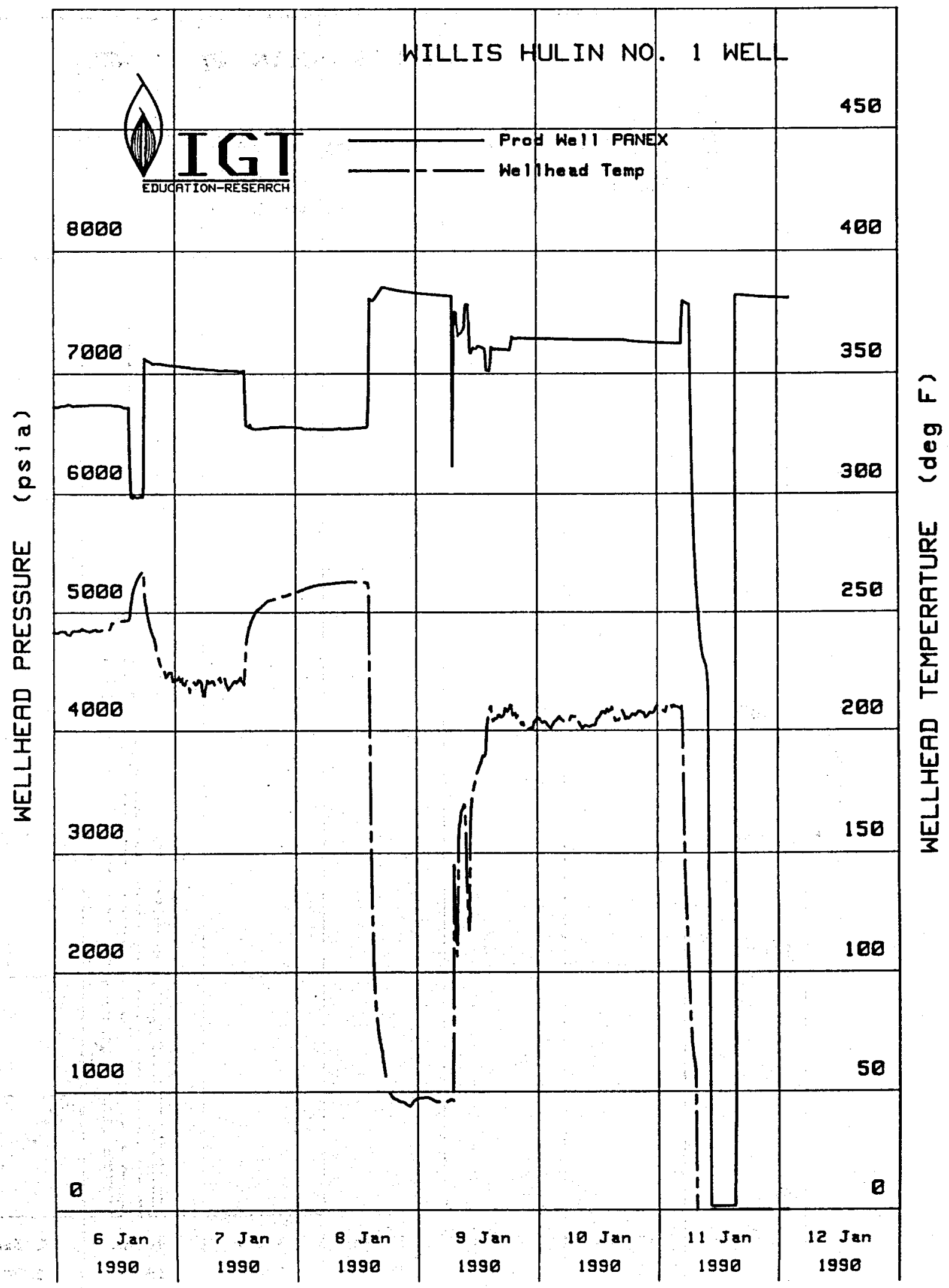

\section{- Exhibit 8.0-2. PLOT OF WELLHEAD PRESSURE AND TEMPERATURE} FOR 1/6/90 THROUGH 1/12/90

INSTITUTE OFF GAS TECHNOLOG Y




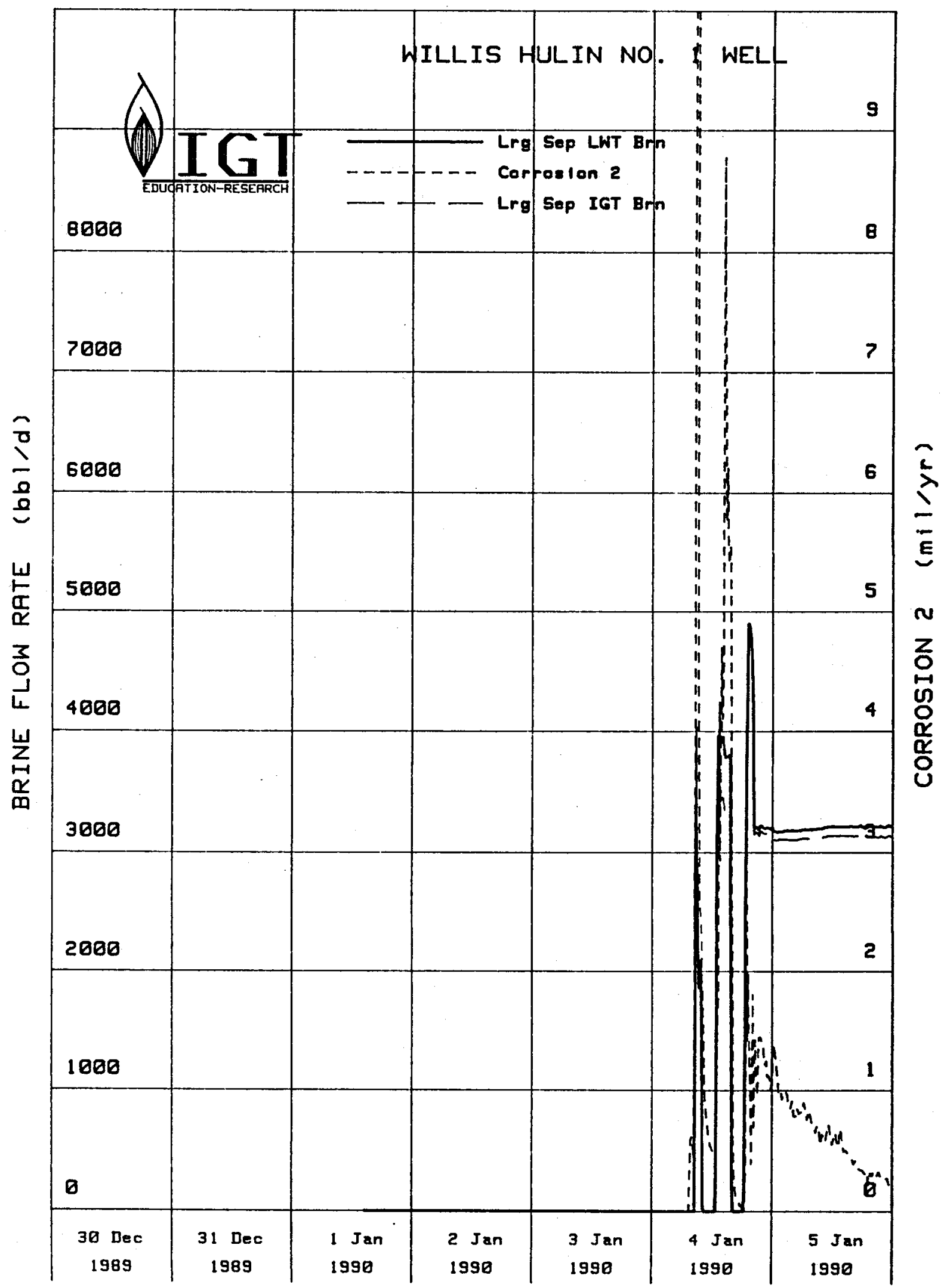

Exhibit 8.0-3. PLOT OF BRINE FLOW RATE AND CORROSION RATE FOR 12/30/89 THROUGH $1 / 5 / 90$

60
I N S S T I T U T E
O F
G A S
TECH NOL L O G Y 


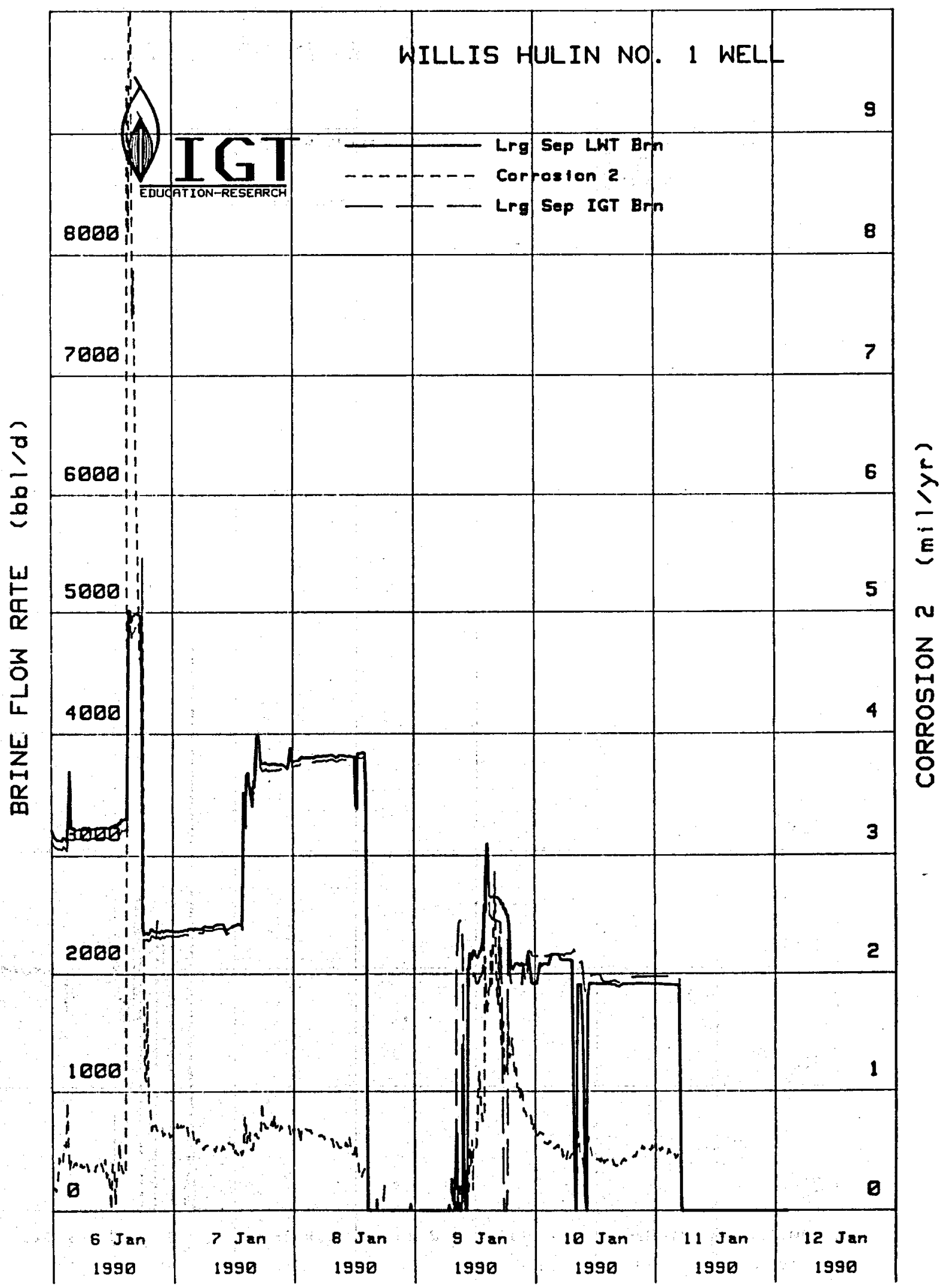

Exhibit 8.0-4. PLOT OF BRINE FLOW RATE AND CORROSION RATE FOR 1/6/90 THROUGH 1/12/90
I N S T I T U T E
O F
G A S
T E C H N O L O 


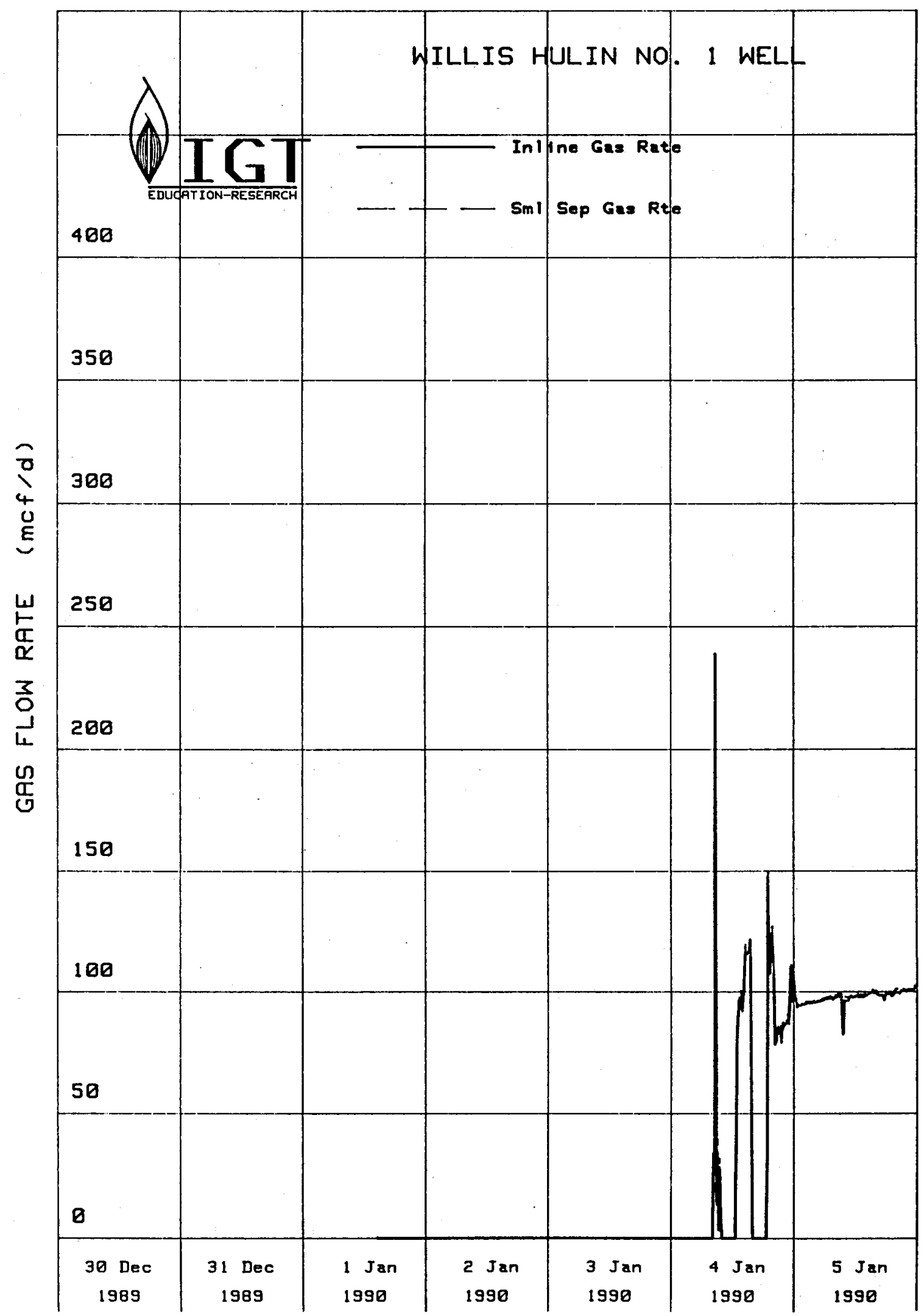

Exhibit 8.0-5. PLOT OF GAS FLOW RATE FOR 12/30/89 THROUGH 1/5/90

62
I N S T I T U T
O F
G A S
T E C H N O L O G Y 


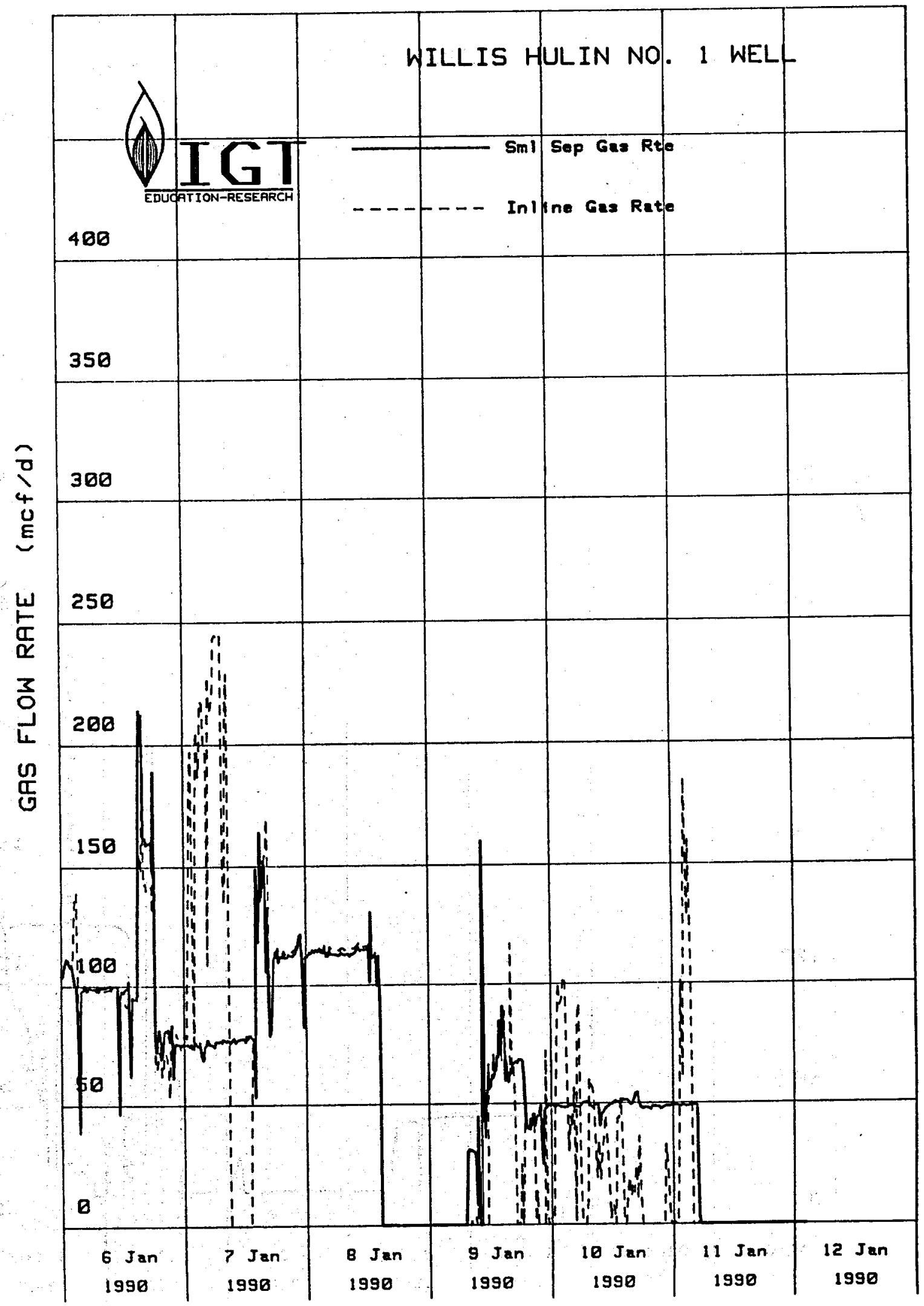

Exhibit 8.0-6. PLOT OF GAS FLOW RATE FOR 1/6/89 THROUGH 1/12/90 


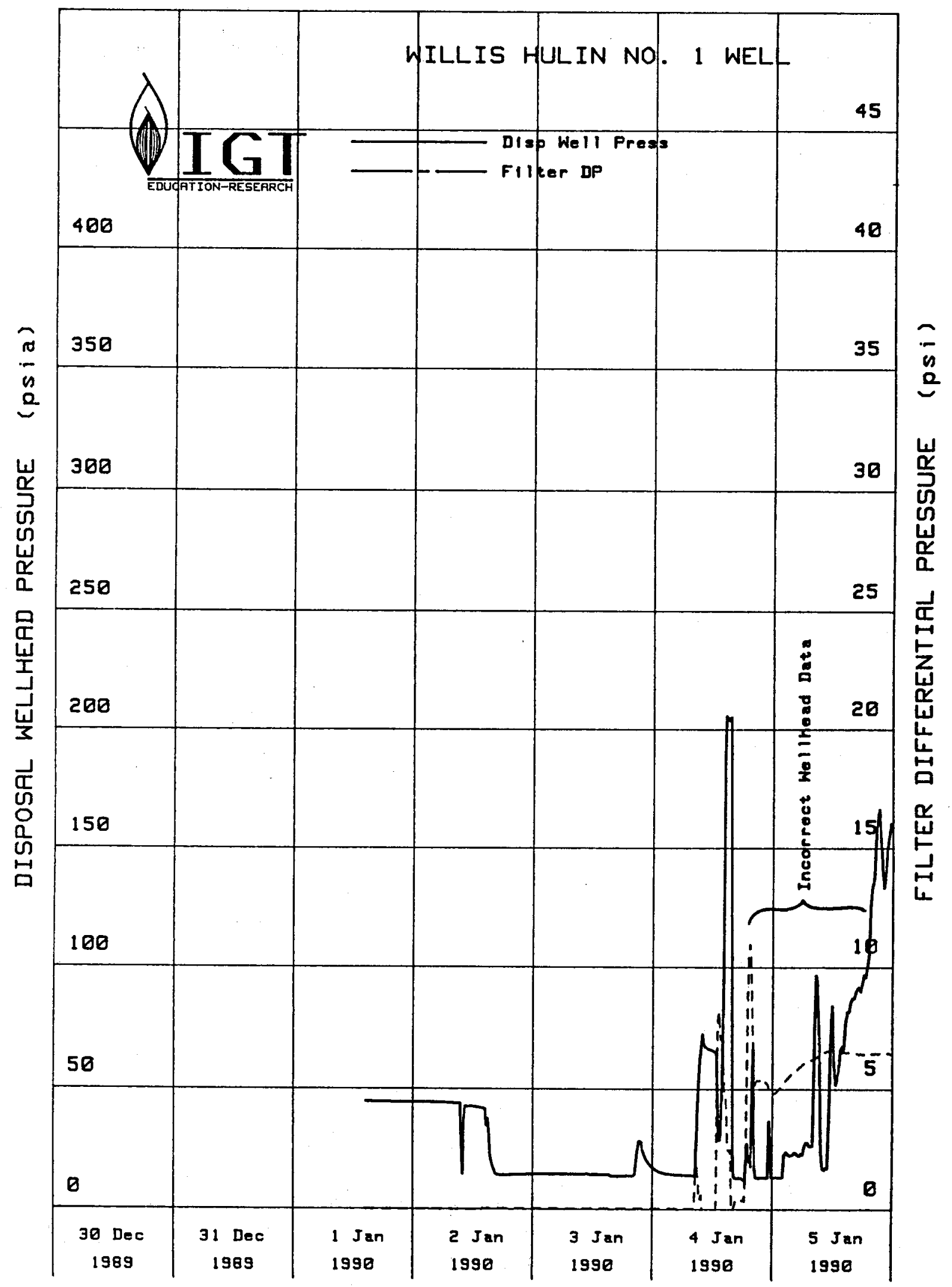

Exhibit 8.0-7. PLOT OF DISPOSAL WELL WELLHEAD PRESSURE AND FILTER DIFFERENTIAL PRESSURE FOR 12/30/89 THROUGH 1/5/90 


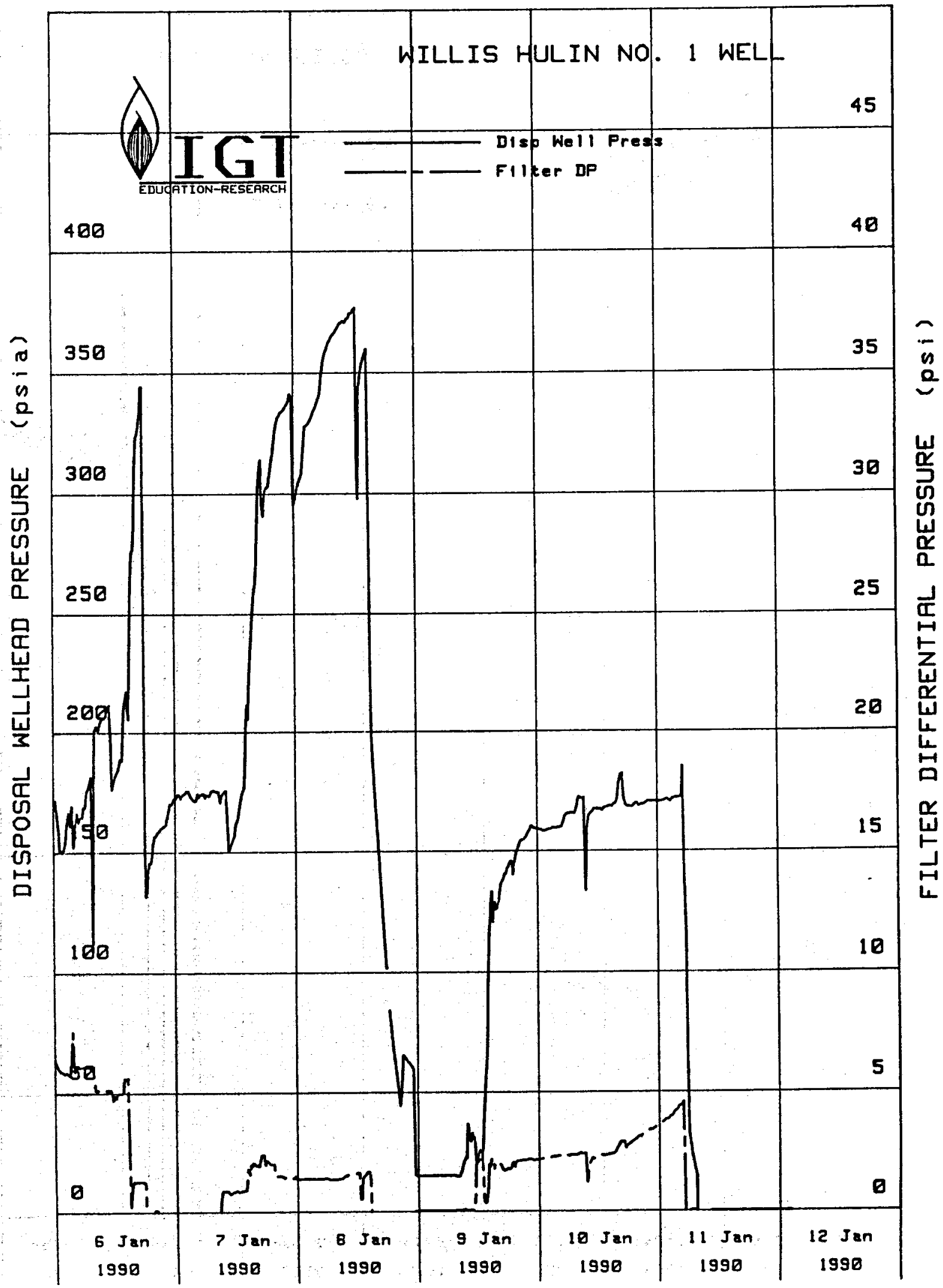

Exhibit 8.0-8. PLOT OF DISPOSAL WELL WELLHEAD PRESSURE AND FILTER DIFFERENTIAL PRESSURE FOR 1/6/89 THROUGH 1/12/90 


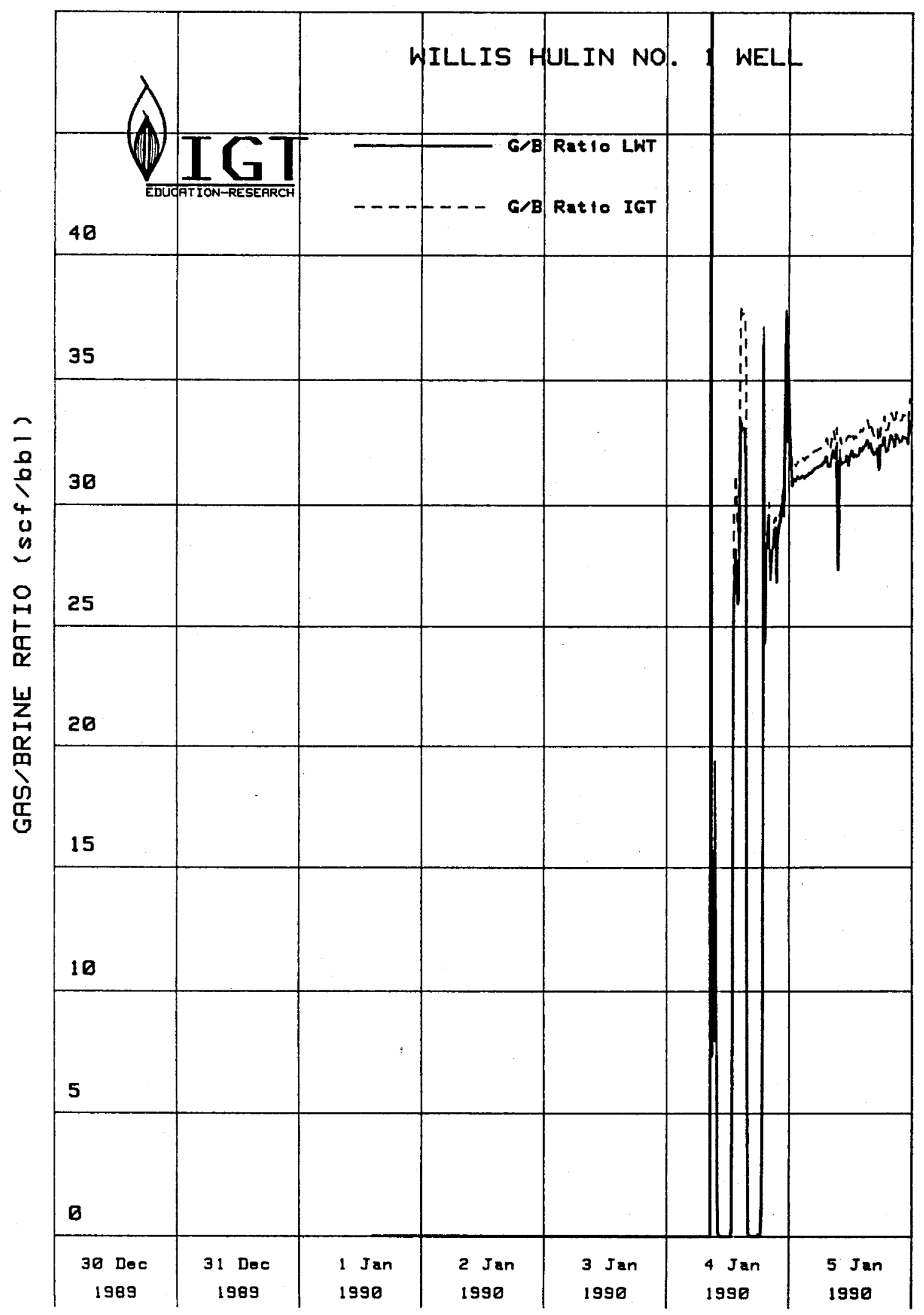

Exhibit 8.0-9. PLOT OF GAS/BRINE RATIO FOR 12/30/89 THROUGH 1/5/90

66
$\begin{array}{lllllllll} & \text { N } & \text { S } & T & \text { I } & T & \text { U } & \text { T } & E\end{array}$
O F
G A S
T E C H N O 


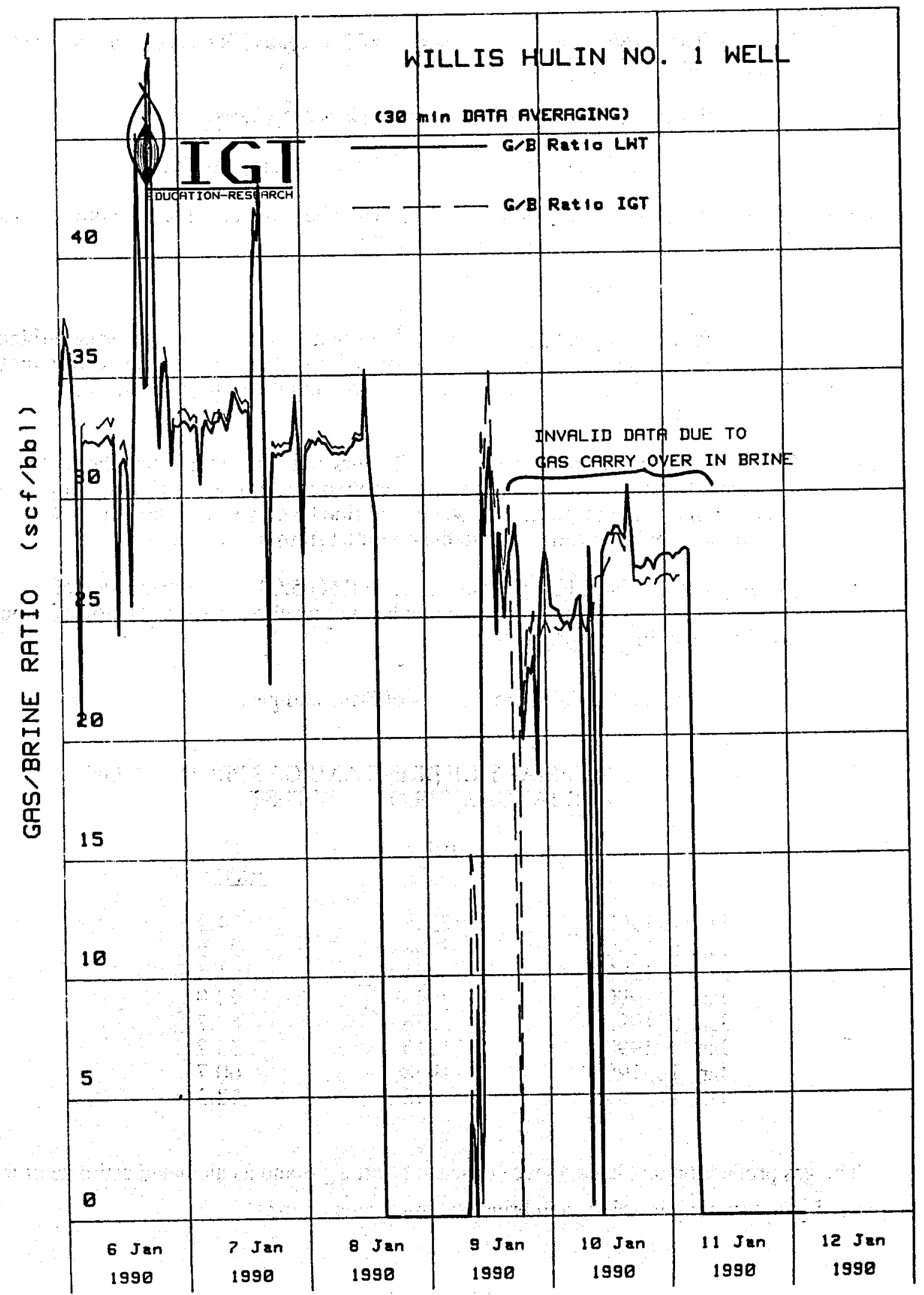

Exhibit 8.0-10. PLOT OF GAS/BRINE RATIO FOR 1/6/89 THROUGH 1/12/90 
18:00 -- Decreased brine rate from about 5000 to about $2300 \mathrm{STB} / \mathrm{d}$ and separator pressure from 735 to 295 psia.

January 7: Evaluated brine spillover to the oil leg of the large separator.

14:00 -- Increased brine rate from about 2300 to about $3500 \mathrm{STB} / \mathrm{d}$.

January 8: $14: 30$-- The production well was shut in so the the primary separator could be opened for interior inspection of the oil and brine weirs.

January 9: 07:30 -- Resumed production.

10:40 -- Produced again after shutting down for an hour to clean the brine turbine meters. Varied rate to determine the maximum possible without brine flow over the oil weir. This was found to be about $2000 \mathrm{STB} / \mathrm{d}$, and the gas/brine ratio was anomalously low.

January 10: 08:00 -- Cleaned turbine meter twice in 2 hours and performed other checks that indicated the low gas/brine ratio being measured was erroneous because of gas carryover in brine to the disposal well when the brine level was low enough for the brine weir to prevent brine carry-over to the oil outlet from the separator.

January 11: Testing was terminated by shutting in the well at 05:00. More than a day of operation without brine carry-over to the oil outlet had not resulted in accumulation of enough condensate to be measurable.

Exhibit 8.0-11 tabulates the daily productions of brine and gas.

\section{Exhibit 8.0-11. SUMMARY OF BRINE AND GAS PRODUCTION FOR JANUARY 1990 FLOW TEST}

\begin{tabular}{ccc} 
Date & $\begin{array}{c}\text { Brine, } \\
\text { STB }\end{array}$ & $\begin{array}{c}\text { Gas, } \\
1000 \text { SCF }\end{array}$ \\
\cline { 1 - 1 } Jan. 4, 1990 & & \\
Jan. 5, 1990 & 2558 & \\
Jan. 6, 1990 & 3204 & \\
Jan. 7, 1990 & 3191 & 98.6 \\
Jan. 8, 1990 & 2946 & 101.4 \\
Jan. 9, 1990 & 2256 & 92.0 \\
Jan. 10, 1990 & 1115 & 67.7 \\
Jan. 11, 1990 & 1958 & 33.2 \\
& 398 & 60.7 \\
& & 12.3
\end{tabular}

The gas production tabulated above consists of flared gas and a calculated estimate of the amount of gas remaining in solution in brine leaving the separator. 


\subsection{Perforation of the 20,220 to 20.260 -Foot Interval}

On January 3 the interval between 20,220 and 20,260 feet in the uppermost part of the 600-foot zone of interest was perforated with two Schlumburger perforating guns. Four shots per foot were fired using 3.2-gram Hyperdome charges of HMX explosive with zero degree phasing. The guns were decentralized with magnets.

When the first gun was fired, there was a step change in the static wellhead pressure of about $20 \mathrm{psi}$, which was a good indication that communication with the formation had been achieved. When the second gun was fired, there was also a similar step change in pressure of another $20 \mathrm{psi}$. This second step in pressure raised the speculation that these new perforations might be producing fluid that was in crossflow with the lower perforations. The observed changes in the wellhead pressure could be caused by the relative efficiency of the upper sets of perforations to produce fluid and the lower set of perforations to accept fluid. A large quantity of drilling mud-like material, such as was produced to the surface during the perforation cleanup flow of the December 1989, might quickly plug off the lower zone and minimize crossflow. Both intervals, however, would be expected to contribute to production.

\subsection{Production Well Performance}

Production was initiated by first flowing the diesel on the top of the fluid column to a tank and then flowing to the disposal well when clean brine was being produced. The well was surged at a flow rate of about $11,000 \mathrm{STB} / \mathrm{d}$ for a few minutes to help clean the perforations by opening the choke to 32/64". At bottoms up, debris from the new perforations began flowing into the separator, so flow was switched to the tanks. The debris produced to the tanks consisted of solids and black oil that appeared to be old drilling mud. About 700 barrels of brine were produced to tanks in an attempt to remove most of the debris that might have come from the previous perforations in addition to the new perforations.

Following the cleanup flow, the choke was briefly adjusted between 6/64" and $16 / 64$ " to determine flow rates versus choke settings and then set at $12 / 64$ " for a steady flow of about $3200 \mathrm{STB} / \mathrm{d}$. At this stabilized brine flow rate, gas was being produced at a rate of about $80,000 \mathrm{SCF} / \mathrm{d}$, for a gas/brine ratio of 28 to $29 \mathrm{SCF} / \mathrm{STB}$.

About midnight on January 4 there was a brief burst of gas followed by a continued increase in gas production. This resulted in a change of the gas/brine ratio from the previous 28-29 to 3031 SCF/STB, with the higher value being reached the evening of January 5. After January 5 the data became too erroneous for careful examination in the context of gas/brine ratio. 
The additional perforations at the top of the sand (20,020 to 20,060 feet) significantly increased the productivity of the well. With only the bottom zone open, the productivity was about $1 \mathrm{STB} / \mathrm{d} / \mathrm{psi}$ of drawdown. The additional perforations raised the productivity to about $3 \mathrm{STB} / \mathrm{d} /$ psi of drawdown. At a flow rate of $2000 \mathrm{STB} / \mathrm{d}$, the new pressure drawdown is about $1000 \mathrm{psi}$ less than before the additional perforations, and at $4000 \mathrm{STB} / \mathrm{d}$ the drawdown was about $2000 \mathrm{psi}$ less. The increased wellhead pressures combined with the low flow rates kept the scale formation saturation index below 1.0 and precluded scale formation in the wellbore and wellhead.

\subsection{Disposal Well Performance}

When operations were resumed on January 2 there was approximately 44 psi of pressure on the disposal wellhead remaining from the previous flow test. This pressure was in part the result of the gas trapped in the well on top of the brine, depressing the brine below its static level. The pressure was bled off and the next day a measurement was made to determine the depth to the top of the brine by injecting a known volume of nitrogen. This inexpensive method, using materials already at hand, was used after permission to run a wireline to measure the fluid level was not granted. Using the measured pressure change and Boyle's law, the static level of the brine was calculated to be 445 feet. Previous measurements with a different brine in the well had found a fluid level near $\mathbf{4 7 4}$ feet. The difference between these two measurements is not significant because of the limited accuracy of the methods employed.

The wellhead pressure in the disposal well increased with production. Accurate measurement of the pressure was not made on January 4 and 5 because gas was being vented from the instrument tubing as part of the test to determine the amount of free gas going into the disposal well. This caused the gauges to read low. Near midnight on the January 5, the pressure of 320 psia in the large separator could no longer drive all of the brine into the disposal well, causing the separator to flood and send brine over the top through the gas line to the small separator. Increasing the back pressure in the large separator to 400 psia restored the ability to drive all of the brine from the separator into the disposal well. Accurate measurement of the disposal wellhead pressure was restored on the January 6 by changing the disposal well pressure-gauge location to read the pressure in the flow line ahead of the disposal well where gas was not being bled through the gauge line.

The maximum injection pressure used during this test was $365 \mathrm{psia}$. At that pressure, the injection pressure continued to increase at a constant brine rate. The filter elements used during this flow test were nominally rated at 50 micron. Whether the plugging was caused by calcite 
particles or other solids passing through the 50-micron filters is not known. Previous flow tests had shown that 10 -micron filters would accumulate solids loading whereas 50 -micron filters would not.

\subsection{Surface Facility Ferformance}

Some difficulty was experienced in keeping the brine turbine meters functioning properly. Chips of rust or other debris from the separator lodged in one or the other turbine meter several times, causing it to read incorrectly. Shortly after start-up, the well had to be shut in to replace an elbow joint in a gas flow line that sprung a leak. The turbines were again cleaned during this shutdown. Once the flow had been resumed and the rate stabilized at about $3200 \mathrm{STB} / \mathrm{d}$, the turbine meters appeared to function properly.

There was some concern about how much gas was going through the separator to the disposal well. Such losses could be a contributing factor to a low measured gas/brine ratio. To answer this question, a small orifice "flow-prover" meter was connected to the bleed-down line on the filter pot, and the valve was operated manually to continually bleed off the gas that would otherwise collect in the top of the filter pot and eventually go through the filter to the disposal well. This would give a crude measurement, perhaps within a factor of 2 or 3 , of the amount of gas going to the disposal well with the brine. For most of January 5 , when the well was flowing steady at $3200 \mathrm{STB} / \mathrm{d}$, the flow-prover meter measured $4000 \mathrm{SCF} / \mathrm{d}$. This measurement includes steam and carbon dioxide that also come out of the brine with pressure reduction. The gas/brine ratio is 1.2 SCF/STB. The dilution of the exsolved gas with carbon dioxide as the pressure drops between the separator and the disposal well is evident from the gas analysis presented in Section 9.3.

At the time of this flow measurement, the separator pressure was 264 psia and the IGT data acquisition computer program calculated that 3.2 SCF/STB of methane was leaving the separator. The bleeding gas precluded measurement of the disposal well injection pressure. But it is clear that the amount of gas being bled from the filter skid was too small for a significant amount of gas to have been leaving the separator in the form of bubbles in the exiting brine. Although the gas-flow measurement was not very accurate, it did show that no large volumes of gas, which would give a low gas/brine ratio, were getting past the separator and into the disposal well.

A separator study was performed to measure the quantity of gas remaining in the brine after the separator. This test entails collecting gas samples and samples of brine under pressure from the separator. The brine samples were then flashed to atmospheric pressure and the exsolved gas was measured and analyzed. These data, presented in Section 9.2.4, agreed reasonably well with the amount calculated by the algorithm. 
The control to the oil leg of the large separator was shut off most of the time because the oil box continued to be flooded with brine and would dump brine to the tank. Shutting off the oil dump allowed any produced oil to go out with the brine. It was speculated that solids from the well had plugged the flow path or that there was a hole in the oil partition that let brine into the oil box. The decision was made to shut in the well and open the separator for internal inspection.

When the separator was opened on January 8, a significant amount of solids was found (perhaps 1 to 2 cubic feet), but that was not the problem. The problem was that the heights of the oil and water weirs in the separator were set to handle a large volume of oil but only a small volume of water. There was only a 1-1/4 inch difference in elevation in the weirs, and the adjustable plate on the notch in the water weir was set at its highest point to pass the smallest amount of water. The relatively high brine rates caused the brine level to stabilize at an elevation above the top edge of the oil weir rather than below it. Consequently, brine would always flow over the oil weir into the oil box. The solids in the separator, which looked like old drilling mud, were flushed out. The adjustment plate over the notch in the water weir gate was removed to get the maximum brine flow capacity. The weir was 20 inches wide and the notch was 3 inches deep and 4 inches wide.

The well had been shut in to inspect the separator by closing the block valve on the choke manifold without changing the choke setting. To resume flow on January 9, the block valve was opened and the choke was left at the same setting. Within a few minutes, while Lafayette Well Testing operators were adjusting the level controllers, the brine level and separator pressure rapidly rose and a safety relief valve opened. The choke was immediately turned to zero, but this did not stop the flow. It was necessary to reclose the block valves to stop the flow. Inspection of the choke found the stem and seat to be severely eroded. The threads and seat on the outside of the choke stem were also cut. The flow was resumed through a second choke on the manifold.

On January 9, flow was resumed with the oil box in the separator initially empty. The choke was opened in steps of $4 / 64 ", 8 / 64 ", 10 / 64$ ", and $12 / 64$ " to experimentally find the maximum flow rate the separator could handle before brine overflowed into the oil box. This overflow began when the choke was changed from 10/64" to 12/64" and the flow was between about 2100 and $2600 \mathrm{STB} / \mathrm{d}$.

At the 8/64" setting, both turbine meters began to malfunction. First, the turbine that could be bypassed was removed and cleaned. Coin-sized flakes of rust were lodged in it. When it was returned to service, there was a very large discrepancy between it and the other turbine meter (which could not be bypassed). The well was shut in to clean this turbine. Coin-sized flakes of rust were also found lodged in this second turbine meter. During the next few hours, when the 
choke was at $10 / 64 "$ and $12 / 64 "$ ", the turbine meters would occasionally begin reading high, presumably from more flakes of rust again lodging in them. Pounding on the turbines with a hammer usually caused them to return to lower readings, presumably dislodging whatever was caught in them and causing them to read high. However, whether all debris was cleaned out of the turbines with these hammer strikes could not be determined. The accuracy of brine-rate measurements is questionable.

Once it was determined that rates much over $2000 \mathrm{STB} / \mathrm{d}$ would cause brine to spill into the oil box, the choke was set first at 10/64" (approximately $2500 \mathrm{STB} / \mathrm{d}$ ) for 3 hours, but this was too close to the limit and some brine would occasionally spill into the oil box. The choke was then set at 9/64" at 7:00 p.m. on January 9 and left at that setting for the remainder of the flow test.

Discussions between Lafayette Well Testing personnel and representatives of the manufacturer of the separator concluded that the entire water weir needed to be lowered. The $3 \mathrm{X}$ 4-inch notch in the weir was not adequate to handle the high brine rates we had planned. To make this change, the well would need to be shut in and the vessel opened up again. At the same time (January 10) an EOC management decision was made to terminate the flow test immediately. Thus, no modification was made. Rather, the flow was held constant in order to trap any oil that might be produced from the well.

These field conclusions are reasonably consistent with calculations of flow through a rectangular weir that were performed at the time of writing this report. For a head of 3 inches, water flow through a 4-inch-wide opening is calculated to be 1650 barrels per day.

\subsection{Gas/Brine Ratio}

Immediately after well cleanup on January 4 , when the flow was changed from the tanks to the separator and the flow was about $4000 \mathrm{STB} / \mathrm{d}$, the gas/brine ratio measured between 27 and 31 SCF/STB. After the measured gas/brine ratio jumped to between 33 and 37 SCF/STB a few hours later without a corresponding increase in the wellhead pressure, the turbine meters became suspect. The well was shut in for work on the turbine meters. When flow was resumed, first at a rate of $4800 \mathrm{STB} / \mathrm{d}$ for an hour and then to a rate of $3200 \mathrm{STB} / \mathrm{d}$ for stabilized flow, the measured gas/brine ratio was again back in the range of 27 and 29 SCF/STB. In about 2 hours, or the time for bottoms up in the well, there was a burst of gas and an increase in the gas/brine ratio to between 31 and 32 SCF/STB. The gas/brine ratio then increased monotonically up to between 32 and 33 SCF/STB for the next 24 hours. This increase in the gas/brine ratio is believed to be real and was documented by redundant gas and brine measurements.

The gas/brine ratio exhibited some small dependance on brine flow rate. When the brine flow rate was steady at $3200 \mathrm{STB} / \mathrm{d}$, the ratio was 31 to $32 \mathrm{SCF} / \mathrm{STB}$. When the rates and 
separator conditions were varied for chemistry sampling during the separator study on January 6 and 7, the measured gas/brine ratio also varied somewhat. At the 5000 STB/d flow rate, the ratio went to about 35 SCF/STB. Changing the flow rates back down to 2400 and $3800 \mathrm{STB} / \mathrm{d}$ and separator pressure between 295 and 737 psia resulted in the gas/brine ratio varying between 32 and 33 SCF/STB. These variations may be caused by measurement inaccuracies.

The gas/brine ratio measured after the large separator was put back into service as a threephase separator was largely incorrect. By removing the plate that covered the notch in the water weir gate to allow proper separation of oil and brine, the level controller had to be adjusted to hold the brine level at a point below the notch. This level was so low in the vessel that it allowed gas bubbles caught by the brine flowing through the notch to be carried down and out with the brine. This caused the brine turbines to read high and the gas meter to read low, for the net effect of an incorrect, low gas/brine measurement.

When the separator was first put back in service at a choke setting of 4/64" (at a rate too low to accurately measure with the turbine meters), the indicated gas/brine ratio was in the range of 31 to 34 SCF/STB. At this low rate there was apparently little carry-over of gas with the brine. At larger choke openings and higher flow rates, the indicated ratio became quite erratic but somewhat related to the brine flow rate. When the choke was set at 10/64" and the flow rate was about $2500 \mathrm{STB} / \mathrm{d}$, the indicated gas/brine ratio was about $23 \mathrm{SCF} / \mathrm{STB}$. When the choke was changed to $9 / 64$ " and the flow rate was lowered to about $1900 \mathrm{STB} / \mathrm{d}$, the indicated gas/brine ratio increased to the range of 26 to $28 \mathrm{SCF} / \mathrm{STB}$.

Considerable editing was required to estimate the produced gas/brine ratio after the weir was "fixed," and the data accuracy is marginal.

\subsection{Liquid Hydrocarbon Production}

A small amount of condensate was collecting in the small separator but was flushed to the tank when the large separator overflowed during the night of the January 4 and sent brine into the gas lines and small separator. During the stabilized flow on January 5, small amounts of condensate collected in the small separator, but the quantity was in the range of a few gallons and too small to get a good measurement of it.

During the time that the oil bucket in the large separator continued to be flooded with water, no oil or condensate was collected from it. Any liquid oil being produced by the well at that time was carried over to the disposal well with the brine. 
For the last day and a half of the test, the large separator was finally operated as a three-phase separator. During this time no measurable amount of oil was recovered from it. The only liquid in the oil box was a small amount of water that condensed from steam on the inside walls of the vessel.

The overall bottom line on oil or condensate recovery is that the amount recovered never exceeded 5 gallons from the steady-state production of more than 200 barrels of brine. This corresponds to less than $60 \mathrm{ppm}$ by volume. Because the gas production is about 30 SCF/STB of brine, the liquid hydrocarbon recovery is less than 2 barrels per million SCF of gas.

In addition to the straw-colored condensate that consistently collected in the low-pressure separator after condensing from the gas stream leaving the primary separator, cleanup of perforations was accompanied by up to a few gallons of dark-colored hydrocarbon liquid at the filter skid. Production of such liquid did not persist. The liquid may well have been placed in the subsurface by man in conjunction with drilling activity.

\subsection{Scale and Corrosion}

The scale- and corrosion-inhibitor injection pumps required frequent attention. Contributing factors appear to include the high wellhead pressure and dirt from the supply line.

Injection of Coastal Chemical's 1035-SN scale inhibitor and 1036-C corrosion inhibitor was continued throughout the flow period. The pump stroke rates were set to pump 2 quarts/day of scale inhibitor and 10 quarts/day of corrosion inhibitor at the stabilized brine rate of $3200 \mathrm{STB} / \mathrm{d}$. This was a concentration in the brine of about $4 \mathrm{ppmv}$ of scale inhibitor and $20 \mathrm{ppmv}$ of corrosion inhibitor. Because the pumps would occasionally malfunction, the actual amount pumped was less than the set amounts.

New C-1018 corrosion coupons and Petrolite M-6010 corrosion-rate-monitoring probes were installed in the flow line between the choke and large separator and between the filter and disposal well just before the initiation of flow on January 4. The electronic probe in the line between the choke and separator failed during the cleanup flow. The high-rate flow to surge the well apparently bent the three rods in the probe and broke off one of them. Data from the probe between the filter and disposal well were obtained, however, and are shown plotted on the same plot with the brine flow rate (Exhibit 8.0-3). The corrosion rate shows the characteristic high rate for the first few minutes, when flow was initiated and the oxygen had not yet been purged from the system and the corrosion inhibitor had not had time to act. After the flow had been stabilized, the corrosion rate rapidly decreased to about $1 \mathrm{mil}$ per year and then decreased slowly throughout the remainder of the stabilized flow period. 
A high rate of corrosion was measured on January 6 when the flow rate was raised to about $5000 \mathrm{STB} / \mathrm{d}$ for the sampling program. The reason for this was not determined, but it may have been caused by the velocity of the brine in the pipe or by the inhibitor pump not working properly. Following the shut-in period to repair the separator, the electronically monitored corrosion rate showed the characteristic increased rate for early flow time when the oxygen had not yet been purged from the system and the corrosion inhibitor has not had time to act. After the flow had been stabilized, the corrosion rate returned to about $1 / 2$ mil per year for the remainder of the test.

The results of the scale and corrosion coupons provided and analyzed by Coastal Fluid Technologies are given in Exhibit 8.7-1.

\section{Exhibit 8.7-1. ANALYSIS OF CORROSION COUPONS FOR FINAL FLOW TEST}

\section{Upstream Coupons Downstream Coupons}

$\begin{array}{lll}\text { Corrosion Rate, mils/yr } & 4.601 & 0.349 \\ \text { Deposits.g/sq in./yr } & & \\ \text { Hydrocarbons } & 0.778 & 0.375 \\ \text { Water-Soluble Salts } & 0.251 & 0.389 \\ \text { Calcium Carbonate } & 1.569 & 1.508 \\ \text { Iron Compounds } & 1.681 & 0.377 \\ \text { Acid-Soluble } & 0.182 & 0.000\end{array}$

\subsection{Filters}

One filter pot (50-micron elements) was on-line during the flow. The filter cartridges were changed during the shutdown for the separator examination on January 8, although it may not have been necessary. The differential pressure remained quite constant at less than 10 psi throughout most of the flow period, indicating that there was little accumulation of solids or other plugging material. On the evening of January 10 , the differential pressure started to rise somewhat, but the test ended before any further filter changes were needed.

\subsection{Gas and Brine Analyses}

On January 6 and 7 extensive sampling was done on the gas and brine for varying operating conditions. Some analyses were done onsite by IGT personnel. Gas samples were sent to Southern Petroleum Labs for routine gas analysis up through C6 hydrocarbons. Gas and brine samples were sent to the IGT laboratories for more extensive analysis. The results of the analyses are presented in Section 9. 


\subsection{SAMPLING AND ANALYSIS}

Results from the analyses of brine and hydrocarbon samples collected during the series of flow tests are presented under headings that follow. Each of these in turn has subheadings for the different types of analyses and the discussion of the results. Details of the methodologies for sample collection and analysis, including discussion of solids precipitation in brine sample containers, are in Appendix A.

\subsection{Results of Brine Analyses}

The results of analyses of brine samples for inorganic species are covered in Section 9.1.1 below. Then, results of analyses for radium and for carboxylic acids are covered in Section 9.1.2. Finally, all of the results from brine analyses are discussed in relation to the reservoir in Section 9.1.3.

\subsubsection{Inorganic Species}

Exhibit 9.1.1-1 presents the results of laboratory analyses for most inorganic species. The February 9, 1989, sample was collected from between the choke manifold and the tanks during the initial cleanup of the deepest 20 feet of perforations (20,270 to 20,690 feet). All other samples were collected at the outlet of the separator. The samples from the separator were cooled by passing through a water bath prior to flashing to atmospheric pressure and were collected under carbon dioxide.

Certain elements were looked for but have not been seen using our established procedures. These elements, and the detection limits for each, are --

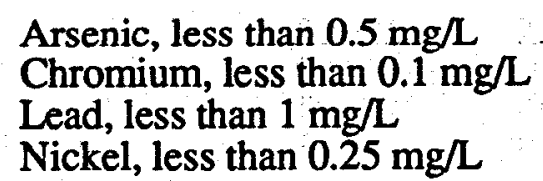

Arsenic, less than $0.5 \mathrm{mg} / \mathrm{L}$ Lead, less than $1 \mathrm{mg} / \mathrm{L}$ Nickel, less than $0.25 \mathrm{mg} / \mathrm{L}$
Cadmium, less than $0.1 \mathrm{mg} / \mathrm{L}$ Copper, less than $0.1 \mathrm{mg} / \mathrm{L}$ Mercury, less than $0.05 \mathrm{mg} / \mathrm{L}$ Tin, less than $0.25 \mathrm{mg} / \mathrm{L}$

Several brine analyses were performed on location because the time needed to transport the samples to a laboratory might have seriously affected the accuracy of the analyses. Exhibit 9.1.1-2 presents the results of onsite analyses to determine alkalinity and the concentrations of iron, sulfate, and sulfide in the brine.

Alkalinity measurements made in the field are the only reliable alkalinity measurements. Subsequent tests in the laboratory have conclusively shown that there is poor reproducibility and poor stability in alkalinity results measured by laboratories on samples that are several days old. 
Exhibit 9.1.1-1. BRINE ANALYSESa

\begin{tabular}{|c|c|c|c|c|c|c|c|}
\hline \multirow{2}{*}{\multicolumn{8}{|c|}{$\begin{array}{l}\text { Date } \\
\text { Time, h } \\
\text { Dilution }\end{array}$}} \\
\hline & none & none & none & none & $1: 1$ & none & \\
\hline Brine Temp, ${ }^{\circ} \mathrm{F}$ & & & & & & & \\
\hline & & & & & & & \\
\hline Solids, mg/L & 201,600 & 209,540 & 206,040 & 208,140 & 204,700 & 200,780 & 201,440 \\
\hline $\begin{array}{l}\text { Alkalinity, } \\
\text { me } \mathrm{CaCO} 3 /\end{array}$ & 32 & 126 & 137 & 139 & & 246 & \\
\hline Ammonia & & & & 176 & 177 & 165 & 164 \\
\hline Barium & 180 & 198 & 125 & 114 & 131 & 24 & 38 \\
\hline Boron & 67 & 62.9 & 62.2 & 62.6 & 63.6 & 65.5 & 70.6 \\
\hline Bromide & 76 & $N A^{b}$ & NA & 76.2 & 75.6 & 89.1 & 92.2 \\
\hline Calcium & 16,830 & 18,100 & 18,400 & 18,400 & 18,300 & 16,200 & 16,600 \\
\hline Chloride & 115,400 & 114,400 & 115,000 & 116,300 & & 114,600 & \\
\hline Fluoride & 2.1 & NA & NA & 2.61 & 2.98 & 2.99 & 2.78 \\
\hline Iodide & 12 & NA & NA & 14.3 & 13.9 & 14.6 & 13.2 \\
\hline Iron & 415 & 219 & 222 & 203 & 203 & 160 & 176 \\
\hline Lithium & 29 & 28.0 & 30.2 & 27.8 & 27.8 & 30.1 & 32.6 \\
\hline Manganese & 56 & 49.2 & 50.9 & 48.4 & 48.1 & 30.0 & 32.2 \\
\hline Magnesium & 892 & 989 & 995 & 1,000 & 992 & 829 & 830 \\
\hline Potassium & 420 & 535 & 513 & 570 & 568 & 358 & 376 \\
\hline Silica, as $\mathrm{SiO}_{2}$ & 150 & 126 & 126 & 121 & 125 & 104 & 134 \\
\hline Sodium & 52,200 & 54,400 & 55,200 & 56,200 & 55,200 & 51,200 & 51,700 \\
\hline Strontium & 1,020 & 1,040 & 1,080 & 1,090 & 1,150 & 1,028 & 1,054 \\
\hline Sulfate & - & & & $\delta$ & 6.8 & 2 & 32 \\
\hline Zinc & 11 & 9.5 & 10.0 & 9.5 & 9.5 & 8.0 & 8.6 \\
\hline
\end{tabular}

a All results in milligrams per liter unless otherwise specified.

b NA = Not analyzed.

\section{Exhibit 9.1.1-2. BRINE ANALYSES PERFORMED ONSITE}

\begin{tabular}{|c|c|c|c|c|c|c|}
\hline Date & $12 / 6 / 89$ & $12 / 6 / 89$ & $12 / 7 / 89$ & $12 / 20 / 89$ & $1 / 6 / 90$ & $1 / 600$ \\
\hline Time & $19: 30$ & $23: 30$ & $10: 00$ & $14: 00$ & $09: 30$ & $17: 00$ \\
\hline Sep Press, psia & 310 & 309 & 310 & 483 & 406 & 736 \\
\hline $\begin{array}{l}\text { Sep Temp, }{ }^{\circ} \mathrm{F} \\
\text { Alkalinity }\end{array}$ & 139 & 170 & 189 & 257 & 242 & 265 \\
\hline $\mathrm{mg} \mathrm{CaCO}_{3} / \mathrm{L}$ & 456 & 398 & 380 & 325 & 329 & 326 \\
\hline Iron, $\mathrm{mg} / \mathrm{L}$ & 320 & 280 & 288 & 255 & 213 & 226 \\
\hline $\begin{array}{l}\text { Sulfate, } \mathrm{mg} / \mathrm{L} \\
\text { Sulfide, } \mathrm{mg} / \mathrm{L}\end{array}$ & $\begin{array}{r}30 \\
\text { NA }\end{array}$ & $\begin{array}{r}30 \\
\text { NA }\end{array}$ & $\begin{array}{r}34 \\
<0.1\end{array}$ & $\begin{array}{r}46 \\
<0.1\end{array}$ & $\begin{array}{r}78 \\
\text { NA }\end{array}$ & $\begin{array}{l}N^{2} \\
<0.1\end{array}$ \\
\hline
\end{tabular}

a NA $=$ Not analyzed.

Comparison of the field and laboratory results for iron reveals that the laboratory measurements follow the trend of the field measurements but are on average $25 \%$ lower than the field measurements. We cannot say with certainty which data are more accurate. The field analysis required a 500 to 1 dilution prior to the analysis, which is difficult to perform accurately in the field 
and may result in an error of a few percent. The laboratory analyses were performed simultaneously with numerous other compounds in the ICP, and there is a possibility of substantial interferences. There was no difference in the measured iron concentrations between neat, diluted, and acidified samples.

The sulfate concentrations measured in the laboratory are more accurate than those measured in the field. Sulfate numbers gathered in the field were consistently higher than laboratory values. The field analysis method used was a modification of the barium sulfate turbidimetric method. It was later noted that the very high concentrations of chloride and calcium would probably interfere with these analyses. When an unreasonably high sulfate concentration, $86 \mathrm{mg} / \mathrm{L}$, was found in a January 6, 1990, sample, the brine was diluted 1:1 and reanalyzed. The second analysis revealed $70 \mathrm{mg} / \mathrm{L}$, down significantly from the undiluted sample analysis. It was later determined that a 2:1 dilution would have removed the interferences. The laboratory analyses of these samples found 22 to $32 \mathrm{mg} / \mathrm{L}$ of sulfate.

\subsubsection{Carboxylic Acids and Radium}

Concentrations of carboxylic acids in the brine are shown in Exhibit 9.1.2-1. Exhibit 9.1.22 presents the results of radium activity determinations performed by Dr. T. Kraemer of the United States Geological Survey (USGS).

\section{Exhibit 9.1.2-1. CARBOXYLIC ACIDS IN THE BRINE}

$\begin{array}{lrcc} & \text { Acetic Acid } & \text { Propionic Acid } & \text { Butyric Acid } \\ 2 / 9 / 89 & 45 \mathrm{mg} / \mathrm{L} & \mathrm{NA}^{\mathrm{a}} & \mathrm{NA} \\ 1 / 6 / 90 & 110 \mathrm{mg} / \mathrm{L} & 4 \mathrm{mg} / \mathrm{L} & 1 \mathrm{mg} / \mathrm{L} \\ \text { a NA }=\text { Not analyzed. } & & \end{array}$

The February 9, 1989, sample was not properly collected or preserved for organic acid analysis and therefore could only provide a lower limit on the quantity of organic acids in the brine. The January 6,1990, sample was collected, preserved, and analyzed following procedures that should not result in the loss of organic acids, and these results are believed to be representative of what was in the produced brine. This quantity, $110 \mathrm{mg} / \mathrm{L}$ of acetic acid, $4 \mathrm{mg} / \mathrm{L}$ of propionic acid, and $1 \mathrm{mg} / \mathrm{L}$ of butyric acid, comprises more than one-third of the total alkalinity of the January 6, 1990, sample.

There were significant problems with the radium activity measurements. Precipitation was occurring while the samples were being analyzed, although at concentrations so low that the samples became only very slightly cloudy after several days. When precipitates form, radium 
Exhibit 9.1.2-2. RADIUM ACTIVITY IN THE BRINE, MINIMUM VALUESa

$\begin{array}{lll} & \text { Radium 226 } & \text { Radium 228 } \\ 12 / 20 / 89 & 313 \mathrm{dpm} / \mathrm{L} & 528 \mathrm{dpm} / \mathrm{L} \\ 1 / 7 / 90 & 891 \mathrm{dpm} / \mathrm{L} & 707 \mathrm{dpm} / \mathrm{L}\end{array}$

a Values reported are low because of precipitation in the laboratory as well as probable precipitation in the reservoir and the production facilities.

accompanies the precipitate and a low reading is the result. Activity levels were observed to decline while samples were in the process of being analyzed. Previous correlations developed by Dr. Kraemer for these geopressured-geothermal wells suggest, based on salinity, that the radium 226 concentration is expected to be about $2000 \mathrm{dpm} / \mathrm{L} .4$ This is twice the highest measured value of $891 \mathrm{dpm} / \mathrm{L}$ for the January 7 sample.

\subsubsection{Discussion of Results of Brine Analyses}

The brine contained the highest total dissolved solids concentration (salinity) of any brine tested in the DOE Geopressured-Geothermal Program. The total dissolved solids averaged $205,000 \mathrm{mg} / \mathrm{L}$. The calcium concentration, $18,000 \mathrm{mg} / \mathrm{L}$, is also higher than had been previously encountered. Iron and manganese concentrations, which are affected by corrosion rates, declined during the test.

There were no significant differences in the brine composition between the cleanout flow and all the December 1989 samples. Certain anthropogenic elements, such as iron and manganese from the tubulars, zinc from the pipe dope, and barite from drilling mud, declined with production. This is expected and is usually observed during flow tests.

There is a significant compositional difference between the December 1989 brine samples and the January 1990 brine samples. The December 1989 samples came from the the interval from 20,602 to 20,690 feet. The gas and brine produced during January 1990 came from commingled production from both the 20,602 to 20,690 -foot interval and the 20,220 to 20,260-foot interval. Percent changes in each element are presented in Exhibit 9.1.3-1. Many of the differences are not statistically significant. But the total dissolved solids and the concentrations of several elements -barium, calcium, iron, manganese, magnesium, potassium, sodium, and sulfate -- changed more than could be expected based on random scatter. It appears that the new perforations shot between 20,020 and 20,060 feet contacted a previously isolated reservoir body. The upper zone contained brine that was less concentrated and contained considerably less calcium than the lower zone. 


\section{Exhibit 9.1.3-1. DIFFERENCES BETWEEN DECEMBER 1989} AND JANUARY 1990 BRINE ANALYSES

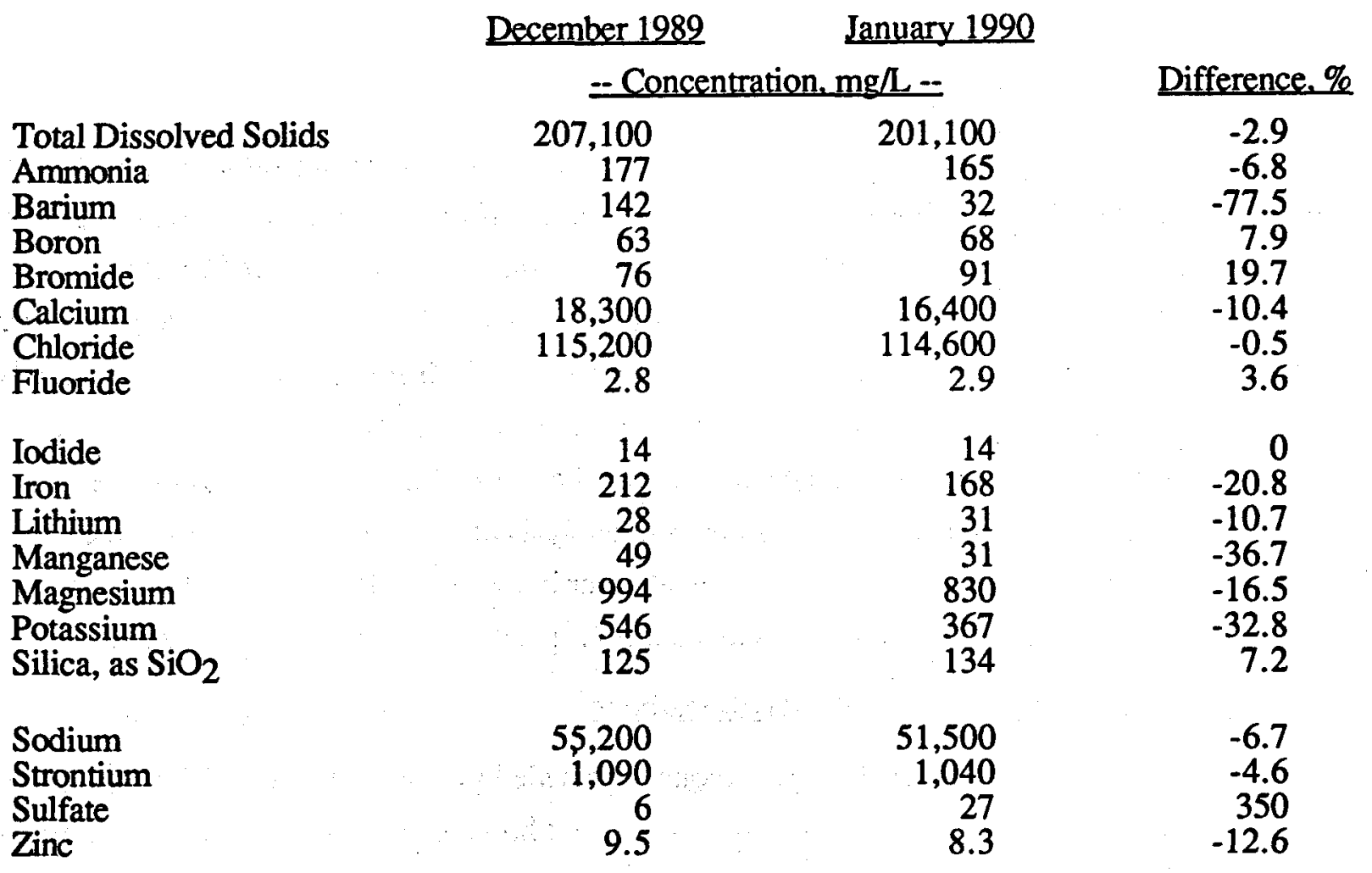

The alkalinity values are on the low end of the range for geopressured-geothermal wells. This low alkalinity is directly related to the high calcium concentration in the produced brine through the equilibrium of calcium carbonate. The declining alkalinity in the brine during the test suggests scale formation in the wellbore and surface facilities. If the true alkalinity concentration were $400 \mathrm{mg} / \mathrm{L}$, the lower concentrations measured during the tests could be accounted for by the precipitation of less than 1000 pounds of calcite. This is an order of magnitude greater than the amount of solids removed form the surface hardware. Whether precipitation of this quantity of calcite upstream of the sample point would have been detected is conjectural.

The concentration of $110 \mathrm{ppm}$ of acetic acid is higher than anticipated. Carboxylic acids such as acetic acid and propionic acid begin to decarboxylate between $100^{\circ}$ and $130^{\circ} \mathrm{C}$. The result is carbonate ions and hydrocarbons. Generally, over geologic time this leads to a system whose alkalinity is controlled by carbonate species as temperatures exceed $130^{\circ} \mathrm{C}$. The bottomhole temperature of the Hulin well is about $170^{\circ} \mathrm{C}$, and about one-third of the total alkalinity was caused 
by organic acids. It should be noted, however, that carboxylic acid concentrations are within the envelope of 4 to $500 \mathrm{ppm}$ for formation waters from the Louisiana Gulf Coast and/or San Joaquin Basin. 5

\subsection{Results of Hydrocarbon Analyses}

The first sample for hydrocarbon analysis was collected from the production wellhead after the cleanup flow in February 1989. During the production through the surface equipment that was made operational at the beginning of December 1989, gas samples were collected from four different sample points and were analyzed at two different laboratories. These sample points were 1) directly from the top of the primary (large) separator vessel, 2) from the meter run immediately downstream of the secondary (small) separator, 3) from the tops of filter pots or the top of the wellhead on the disposal well, and 4) catching the gas that flashed from brine samples when the pressure was reduced to atmospheric. Results from analysis of samples from these sample points are tabulated by sample point and in chronological order in Appendix B. Many of these same results are presented below in subheadings that address specific technical considerations.

\subsubsection{Composition of Separated Hydrocarbons}

An overview of the produced hydrocarbons is provided in Exhibit 9.2.1-1. This table presents results from chromatographic analysis of gas and liquid samples collected at two different times. The February 9,1989 , sample was collected from the gas cap that developed at the wellhead after cleanup flow of about 800 barrels to remove heavy mud from the well. It was collected at a pressure of about 7300 psi. Gas and a very light oil or condensate were observed leaking from a seal on the Ruska cylinder the following morning. This leak resulted in the need to accelerate the analytical process. IGT and Chromaspec (Core Lab) personnel flashed the sample during the morning of February 10 , collecting both gas and condensate fractions. The sample pressure was over 5000 psig prior to flashing the sample from the Ruska cylinder, indicating that very little of the sample had been lost. There were about 10 barrels of condensate per million cubic feet of gas, and the dew-point pressure was estimated to be below 3000 psig. A portion of the gas and a portion of the condensate were sent to IGT. Results of the gas and condensate analyses are tabulated in the first three data columns of Exhibit 9.2.1-1.

The gas and brine samples collected on December 20, 1989, were from the production equipment at a time two-thirds of the way through the 4-1/2 day test of the perforated interval between 20,602 and 20,690 feet. At the time of sampling, gaseous hydrocarbons were being separated from the brine in the large separator (L. Sep) at a temperature of $257^{\circ} \mathrm{F}$ and a pressure of 482 psia. After this gas was cooled to a temperature of $50^{\circ} \mathrm{F}$, it was separated from the condensed 
Exhibit 9.2.1-1. HYDROCARBON ANALYSES, INCLUDING OIL ${ }^{2}$

Date of Samples

Brine Sep Pres, psia

Laboratory

Component

Helium

Hydrogen

Nitrogen

Carbon Dioxide

Methane

Ethane

Propane

iso-Butane

n-Butane

iso-Pentane

n-Pentane

neo-Pentane

Hexanes

Heptanes

Octanes (C8)

Nonanes

Decanes (C10)

Undecanes

Dodecanes (C12)

Tridecanes

Tetradecanes (C14)

Pentadecanes

Hexadecanes C16)

Heptadecanes

Octadecanes (C18)

Nonadecanes

Eicosanes (C20)

Heneicosanes

Docosanes (C22)

Tricosanes+

Benzene

Toluene

C2 Benzenes

C3 Benzenes

Naphthalenes

C1 Naphthalenes

C2 Naphthalenes

C3 Naphthalenes
February 9.1989

$\begin{array}{lll} & 7300 & \\ \text { Core Lab } & \text { IGT } & \text { IGT }\end{array}$

W.H.Gas W.H. Gas W.H. Oil

0.11

0.33

4.31

93.09

2.04

0.11

0.01

0.01

Trec

$\operatorname{Trc}$

Tre

$\operatorname{Trc}$

Trc

Tre

Trc

0.13

0.24

4.12

93.20

2.03

0.12

0.008

0.007

0.003

0.001

0.0001

0.002

0.002

0.002

0.003

0.009

0.024

0.025

0.025

0.014

0.013

0.006

0.004

0.003

0.002

0.001

0.001

0.001

0.001

0.013

0.004

0.003

0.006

0.004

0.007

0.004

$<0.001$

$-$

0.01

0.03

0.08

0.32

1.88

8.92

17.50

21.24

17.07

12.40

7.22

4.48

2.48

1.00

0.38

0.15

0.06

0.05

0.10

0.27

0.81

0.06

0.23

2.27
December 20.1989

482

IGT IGT IGT

LSepGas SSepGas S Sep Oil

$0.006 \quad 0.008$

$0.025 \cdots 0.025$

$0.12 \quad 0.12$

16.9

$-80.3 \quad 80.4$
$-\quad 8.9$

2.17

0.26

16.8

0.03

2.18

0.26

0.06

0.03

0.03

0.03

0.02

0.03

0.02

0.01

$<0.001$

0.003

0.01

0.05

0.01

0.05

0.005

$<0.001$

0.007

-

0.006

0.007

0.23

0.012

0.006

.80

0.008

0.003

0.011

0.015

0.003

0.011

0.006

15.3

0.005

0.005

21.6

0.002

19.0

0.002

0.001

11.4

0.001

$<0.001$

6.94

$<0.001$

$<0.001$

3.02

0.001

$<0.001$

1.37

$<0.001$

$<0.001$

0.55

$<0.001$

$<0.001$

0.51

$<0.001$

$<0.001$

0.21

$<0.001$

$<0.001$

0.14

$<0.001$

$<0.001$

0.14

0.015

0.018

0.010

1.24

0.019

$<0.001$

$<0.001$

$<0.001$

$<0.001$

3.22

$<0.001$

$<0.001$

$+d$

$<0.001$

$<0.001$

$<0.001$

$<0.001$

$<0.001$

a Gas analyses are in mole percent. Condensate analyses are in weight percent.

$b_{-}=$Not detected.

c $\operatorname{Trc}=$ Trace, or less than $0.01 \%$.

$\mathrm{d}_{+}=$Obscured by large overlapping alkane peak. 
liquids at a pressure of 107 psia in the small separator (S. Sep). The small separator was operating properly as a three-phase separator and had collected enough condensate for the dump valves to be operational when the gas and oil (condensate) samples were collected.

The excellent agreement between Core Lab and IGT on the February 1989 sample is gratifying but not surprising. The possibility of differences due to calibration standards or procedures had been resolved in cooperative work on other projects.

The results from the analysis of the December 1989 samples from the top of the large separator and the gas meter run just after the small separator clearly indicate that the quantity of hydrocarbons condensing from the gas stream due to cooling to ambient temperature is too small to cause a detectable difference in the concentrations of alkane species lighter than octane.

The lack of hydrocarbons in the natural gas liquids range of butane through hexane is a striking feature of both of the suites of analyses. This is particularly surprising when there are significant amounts of heavier alkanes and aromatics. The composition of the condensate mirrored the concentration of heavy hydrocarbons in the gas, peaking at $\mathrm{C} 13$ and declining to negligible quantities above $\mathrm{C} 16$.

The unusual nature of this bimodal distribution is apparent when compared to results of analyses of hydrocarbon samples from other geopressured-geothermal wells that are summarized in Exhibit 9.2.1-2. The gas produced from the Hulin is leaner than the gas from the other well tests. Only the Girouard and the Amoco Fee (Sweetlake) gases were close, and these other wells contained more than twice the propane-plus hydrocarbons of the Hulin gas.

The laboratory personnel who analyzed the liquid hydrocarbon samples offered the gratuitous observation that the material "looked like diesel oil." This observation, combined with the small amount of produced butane-through-hexane hydrocarbons, fueled the question of whether the condensate was from the reservoir or was introduced by man. One step in addressing this question was to perform a similar analysis of the diesel oil being pumped into the top 1500 feet of the tubing to prevent hydrate formation when the well was shut in. The composition of two condensate samples and of the diesel pumped into the well after each shut-in are tabulated in order of increasing molecular weight in Exhibit 9.2.1-3.

Exhibit 9.2.1-4 shows chromatograms for the December 1989 condensate from the small separator and the diesel from the tank on location. The three tall peaks on the left side of the condensate chromatogram are benzene, toluene, and xylenes. These aromatic compounds have a high solubility in brine and are not relevant to the question of whether the alkanes are from the reservoir or were introduced by man. The distribution in molecular weight for the alkane 
Exhibit 9.2.1-2. TYPICAL GEOPRESSURED-GEOTHERMAL WELL GAS ANALYSES ${ }^{a}$

Analyses performed at IGT by mass spectrometry or gas chromatography.

b Not recorded.

c Not analyzed.

d Heating value in Btu/SCF; Dry, $14.7 \mathrm{psia}, 60^{\circ} \mathrm{F}$.

\begin{tabular}{|c|c|c|c|c|c|}
\hline $\begin{array}{r}\text { Prairie } \\
\text { Canal }\end{array}$ & $\begin{array}{r}\text { Crown } \\
\text { Zellerbach }\end{array}$ & $\begin{array}{r}\text { Amoco } \\
\text { Fee }\end{array}$ & Sweezy & $\begin{array}{l}\text { Gladys } \\
\text { McCall }\end{array}$ & $\begin{array}{r}\text { Pleasant } \\
\text { Bayou }\end{array}$ \\
\hline $2 / 81$ & $6 / 81$ & $8 / 81$ & $9 / 82$ & $6 / 87$ & $2 / 90$ \\
\hline 272 & 283 & 236 & $N_{R}^{b}$ & 1015 & 693 \\
\hline 160 & 110 & & NR & 300 & 292 \\
\hline 229 & 197 & 160 & NR & 294 & 271 \\
\hline$<0.01$ & 0.03 & $<0.01$ & $N^{c}{ }^{c}$ & $<0.01$ & 0.01 \\
\hline NA & NA & 0.01 & NA & $<0.01$ & 0.02 \\
\hline 0.11 & 0.44 & 0.20 & 0.12 & 0.28 & 0.52 \\
\hline 10.06 & 25.00 & 8.13 & 1.08 & 8.47 & 10.40 \\
\hline 86.94 & 69.10 & 89.28 & 95.61 & 88.04 & 84.70 \\
\hline 2.29 & 4.03 & 1.74 & 1.95 & 2.41 & 2.88 \\
\hline 0.30 & 0.76 & 0.39 & 0.32 & 0.52 & 0.97 \\
\hline 0.03 & 0.10 & 0.02 & 0.06 & 0.08 & 0.15 \\
\hline 0.02 & 0.10 & 0.05 & 0.11 & 0.07 & 0.14 \\
\hline$<0.01$ & 0.04 & 0.01 & NR & 0.03 & 0.06 \\
\hline$<0.01$ & 0.03 & $<0.01$ & NR & 0.03 & 0.06 \\
\hline 0.02 & 0.18 & 0.10 & 0.02 & 0.05 & 0.07 \\
\hline 0.01 & 0.18 & 0.07 & 0.01 & 0.01 & 0.04 \\
\hline$<0.01$ & 0.01 & $<0.01$ & $<0.01$ & $<0.01$ & 0.02 \\
\hline 928 & 815 & NR & NR & 960 & 951 \\
\hline 0.667 & 0.838 & NR & NR & 0.660 & 0.691 \\
\hline
\end{tabular}


Exhibit 9.2.1-3. ANALYSES OF HULIN LIQUID HYDROCARBONSa

$\begin{array}{lrrr}\text { Sample --> } & \text { Condensate } & \text { Condensate } & \text { Site Diesel } \\ \text { Date -- } & 2 / 9 / 89 & 12 / 20 / 89 & 12 / 20 / 89 \\ \text { Benzene } & & & \\ \text { C7 } & 0.10 & 1.24 & <0.01 \\ \text { Toluene } & 0.03 & 0.80 & 0.02 \\ \text { C8 } & 0.27 & 3.22 & <0.01 \\ \text { Ethylbenzene } & 0.08 & 1.78 & 0.12 \\ \text { m,p-Xylenes } & 0.02 & 0.18 & +b \\ \text { o-Xylene } & 0.06 & 1.97 & + \\ \text { C9 } & 0.02 & 0.56 & + \\ \text { C3-Benzenes } & 0.32 & 1.86 & 0.38 \\ \text { C10 } & 0.81 & + & + \\ \text { C11 } & 1.88 & 7.32 & 1.19 \\ \text { Naphthalene } & 8.92 & 15.3 & 2.32 \\ \text { C12 } & 0.06 & 0.36 & + \\ \text { C13 } & 17.50 & 21.6 & 3.69 \\ \text { C1-Naphthalenes } & 21.24 & 19.0 & 6.23 \\ \text { C14 } & 0.23 & + & + \\ \text { C2-Naphthalenes } & 17.07 & 11.4 & 9.10 \\ \text { C15 } & 2.27 & + & + \\ \text { C3-Naphthalenes } & 12.40 & 6.94 & + \\ \text { C16 } & 0.84 & + & 13.26 \\ \text { C17 } & 7.22 & 3.02 & 13.46 \\ \text { C18 } & 4.48 & 1.37 & 10.83 \\ \text { C19 } & 2.48 & 0.55 & 8.87 \\ \text { C20 } & 1.00 & 0.51 & 6.78 \\ \text { C21 } & 0.38 & 0.21 & 5.34 \\ \text { C22 } & 0.15 & 3.56 \\ \text { C23+ } & 0.06 & 0.09 & 2.79\end{array}$

a Gas analyses are in mole percent. Condensate analyses are in weight percent.

$\mathbf{b}_{+}=$Compounds are obscured by large overlapping alkane peaks.

component of the condensate is even narrower than that for the diesel and peaks at 11 to 13 carbons, whereas the diesel peak is for 15 to 16 carbon atoms per molecule. However, this difference is not conclusive evidence that the condensate is not a light fraction of diesel introduced by man. The reason is that the heavier components of the diesel may well have stayed in the large separator, rather than moving on to the small separator in the form of a gas at the separator temperature of $257^{\circ} \mathrm{F}$.

On the other hand, the February 1989 liquid hydrocarbon sample was condensed from gas before the pumping of any condensate to prevent hydrates. Furthermore, a check with appropriate personnel from Eaton Operating Company revealed that no oil was displaced into the formation 


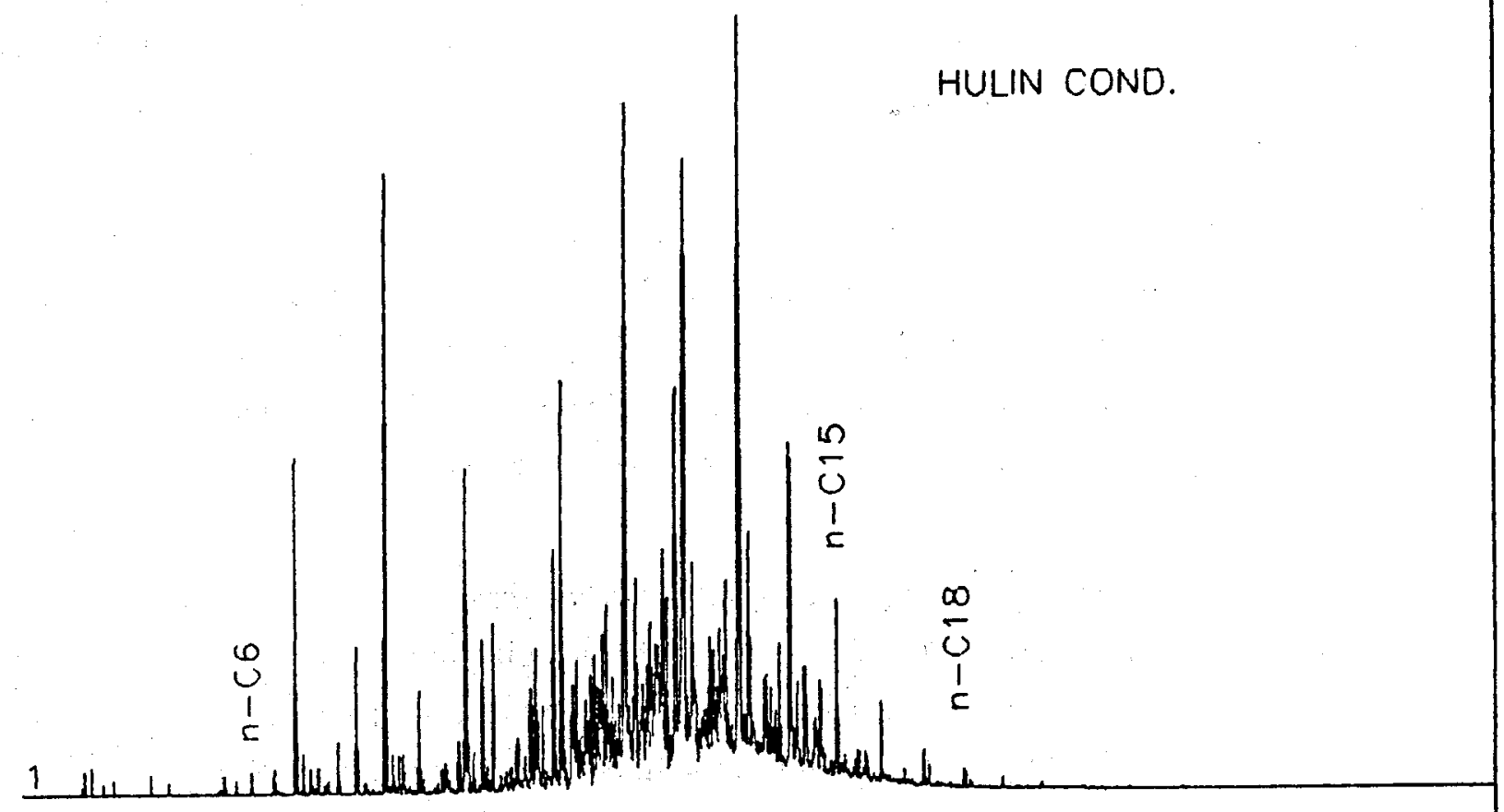

\section{HLNO20.raw}

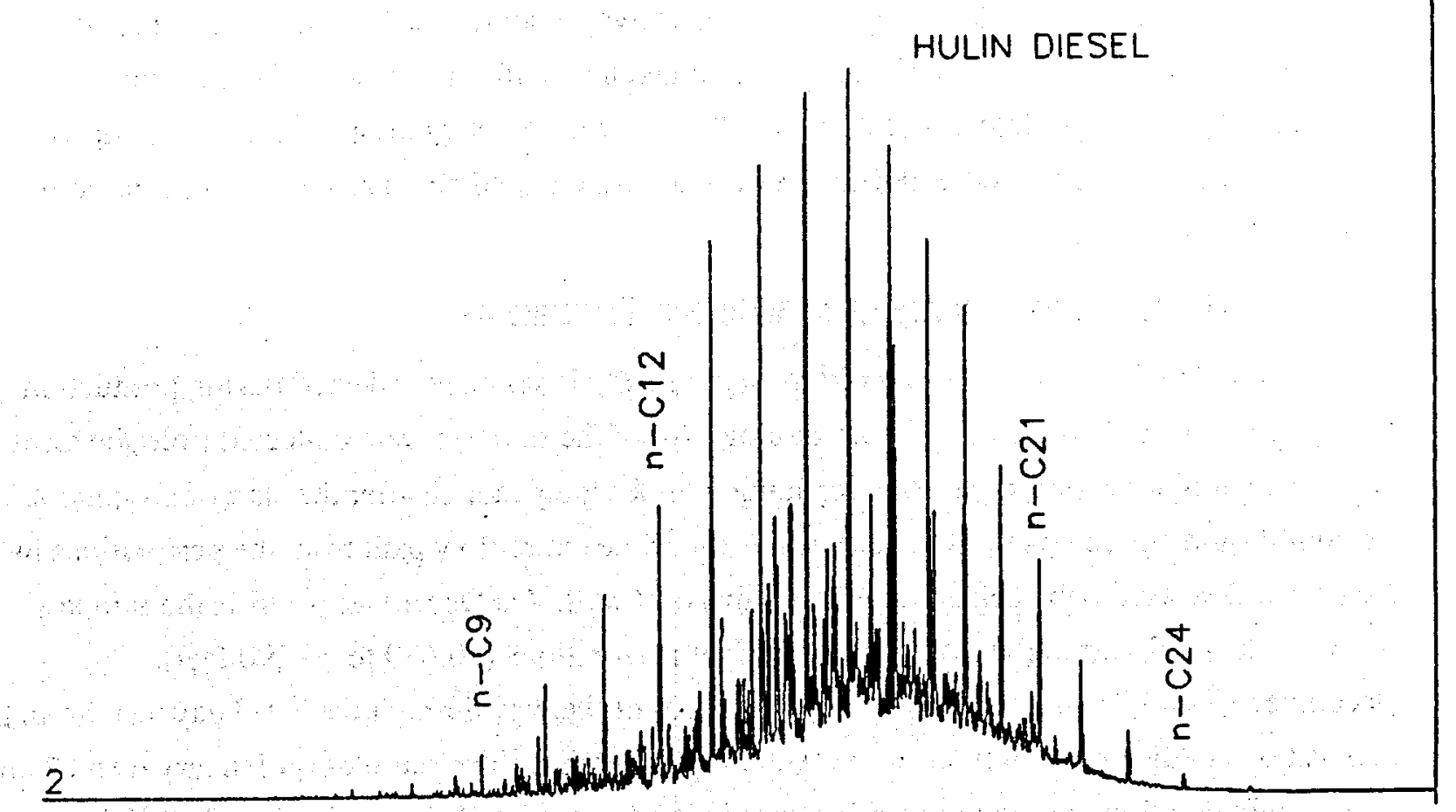

Exhibit 9.2.1-4. CHROMATOGRAMS FOR CONDENSATE AND DIESEL 
during the 1989 workover of the well. An examination of the well records, however, shows that the original driller had penetrated the producing formation, had gotten stuck, and had subsequently sidetracked the well from a kick-off point at a depth of 20,174 feet. The original hole had reached a depth of 21,100 feet. It completely penetrated both the target sand for this project and the sand that had been completed and produced from the depth interval of 21,059 to 21,094 feet in the sidetrack hole.

Thus, there is a second hole through the formation, close to the producing well, that was almost certainly drilled with an oil-based drilling mud. Attempts to free the stuck pipe probably involved displacing special oil-based drilling fluids to the bottom of the hole to lubricate the pipe. These events provide both a mechanism and a reasonable scenario whereby small quantities of diesel could have been displaced into the formation and produced during the February 1989 cleanup flow.

Debris produced through the separator to the filter skid during cleanup of the second set of perforations (20,602 to 20,666 feet) included a slug of black oil that had an estimated volume of gallons but probably less than barrels. This material provides a clear indication of oil that is either entrapped in a poor cement job on the sidetracked well or from the nearby original hole that contains drill collars and was never cemented.

In either case, oil introduced by man is a conceivable source of the hydrocarbons condensed from the gas sample collected at $7300 \mathrm{psi}$ an hour and a half after the cleanup flow for the perforations in the depth interval of 20,670 to 20,690 feet. As a result, we are unable to draw a definitive conclusion on whether the observed condensate would be representative of long-term hydrocarbon production.

\subsubsection{Composition Changes After Additional Perforations}

Exhibit 9.2.2-1 provides results from analyses of gas samples collected during production after each of the three increments in perforating. All of the samples were collected from the same point at the top of the primary (large) separator at times long enough after the start of production for equilibrium conditions to have been achieved for the entire flow path from the perforations in the production well to the perforations in the disposal well. On December 6 and 7, the samples were for flow only through the deepest 20 feet of perforations (20,670 to 20,690 feet). The December 20 sample was collected about two-thirds of the way through the 4-1/2 day test through perforations in the depth interval from 20,602 to 20,690 feet. The samples on January 6 and 7 are for commingled flow through the perforations in the lower part of the sand below 20.602 feet and the perforations in the upper portion between 20,220 and 20,260 feet. 
Exhibit 9.2.2-1. LARGE SEPARATOR GAS ANALYSES, IGT ${ }^{a}$

\begin{tabular}{|c|c|c|c|c|c|c|}
\hline $\begin{array}{l}\text { Date } \\
\text { Time } \\
\text { Pressure, psia } \\
\text { Gas Temp, }{ }^{\circ} \text { F } \\
\text { Brine Temp, }{ }^{\circ} \mathrm{F}\end{array}$ & $\begin{array}{c}\frac{12 / 06 / 89}{23: 30} \\
309 \\
133 \\
171\end{array}$ & $\begin{array}{c}\frac{12 / 07 / 89}{08: 15} \\
310 \\
134 \\
190\end{array}$ & $\begin{array}{c}\frac{12 / 20 / 89}{17: 40} \\
482 \\
221 \\
251\end{array}$ & $\begin{array}{l}\frac{1 / 6 / 90}{11: 00} \\
406 \\
208 \\
243\end{array}$ & $\begin{array}{l}\frac{1 / 6 / 90}{14: 45} \\
735 \\
210 \\
265\end{array}$ & $\begin{array}{l}\frac{17 / 90}{09: 15} \\
295 \\
185 \\
221\end{array}$ \\
\hline \multicolumn{7}{|l|}{ Mole Percent of: } \\
\hline Helium & 0.008 & 0.008 & 0.006 & 0.006 & 0.006 & 0.005 \\
\hline Hydrogen & 0.064 & 0.071 & 0.025 & 0.029 & 0.029 & 0.047 \\
\hline Nitrogen & 0.29 & 0.15 & 0.12 & 0.15 & 0.13 & 0.11 \\
\hline Carbon Dioxide & 17.8 & 18.2 & 16.9 & 15.9 & 13.1 & 16.7 \\
\hline Methane & 80.1 & 79.4 & 80.3 & 82.0 & 84.6 & 81.2 \\
\hline Ethane & 1.59 & 1.65 & 2.17 & 1.68 & 1.78 & 1.68 \\
\hline Propane & 0.12 & 0.38 & 0.26 & 0.17 & 0.19 & 0.16 \\
\hline iso-Butane & $<0.01$ & $<0.01$ & 0.03 & 0.02 & 0.02 & 0.01 \\
\hline$n$-Butane & $<0.01$ & $<0.01$ & 0.03 & 0.02 & 0.02 & 0.01 \\
\hline iso-Pentane & $<0.01$ & $<0.01$ & 0.02 & 0.004 & 0.004 & 0.003 \\
\hline$n$-Pentane & $<0.01$ & $<0.01$ & 0.01 & 0.001 & 0.002 & 0.001 \\
\hline neo-Pentane & $<0.001$ & $<0.001$ & $<0.001$ & $<0.001$ & $<0.001$ & $<0.001$ \\
\hline exanes & 0.001 & 0.001 & 0.003 & 0.002 & 0.003 & 0.001 \\
\hline Heptanes & 0.001 & 0.003 & 0.005 & 0.002 & 0.003 & 0.002 \\
\hline tanes & 0.001 & 0.003 & 0.006 & 0.001 & 0.002 & 0.001 \\
\hline Nonanes & 0.001 & 0.003 & 0.012 & 0.010 & 0.002 & 0.002 \\
\hline Decanes & 0.001 & 0.002 & 0.008 & 0.001 & 0.002 & 0.004 \\
\hline Undecanes & 0.002 & 0.001 & 0.011 & 0.004 & 0.006 & 0.006 \\
\hline Dodecanes & 0.005 & 0.002 & 0.015 & 0.004 & 0.008 & 0.005 \\
\hline Tridecanes & 0.007 & 0.004 & 0.0 & 0.0 & 0.003 & 0.002 \\
\hline Tetradecanes + & 0.003 & 0.003 & 0.009 & 0.002 & 0.002 & 0.001 \\
\hline Benzene & 0.009 & 0.010 & 0.015 & 0.025 & 0.032 & 0.030 \\
\hline Toluene & 0.002 & 0.005 & 0.019 & 0.008 & 0.009 & 0.012 \\
\hline C2 Benzenes & $<0.001$ & $<0.001$ & $<0.001$ & $<0.001$ & $<0.001$ & $<0.001$ \\
\hline C3 Benzenes & $<0.001$ & $<0.001$ & $<0.001$ & $<0.001$ & $<0.001$ & $<0.001$ \\
\hline Naphthalene & $<0.001$ & $<0.001$ & $<0.001$ & $<0.001$ & $<0.001$ & $<0.001$ \\
\hline C1 Naphthalenes & $<0.001$ & $<0.001$ & $<0.001$ & $<0.001$ & $<0.001$ & $<0.001$ \\
\hline C2 Naphthalenes + & $<0.001$ & $<0.001$ & $<0.001$ & $<0.001$ & $<0.001$ & $<0.001$ \\
\hline \multicolumn{7}{|l|}{ Heating Value, } \\
\hline $\mathrm{SCF}$ & 862 & 864 & 885 & 887 & 918 & 879 \\
\hline 3 & & & & & & \\
\hline & 0.73 & 0.744 & 0.736 & 0.720 & 0.695 & 0.728 \\
\hline $\begin{array}{l}\text { NGL, Gal/ } \\
1000 \text { SCF }\end{array}$ & 0.484 & 0.575 & 0.758 & 0.551 & 0.590 & 0.544 \\
\hline
\end{tabular}

a Analyses performed at IGT using gas chromatography with TC and FID detectors.

b Dry, 15.025 psia, $60^{\circ} \mathrm{F}$. 
Comparison of gas samples from production through the three different perforation configurations is complicated by the changes in gas composition due to variations in separator pressure. Exhibit 9.2.2-2 has been constructed from the data in Exhibit 9.2.2-1 to facilitate the comparison of the properties of gas produced from deeper than 20,602 feet with those for the gas commingled with gas through the shallower perforations in the depth interval of 20,220 to 20,260 feet. On the basis of the much smaller drawdown for a given flow rate, it is estimated that roughly two-thirds of the commingled flow is from the shallower perforations.

With the exception of NGL content, the plots in Exhibit 9.2.2-2 suggest substantial differences in properties for the gas from the deep perforations and the commingled flow. The complication in the plot for NGL content is that the sample collected on December 20 contains much more ethane than any of the other samples. On the other hand, there is no doubt that the high ethane content was real. Another sample was simultaneously collected from the low-pressure separator. The previous side-by-side tabulation of analysis results for these two samples (Exhibit 9.2.1-1) clearly show identical high ethane content for the samples from both separators.

One intriguing possibility is that the 3 days of steady production though the perforations in the depth interval below 20,602 feet was beginning to cone in hydrocarbons from an updip gas cap. Increasing NGL content was a precursor of such behavior on the Keolemay Well of Opportunity. The observed increasing gas/brine ratio (Section 6.5) further fuels such speculation.

Radon and isotopic analyses of the gas provide another handle on whether there was a change in composition when the gas from the shallower perforations was commingled with gas from the bottom of the sand. Results from analyses of gas samples for radon $222, \partial^{13} \mathrm{C}$, and $\partial \mathrm{D}$ were provided in a letter from Dr. Thomas F. Kraemer and are shown in Exhibit 9.2.2-3. The December 20 sample was from the 20,602 to 20,690-foot interval and the January 7 sample contained gas from 20,220 to 20,260 feet commingled with gas from the deeper interval. The radon content of the commingled gas was less than two-thirds that of the gas from the deep zone.

Dr. Kraemer observed that the radon content is fairly typical for gas from geopressuredgeothermal brines. This radon activity is at the low end of the range of radon activity in gas produced from other geopressured-geothermal tests and is comparable to the radon activity of conventional natural gas produced throughout the United States. It is considerably higher than the $10 \mathrm{dpm} / \mathrm{L}$ average for gas produced from conventional Gulf Coast reservoirs.

The carbon 13 and deuterium analyses had been performed by Dr. George Claypool, of the USGS, Denver, Colorado. The value reported for the methane $\partial^{13} \mathrm{C}$ isotope ratios is the difference between the ${ }^{13} \mathrm{C} /{ }^{12} \mathrm{C}$ isotope ratios obtained from the sample and from an international standard 

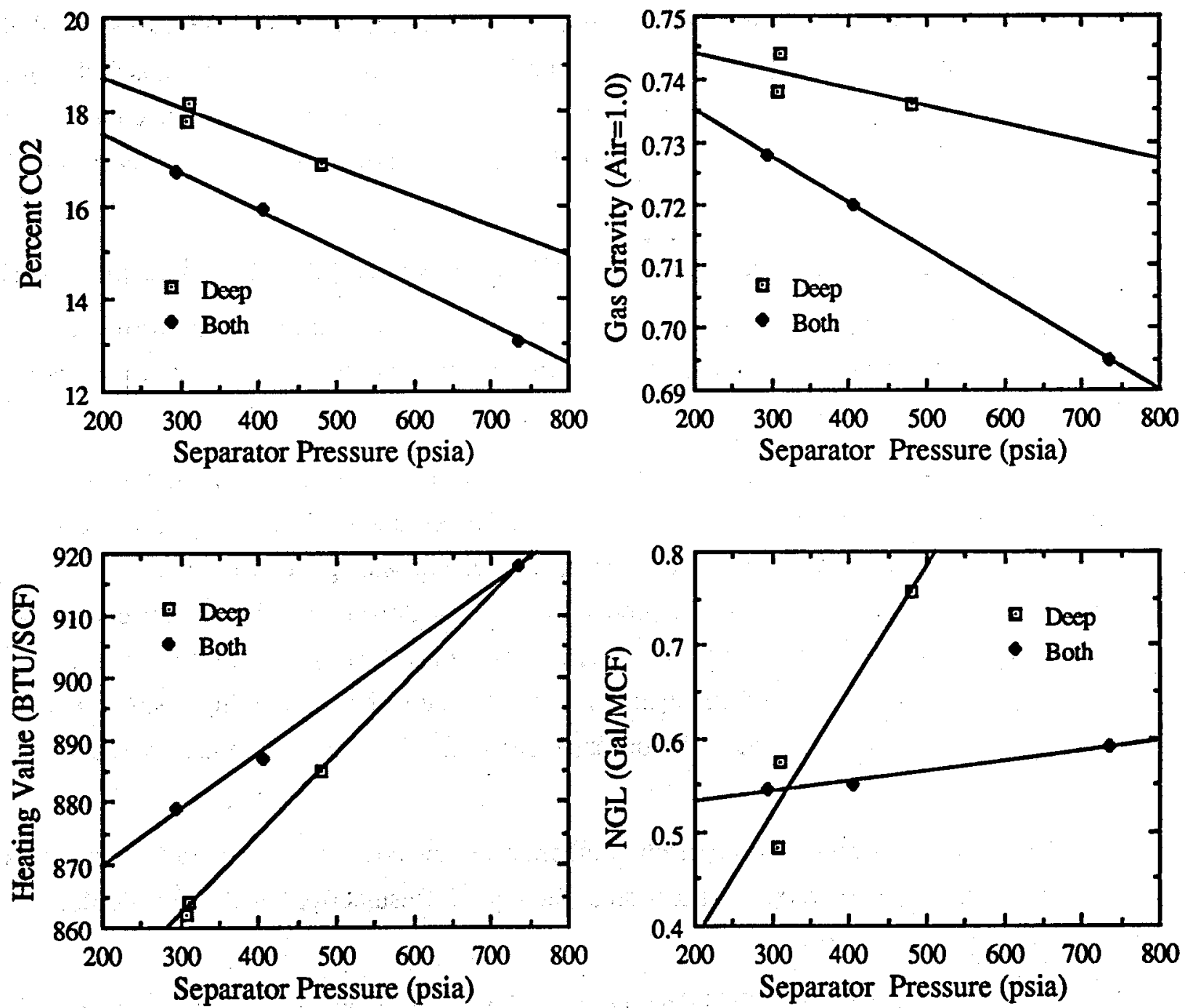

Exhibit 9.2.2-2. PROPERTIES OF DEEP AND COMMINGLED GAS

Exhibit 9.2.2-3. RADIOISOTOPE ACTIVITY AND ISOTOPIC ANALYSES OF THE GAS ${ }^{a}$

$\begin{array}{lcc} & \frac{12 / 20 / 89}{} & \frac{17 / 90}{92} \\ \text { 222Rn, dpm/L @ STP } & 153 & 96 \\ \text { 213C, parts per thousand } & -42.02 & -41.70 \\ \text { JD, parts per thousand } & -147.5 & \end{array}$

a ${ }^{13}$ C relative to P.D.B. and $\partial D$ relative to V.S.M.O. analyses by USGS, Denver, CO. 
(Pee Dee Belemnite). Values for gas of thermogenic origin usually range from -40 to -55; more mature gases have more positive values (closer to -40). The values for biogenic gases usually fall between -60 and -100 . Thus, the value of -42 suggests that the produced methane is thermogenic in origin and is mature. Values from five other geopressured-geothermal wells have ranged from -42.4 to -49 , with a median value of -43.3 . The $\partial \mathrm{D}$ value is reported relative to Vienna Standard Mean Ocean Water.

\subsubsection{Comparison of Gas Analyses by IGT and by Southern Petroleum Laboratory (SPL)}

In the plan for the test, gas sample collection and analysis was limited to performing detailed analyses of separator gas samples collected near the end of flow through each set of perforations. Those analyses were previously discussed in Section 9.2.2.

In practice, questions raised by the prime contractor resulted in a substantial number of samples being collected for rapid local analysis. The first sample for local analysis was collected on December 11, after the EOC Site Engineering and Testing Manager observed that "the flare looks different." Initial testing after the production from shallower perforations was commingled with that from the lower portion of the sand was accompanied by requests for proof that gas was not being lost from the bottom of the separator. Use of local laboratory facilities was essential to obtaining results on the short time scale for management decisions on day-by-day conduct of the test.

The analyses relevant to comparison of laboratories and adequacy of separator operation are discussed in this section and the next section of the report. Results from analyzing additional samples are in Appendix B.

Exhibit 9.2.3-1 is a side-by-side tabulation of these cases where gas samples that should give the same result were analyzed by both IGT and by the Southern Petroleum Laboratory facility in Lafayette, Louisiana. The IGT data tabulated is the same as in Exhibit 9.2.2-2 with the exception that the alkanes above hexane and the aromatics have been added together to provide a single number for the percentage of heptanes-plus. Although results from both laboratories are similar in that they show high carbon dioxide and minimal natural gas liquids, the difference in reported carbon dioxide content is larger than would exist with advanced coordination.

We suspect that the primary reason for differences between laboratories is that SPL was not asked to heat the sample container to above the gas temperature at the time of sample collection. Thus, both condensed water and/or condensed hydrocarbons may have remained in the sample cylinders at SPL. The condensed water may in turn have entrapped a substantial amount of carbon 
Exhibit 9.2.3-1. GAS SAMPLES ANALYZED BY BOTH IGT AND SPL

\begin{tabular}{|c|c|c|c|c|c|c|}
\hline $\begin{array}{l}\text { Date } \\
\text { Time } \\
\text { Pressure, psia } \\
\text { Gas Temp, }{ }^{\circ} \mathrm{F} \\
\text { Brine Temp, }{ }^{\circ} \mathrm{F}\end{array}$ & $\begin{array}{l}1 / 6 / 90 \\
09: 30 \\
405 \\
208 \\
242\end{array}$ & $\begin{array}{l}1 / 6 / 90 \\
11: 00 \\
406 \\
208 \\
243\end{array}$ & $\begin{array}{l}1 / 6 / 90 \\
14: 45 \\
735 \\
210 \\
265\end{array}$ & $\begin{array}{l}1 / 6 / 90 \\
14: 45 \\
735 \\
210 \\
265\end{array}$ & $\begin{array}{l}1 / 7 / 90 \\
09: 15 \\
295 \\
185 \\
221\end{array}$ & $\begin{array}{l}1 / 7 / 90 \\
09: 15 \\
295 \\
185 \\
221\end{array}$ \\
\hline Laboratory & SPL & IGT & SPL & IGT & SPL & IGT \\
\hline $\begin{array}{l}\text { Mole Percent of: } \\
\text { Helium } \\
\text { Hydrogen } \\
\text { Nitrogen } \\
\text { Carbon Dioxide } \\
\text { Methane } \\
\text { Ethane } \\
\text { Propane } \\
\text { iso-Butane } \\
n \text {-Butane } \\
\text { iso-Pentane } \\
n \text {-Pentane } \\
\text { neo-Pentane } \\
\text { Hexanes } \\
\text { Heptanest }\end{array}$ & $\begin{array}{r}0.15 \\
12.49 \\
85.22 \\
1.85 \\
0.16 \\
0.01 \\
0.02 \\
<0.01 \\
<0.01 \\
\\
<0.01 \\
0.10\end{array}$ & $\begin{array}{c}0.006 \\
0.029 \\
0.15 \\
15.9 \\
82.0 \\
1.68 \\
0.17 \\
0.02 \\
0.02 \\
0.004 \\
0.001 \\
<0.001 \\
0.002 \\
0.060\end{array}$ & $\begin{array}{r}0.17 \\
14.19 \\
83.66 \\
1.75 \\
0.17 \\
0.01 \\
0.01 \\
<0.01 \\
<0.01 \\
\\
<0.01 \\
.04\end{array}$ & $\begin{array}{c}0.006 \\
0.029 \\
0.13 \\
13.1 \\
84.6 \\
1.78 \\
0.19 \\
0.02 \\
0.02 \\
0.004 \\
0.002 \\
<0.001 \\
0.003 \\
0.070\end{array}$ & $\begin{array}{r}0.10 \\
16.27 \\
81.66 \\
1.76 \\
0.16 \\
0.01 \\
0.01 \\
<0.01 \\
<0.01 \\
\\
<0.01 \\
.03\end{array}$ & $\begin{array}{c}0.005 \\
0.047 \\
0.11 \\
16.7 \\
81.2 \\
1.68 \\
0.16 \\
0.01 \\
0.01 \\
0.003 \\
0.001 \\
<0.001 \\
0.001 \\
0.065\end{array}$ \\
\hline $\begin{array}{l}\text { Heating Value, } \\
\text { Btu/SCFa } \\
\text { Gravity } \\
\text { (air=1.0) } \\
\text { NGL, Gal/ } \\
1000 \mathrm{SCF}\end{array}$ & 0.691 & 0.720 & 0.551 & 0.590 & 0.724 & $\begin{array}{l}0.728 \\
0.544\end{array}$ \\
\hline
\end{tabular}

a Dry, 15.025 psia, $60^{\circ} \mathrm{F}$.

dioxide. Also, it is possible that the composition of the standard gas used at SPL differed substantially from the sample being analyzed and that this, in turn, resulted in reduced accuracy for reported results.

\subsubsection{Gas Leaving the Large Separator With the Brine}

During the flow tests, questions were raised about whether the separator was allowing a substantial fraction of the produced gas to leave with the brine and be injected into the disposal well. The reasons behind this speculation apparently included the facts that 1) the gas/brine ratio was lower than anticipated by some officials and 2) some gas was found in the disposal wellhead and filter pots.

Previous work by IGT on other wells had shown that a 30-second residence time was more than sufficient to remove gas from the brine. Prior to January 9, separator residence time was 
much longer for the separator size and brine flow rates in this test. As previously observed, the low level downstream of the weir for the last 2 days (January 9-11, 1990) was accompanied by entrapment of gas bubbles in exiting brine. The results presented below are for operation prior to January 9.

Samples of the brine were collected at the outlet of the separator and were flashed to atmospheric pressure at four different times and at three separator pressures. These samples had gas volumes and compositions (high $\mathrm{CO}^{2}$ and low $\mathrm{C} 3+$ hydrocarbon fractions) that were consistent with our experience on other wells. These brine samples did not contain free-gas bubbles.

The results of SPL analyses of the gas flashed from brine and of simultaneously collected samples of gas leaving the primary separator are tabulated in Exhibits 9.2.4-1 through 9.2.4-4. Results from three of the separator samples were previously compared with results from parallel analysis by IGT in Exhibit 9.2.3-1. At each of the four times, the results of gas analyses and the measured gas/brine ratios were used to computationally reconstruct the composition of the total gas exsolved from the brine. In addition, the amount of carbon dioxide liberated from the brine by acid treatment at 1 atmosphere is near the bottom of each of the four exhibits. The final entry in each exhibit is the total gas in the brine, including the carbon dioxide that is in the form of carbonate or bicarbonate ions.

The gas analysis data clearly show the dependence of carbon dioxide content of gas upon the pressure at which the gas is separated from the brine. Recall that the wellhead gas sample collected at a pressure of 7300 psi contained only about $4.2 \%$ carbon dioxide. For separator pressures in the range of 300 to $700 \mathrm{psi}$, carbon dioxide content of gas in equilibrium with the brine ranges from $14 \%$ to $17 \%$. But gas flashed from brine leaving the separator by reducing pressure to atmospheric contains more than $40 \%$ carbon dioxide.

The quantity of gas remaining in the brine after the separator is dependent primarily on the separator pressure. The absolute quantity of gas and the high carbon dioxide content of that gas was consistent with that seen on other geopressured-geothermal wells. The quantity of flashed gas and total gas leaving the separator with the brine (which includes flashed gas and carbon dioxide liberated from the brine at atmospheric pressure) versus pressure is shown in Exhibit 9.2.4-5. This exhibit also includes the values calculated with the computer algorithm used to estimate the gas content of brine leaving the separator. As on previous well tests, the algorithm calculates a value for the gas content that is lower than the measured flashed gas. It is a fairly accurate predictor of the hydrocarbon content of gas remaining in the brine after the separator. ${ }^{2}$ 
Exhibit 9.2.4-1. TOTAL GAS CALCULATION FOR SEPARATOR PRESSURE OF $405 \mathrm{psia}^{\mathrm{a}}$ January 6, 1990, at 09:00 Hours Flow Rate: 3200 STB/d Brine Temperature: $242^{\circ} \mathrm{F}$

\begin{tabular}{|c|c|c|c|}
\hline Mole Percent of: & $\begin{array}{c}\text { Top of } \\
\text { Large Separator } b\end{array}$ & $\begin{array}{l}\text { Flashed Gas From } \\
\text { Separator Brine }\end{array}$ & Total Gas \\
\hline Nitrogen & 0.14 & 5.14 & 0.45 \\
\hline Carbon Dioxide & 15.90 & 41.83 & 17.52 \\
\hline Methane & 81.90 & 51.78 & 80.02 \\
\hline Ethane & 1.78 & 1.16 & 1.74 \\
\hline Propane & 0.15 & 0.05 & 0.15 \\
\hline iso-Butane & 0.01 & Nil & 0.01 \\
\hline$n$-Butane & 0.02 & Nil & 0.02 \\
\hline iso-Pentane & Nil & Nil & Nil \\
\hline$n$-Pentane & Nil & Nil & Nil \\
\hline Hexanes & Nil & Nil & Nil \\
\hline Heptanes+ & 0.10 & 0.04 & 0.10 \\
\hline GWR, SCF/STB & 31.21 & 2.08 & 33.29 \\
\hline
\end{tabular}

a Carbon dioxide remaining in brine after flashing to atmospheric pressure $=1.97 \mathrm{SCF} / \mathrm{STB}$, total gas/brine ratio including all carbon dioxide $=35.26 \mathrm{SCF} / \mathrm{STB}$.

b SPL analysis had $12.49 \%$ carbon dioxide, which was inconsistent with all other analyses of gas collected at similar pressures and temperatures. The carbon dioxide value used, $15.90 \%$, was obtained from an IGT analysis of a sample collected 2 hours later. The SPL analysis, with the new carbon dioxide value, was then renormalized.

Exhibit 9.2.4-2. TOTAL GAS CALCULATION FOR SEPARATOR PRESSURE OF $735 \mathrm{psia}^{\mathrm{a}}$ January 6, 1990, at 14:45 Hours Flow Rate: 3200 STB/d Brine Temperature: $265^{\circ} \mathrm{F}$

\begin{tabular}{lccr} 
Mole Percent of: & $\begin{array}{c}\text { Top of } \\
\text { Large Separator }\end{array}$ & $\begin{array}{c}\text { Flashed Gas From } \\
\text { Separator Brine }\end{array}$ & Total Gas \\
\hline Nitrogen & 0.17 & 1.89 & $-r$ \\
Carbon Dioxide & 14.19 & 43.27 & 0.38 \\
Methane & 83.66 & 53.77 & 17.70 \\
Ethane & 1.75 & 1.01 & 80.05 \\
Propane & 0.17 & Nil & 1.66 \\
iso-Butane & 0.01 & Nil & 0.15 \\
$n$-Butane & 0.01 & Nil & 0.01 \\
iso-Pentane & Nil & Nil & 0.01 \\
$n$-Pentane & Nil & Nil & Nil \\
Hexanes & Nil & Nil & Nil \\
Heptanes+ & 0.04 & 0.02 & 0.04 \\
GWR, SCF/STB & 28.98 & 3.98 & 32.96
\end{tabular}

a Carbon dioxide remaining in brine after flashing to atmospheric pressure $=2.86 \mathrm{SCF} / \mathrm{STB}$, total gas/brine ratio including all carbon dioxide $=35.82 \mathrm{SCF} / \mathrm{STB}$. 
Exhibit 9.2.4-3. TOTAL GAS CALCULATION FOR SEPARATOR PRESSURE OF $737 \mathrm{psia}^{\mathrm{a}}$ January 6, 1990, at 17:00 Hours Flow Rate: 4900 STB/d Brine Temperature: $265^{\circ} \mathrm{F}$

\begin{tabular}{lccc} 
Mole Percent of: & $\begin{array}{c}\text { Top of } \\
\text { Large Separator }\end{array}$ & $\begin{array}{c}\text { Flashed Gas From } \\
\text { Separator Brine }\end{array}$ & Total Gas \\
\hline Nitrogen & 0.16 & 3.20 & 0.53 \\
Carbon Dioxide & 14.53 & 44.04 & 18.16 \\
Methane & 83.31 & 51.86 & 79.44 \\
Ethane & 1.76 & 0.83 & 1.65 \\
Propane & 0.17 & 0.04 & 0.15 \\
iso-Butane & 0.02 & Nil & 0.02 \\
$n$-Butane & 0.01 & Nil & Nil \\
iso-Pentane & Nil & Nil & Nil \\
$n$-Pentane & Nil & Nil & Nil \\
Hexanes & Nil & Nil & 0.04 \\
Heptanes+ & 0.04 & 0.03 & 33.15 \\
GWR, SCF/STB & 29.07 & 4.08 &
\end{tabular}

a Carbon dioxide remaining in brine after flashing to atmospheric pressure $=2.41 \mathrm{SCF} / \mathrm{STB}$, total gas/brine ratio including all carbon dioxide $=35.56 \mathrm{SCF} / \mathrm{STB}$.

Exhibit 9.2.4-4. TOTAL GAS CALCULATION FOR SEPARATOR PRESSURE OF 295 psia $^{\mathrm{a}}$

January 7, 1990, at 09:15 Hours Flow Rate: 2375 STB/d Brine Temperature: $221^{\circ} \mathrm{F}$

\begin{tabular}{lccc} 
Mole Percent of: & $\begin{array}{c}\text { Top of } \\
\text { Large Separator }\end{array}$ & $\begin{array}{c}\text { Flashed Gas From } \\
\text { Separator Brine }\end{array}$ & Total Gas \\
\hline Nitrogen & -0.10 & 3.68 & -0.25 \\
Carbon Dioxide & 16.27 & 42.53 & 17.40 \\
Methane & 81.66 & 52.17 & 80.39 \\
Ethane & 1.76 & 1.00 & 1.73 \\
Propane & 0.16 & 0.05 & 0.16 \\
iso-Butane & 0.01 & Nil & 0.01 \\
$n$-Butane & 0.01 & Nil & Nil \\
iso-Pentane & Nil & Nil & Nil \\
$n$-Pentane & Nil & Nil & Nil \\
Hexanes & Nil & 0.03 & 0.03 \\
Heptanes+ & 0.03 & 1.45 & 33.75 \\
GWR, SCF/STB & 32.30 & & \\
\multicolumn{4}{l}{ a Carbon dioxide remaining in brine after flashing to atmospheric pressure $=2.09$ SCF/STB, } \\
total gas/brine ratio including all carbon dioxide $=35.84$ SCF/STB.
\end{tabular}




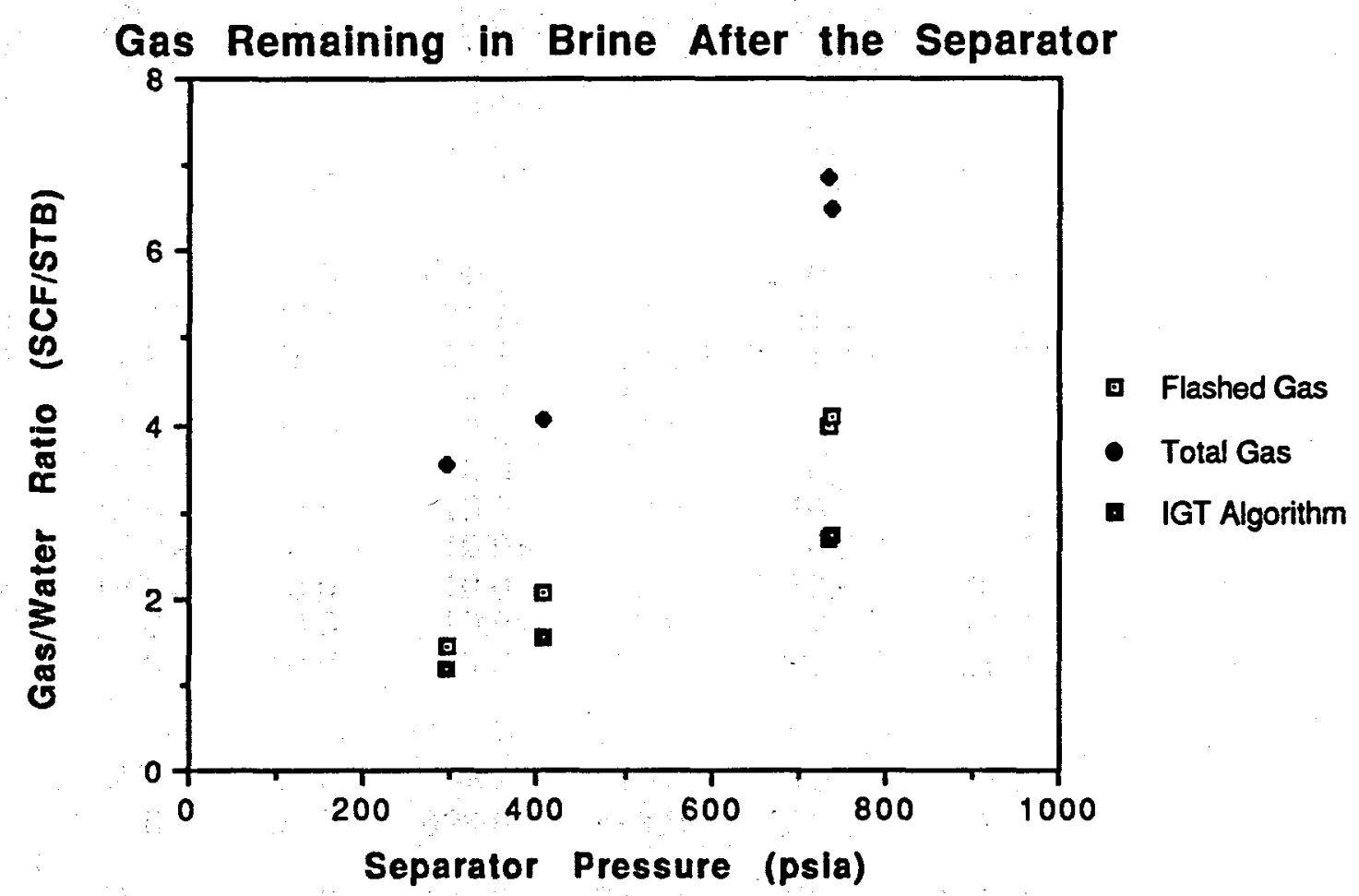

Exhibit 9.2.4-5. GAS FLASHED FROM SEPARATOR BRINE VERSUS PRESSURE

Brine leaving the separator experiences a pressure drop as it flows through the level-control valve at the outlet of the separator. This is accompanied by the flashing of about 0.5 SCF/STB for each 100 psi of pressure drop. This gas accumulates in the filter pots and the wellhead of the disposal well. At Pleasant Bayou, a continuous gas-bleed system was installed at the filter pots to remove this gas.

Results from SPL analyses of several samples of gas collected from the filter skid or the wellhead of the disposal well are shown in Exhibit 9.2.4-6. These samples had carbon dioxide content in the range of $18 \%$ to $37 \%$. The lower end of this range is only slightly above the carbon dioxide content of gas from the separator and the upper end of this range is approaching the $44 \%$ carbon dioxide that is characteristic of the gas liberated when separator brine is flashed to atmospheric pressure Values in the upper portion of this range clearly indicate the lack of a major loss of gas in the form of bubbles entrained in brine leaving the separator, whereas samples that contained less than $25 \%$ carbon dioxide suggest that gas bubbles were exiting the separator with the brine. Similarly, ethane concentrations near $1.5 \%$ suggest the presence of bubbles leaving the separator, whereas ethane concentrations of $1.4 \%$ or lower indicate an absence of gas bubbles leaving the separator through the brine line. 


\section{Exhibit 9.2.4-6. GAS BLED FROM THE DISPOSAL WELLHEAD}

\begin{tabular}{|c|c|c|c|c|c|c|c|}
\hline $\begin{array}{l}\text { Date } \\
\text { Time }\end{array}$ & $\frac{1 / 3 / 90}{N R^{2}}$ & $\frac{1 / 5 / 90}{08 \cdot 30}$. & $\frac{1 / 690}{09: 30}$ & $\frac{1 / 6 / 90}{14: 45}$ & $\frac{1 / 6 / 90}{17: 00}$ & $\frac{17790}{09: 15}$ & $\frac{1 / 10 / 90}{17: 30}$ \\
\hline Pressure, psia & 55 & 95 & 206 & 202 & 327 & 173 & 182 \\
\hline Sep Pres, psia & NR & 264 & 405 & 737 & 737 & 295 & 487 \\
\hline Brine Temp, ${ }^{\circ} \mathrm{F}$ & NR & 232 & 242 & 247 & 265 & 221 & 207 \\
\hline \multicolumn{8}{|l|}{ Mole Percent of: } \\
\hline Nitrogen & 0.19 & 0.06 & 0.07 & $1.90^{\mathrm{b}}$ & 0.09 & 0.10 & 0.10 \\
\hline Carbon Dioxide & 17.75 & 37.18 & 27.77 & 33.35 & 25.27 & 19.96 & 24.91 \\
\hline th & 79.37 & 61.41 & 70.51 & 63.16 & 73.17 & 78.14 & 73.27 \\
\hline Ethane & 2.23 & 1.17 & 1.48 & 1.43 & 1.31 & 1.53 & 1.51 \\
\hline opane & 0.26 & 0.06 & 0.08 & 0.07 & 0.09 & 0.10 & 0.12 \\
\hline -Butane & 0.03 & 0.01 & 0.01 & 0.01 & 0.01 & 0.01 & 0.01 \\
\hline & 0.02 & 0.01 & 0.01 & 0.01 & 0.01 & 0.01 & 0.01 \\
\hline -Pentane & 0.01 & $<0.01$ & $<0.01$ & $<0.01$ & $<0.01$ & $<0.01$ & 0.01 \\
\hline & 0.01 & $<0.01$ & $<0.01$ & $<0.01$ & $<0.01$ & $<0.01$ & $<0.01$ \\
\hline & 0.01 & $<0.01$ & $<0.01$ & $<0.01$ & $<0.01$ & $<0.01$ & $<0.01$ \\
\hline Heptanes+ & 0.12 & 0.10 & 0.07 & 0.07 & 0.05 & 0.15 & 0.06 \\
\hline \multicolumn{8}{|l|}{ Heating Value, } \\
\hline & 879 & 665 & 764 & 687 & 787 & 849 & 794 \\
\hline 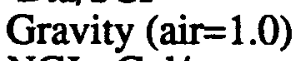 & 0.746 & 0.925 & 0.835 & 0.896 & 0.809 & 0.762 & 0.807 \\
\hline $\begin{array}{l}\text { NGL, Gal/ } \\
1000 \mathrm{SCF}\end{array}$ & 0.768 & 0.391 & 0.467 & 0.451 & 0.413 & 0.525 & 0.480 \\
\hline
\end{tabular}

a Not recorded.

b Probable air contamination.

${ }^{c}$ Dry, 15.025 psia, $60^{\circ} \mathrm{F}$.

The January 3 sample was collected before the start of production of gas commingled from two perforated zones. It is gas from the perforations in the depth interval from 20,602 to 20,690 feet that had been in the disposal well for 12 days before the sample was collected. Carbon dioxide concentrations are not believed to accurately represent the concentration that existed when the well was shut in. Carbon dioxide is lost both through reaction with the tubulars (forming iron carbonate) and by enhanced dissolution in the brine as the brine cooled. The concentration of the hydrocarbon species in the remaining gas subsequently increased.

The other five samples were collected while brine was flowing. At the time of collection of the last sample, January 10,1990, the measured gas/brine ratio was low and a portion of the free gas was believed to be escaping from the separator with the brine. The compositional analyses suggests that gas bubbles were also leaving the separator with the brine at the January 7 samplecollection time. 


\subsection{CONCLUSIONS}

The initial flow test of the Hulin well was done to obtain brine and gas samples and to get a first measure of the reservoir properties. The 20,602 to 20,690-foot interval was perforated and tested in two short-term draw-down and buildup tests. This zone had an initial pressure of $17,308 \mathrm{psia}$ and temperature of $339^{\circ} \mathrm{F}$. The total dissolved solids of $207,000 \mathrm{mg} / \mathrm{L}$ (mostly sodium chloride) is higher than for previously tested Gulf Coast geopressured-geothermal wells. The gas content in the brine of 31 to $32 \mathrm{SCF} / \mathrm{STB}$ indicates that the brine is at or near saturation with natural gas. The permeability, as deduced from the draw-down and buildup tests, is $13 \mathrm{md}$ for the lower 80-foot-thick sand member. The duration of the tests was too short to determine the lateral extent of the reservoir, but declining measured values for static bottomhole pressure prior to each flow test suggests a relatively small reservoir.

When the uppermost interval in the zone of interest (20,220 to 20,260 feet) was perforated such that flow from this zone would commingle with flow from the lower zone, little to no free gas was observed. It had been speculated before the test that there might be free gas in this upper zone. These speculations were generally deduced from logs after assuming the formation contained brine that had a salinity between 70,000 and $100,000 \mathrm{mg} / \mathrm{L}$. The actual salinity was more than twice that number. It is now apparent that the amount of free gas, if any, is too small to make a significant contribution to production in a short-term test. This does not preclude the possibility of mobilization of gas by higher drawdown or coning down from an offsetting gas cap in one or more of the sand members. However, there was no evidence that this was occurring in this test.

No measurements of the reservoir parameters, such as permeability, were made for the shallowest interval tested. But substantially lower drawdown for the commingled zones suggests either higher permeability or lower skin for the shallower perforated interval.

Hydrate formation in the upper part of the wellbore was a problem. To circumvent this problem, about 10 barrels of diesel were pumped into the top of the well after each flow to displace the brine down to a level in the well where the temperature was too high for hydrates to form. Calculations of saturation index indicated that calcium carbonate scale would also form in the well if the pressure was drawn down too far. Thus all the flow tests were performed at low flow rates to preclude formation of scale in the wellbore. Scale inhibitor was injected into the surface flow lines to control possible scale formation in the surface equipment. Corrosion inhibitor was also injected, and coupon monitoring indicated a corrosion rate of less than 5 mils per year. 


\subsection{RECOMMENDATIONS}

Since the short-term flow tests only provided initial chemistry and reservoir properties and did not determine the potential of the Hulin well for long-term energy production, further flow testing is needed. It is IGT's recommendation that the next test of the Hulin well be a sequence of medium-rate flow and pressure-buildup tests of at least 6-months total duration as follows:

1. The entire interval from 20,200 to 20,690 feet should be perforated and tested as a single unit. This recommendation is based on the fact that both the bottom and top of this interval were previously perforated for the short-term flow test and flow communication has now been established across the zone. It is now impractical to attempt flow tests on the individual sand members in between the existing perforations. Furthermore, the program objective of determining the potential of the Hulin well for long-term energy production can best be achieved by opening and testing the entire zone.

2. The flow test should be done at low-to-moderate flow rates, not the high flow rates anticipated for subsequent energy production. Flow rates in the range of 5000 to 10,000 barrels per day are anticipated to be sufficient to provide the pressure drawdown and buildup data needed for reservoir engineering evaluations. Furthermore, these flow rates are within the capability of the existing tubing in the well. If a good set of perforations is achieved, such that the skin factor is low, the pressure drop across the perforations and up the well should be low enough to preclude scale formation in the wellbore. Saturation index calculations indicate that calcium carbonate scale may begin to form in the tubing when the wellhead pressure gets into the range of 4000 to $6000 \mathrm{psi}$, depending on the temperature. It will not be possible to flow at high rates through restricted perforations and the existing tubing without forming scale unless an inhibitor squeeze into the reservoir formation is performed first.

3. The existing wellhead needs to be changed before further down-hole operations or flow testing is done. A wellhead needs to be installed that has valves that open to a diameter larger than the inside diameter of the currently installed tubing and seal assembly (minimum diameter of $2-1 / 4$ inches). This is 1) to provide ability to place a plug in the tubing if needed for safety reasons, 2 ) to allow use of larger perforating guns than were used for the previous perforations, and 3) to prevent the wellhead from being the limiting restriction for flow.

4. The surface facilities for processing the brine and gas can be assembled mostly from the equipment previously used for the McCall well test, provided that the vessels still pass the DOE quality control and certification requirements. If this equipment can be used, there will be a significant cost savings over the use of rental equipment. The piping and valves will need to be replaced, however, and can be either purchased or rented depending on which is less expensive. By limiting the flow rate to a maximum of 10,000 barrels per day, the required piping and valve sizes are in the range of 3 to 4 inches in diameter, which are relatively easy to obtain at modest cost compared to the 6 to 8 -inch pipe and valves needed for higher flow rates. Some new computer-based data acquisition equipment and sensors will also be needed to partially replace the old, and antiquated, system used for the previous McCall and Hulin tests. 
5. Close coordination with all parties doing reservoir evaluation during the test period will be a must. Although a tentative schedule of times for draw-down and buildup periods will need to be made prior to the beginning of the test, the schedule may need to be altered as the tests proceed. By testing the entire zone -- which is comprised of many sand layers -- at once, it will probably be necessary to evaluate the reservoir as a complex, multilayered system. Data analysis and numerical reservoir simulation should be initiated while the test is still in progress and field test parameters can be altered if necessary to evaluate possible alternate scenarios.

Whether a long-term, and high-rate, test of the Hulin well is warranted will depend upon the results of the medium-rate test. To accomplish a high-rate flow test, it will be necessary to replace the current 3-1/2 inch tubing in the well. It is possible that a new well will be needed so that the tubing can be large enough to safely handle the flow rate needed for utilization of the resource.

A basic problem is that the Hulin well casing is longer and smaller in diameter than the two design wells. The Gladys McCall well has 5-inch tubing inside 7-inch casing, and the Pleasant Bayou well has 5-1/2 inch tubing inside 9-5/8 inch casing. In contrast, the deeper 4700 feet of casing in the Hulin well has the same inside diameter as the Gladys McCall tubing (4.276 inches) and the shallower 15,970 feet of 6.05-inch casing has an inside diameter of only 5.000 inches. Production without tubing would be the only way that the Hulin well could achieve the flow rates experienced at the Gladys McCall and Pleasant Bayou wells with comparable flow velocities.

Engineering evaluation of alternatives is a prerequisite to defining the maximum long-term flow rate that can be safely achieved through the existing wellbore. The possibilities to be considered should include annular flow, the use of a "liquid" packer, and conventional completion with tubing and a packer. The surface piping and valving may need to be rebuilt with larger diameter piping and valves, depending on the maximum flow rate.

\subsection{REFERENCES CITED}

1. Eaton Operating Company, Final Contract Report, DOE Contract No. DE-AC0785ID12578, Houston, 1990.

2. Hayden, G. H. and Randolph, P. L., "Parametric Study of Separator Performance." Paper presented at the Fifth Geopressured-Geothermal Energy Conference, Baton Rouge, Louisiana, October 13-15, 1981.

3. Katz, D. L. et al., Handbook of Natural Gas Engineering. New York: McGraw-Hill Book Company, 1959.

4. Kraemer, T., United States Geological Survey, personal communication, June 7, 1990. 
FLOW TESTS OF THE WILLIS HULIN WELL

FINAL REPORT JANUARY 1992

5. MacGowan, D. B. et al., "The Effect of Carboxylic Acid Anions on the Stability of Framework Mineral Grains in Petroleum Reservoirs," SPE Formation Evaluation, 161-66, (1990) June.

6. Katy, J. M. et al., "Control of Scale Associated With Geopressured-Geothermal Brine Production," in Dorfman, M. H. and Morton, R. A., Eds., Geopressured-Geothermal Energy, 137-47. New York: Pergamon Press Inc., 1985.

7. Riney, T. D., "Well Test Overlays and Improved Models for Geopressured-Geothermal Systems," letter report from S-Cubed to the University of Texas, DOE/UTA Cooperative Agreement Contract No. DE-FC07-85NV10412, March 10, 1989.

8. Piney, T. D., personal communication, July 1989.

9. Stevenson, D., Louisiana State University. Viewgraph presented at the GeopressuredGeothermal Project Review meeting, Washington, D.C., December 6, 1990.

102

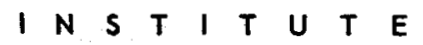

OF

GA S

TE CH NO L O G Y 


\section{APPENDIX A}

\section{Brine Sampling and Analysis Methodology}

\section{A-1}



Brine sampling procedures were similar to those followed by IGT on the other DOE Design Wells. With the exception of the sample collected before the separator was activated, the brine was collected from a port at the outlet end of the large separator. The brine passed through a stainless steel cooling coil, reaching ambient temperature prior to experiencing the pressure drop to atmospheric conditions. The samples were collected in high-density polyethylene bottles under a carbon dioxide head to minimize exposure to atmospheric oxygen. The samples were shipped overnight to the analytical laboratory, where they were refrigerated prior to analysis. These precautions minimized precipitation prior to analysis. If precipitates were noted at the laboratory, the sample was homogenized prior to withdrawing an aliquot for analysis.

In addition to these precautions, two 1-liter sample bottles were prefilled with 0.5 liter of acidified water, giving a final dilution of $1: 1$. The $\mathrm{pH}$ of these samples were about 1.5 . This dilution and acidification resulted in samples that contained no visible precipitation for weeks. Radium analyses, which are extremely sensitive to precipitation, indicated some solids precipitation was occurring even in these diluted and acidified samples, but at a level so small that no turbidity was observed.

IGT contracted for the University of Texas Bureau of Economic Geology's Mineral Studies Laboratory to perform the majority of the brine analyses. This same laboratory has also analyzed Gladys McCall and Pleasant Bayou brines for IGT. The analytical techniques used are listed in Exhibit A-1, and detailed laboratory procedures are included in the Pleasant Bayou Safety Analysis Review document (SAR).

For each suite of samples, a replicate analysis was performed as a check on reproducibility and an analysis of appropriate standards was performed. Exhibits A-2 through A-6 are the five pages that constitute a typical report. In this case, the suite of DOE samples consisted of the two Hulin samples collected January 6, 1990, and a Pleasant Bayou sample collected February 6, 1990. The replicate analyses reported are from a second suite of samples from IGT that were analyzed the same day. The specific sample was from the Prets well in the N.E. Hitchcock field.

Several brine analyses were performed on location because the time needed to transport the samples to a laboratory might have seriously affected the accuracy of the analyses. These analyses include alkalinity, iron, sulfate, sulfide, and total carbon dioxide. The procedures and chemicals used for the first four analyses are described in the Hach Water and Wastewater Analysis Handbook. Three of these tests -- alkalinity, iron, and sulfide -- were also subsequently run in the laboratory, but the field data is believed to be most reliable. 


\section{Exhibit A-1. ANALYTICAL METHODS USED}

Component

Sodium, Potassium, Magnesium, Calcium, Iron, Manganese, Strontium, Barium, Zinc, Lithium, Silica, Chromium, Copper, Nickel, Arsenic, Cadmium, Lead, Tin, Boron

\section{Mercury}

Ammonia

Chloride

Sulfatea

Bromide, Iodide

Fluoride

Alkalinity ${ }^{a}$

Density, TDS

Sulfide ${ }^{a}$, Iron ${ }^{a}$

Radium
Method

Inductively Coupled PlasmaOptical Emission Spectroscopy
Cold-Vapor Atomic Absorption

Distillation-Titration

Titration

Turbidimetric

Spectrophotometric

Ion Electrode

pH Titration

Gravimetric

Colorimetric

Radon Generation

a Sample is also analyzed for this element onsite. The only sulfide measurements, which did not reveal detectable levels of sulfide in the brine, were performed onsite.

Measurements of total carbon dioxide and the gas content of separator brine were made following procedures described in the "Parametric Study of Separator Performance." 2 This entailed collecting brine samples under pressure, cooling the samples, quantitatively flashing off and measuring dissolved gas, and finally using an acid liberation/nitrogen purge gravimetric technique to recover any remaining carbon dioxide.

Brine samples were also collected for and sent to Dr. T. Kraemer of the USGS. Those samples, analyzed for radium 226 and radium 228, were cooled, filtered, acidified, and diluted.

Finally, the IGT inhouse analytical laboratory performed part-per-million quantification of organic acids in the brine. The organic acids were determined by gas chromatography/mass spectroscopy. These samples were collected in glass bottles, without the carbon dioxide gas head, and with mercuric chloride added as a biological inhibitor. 


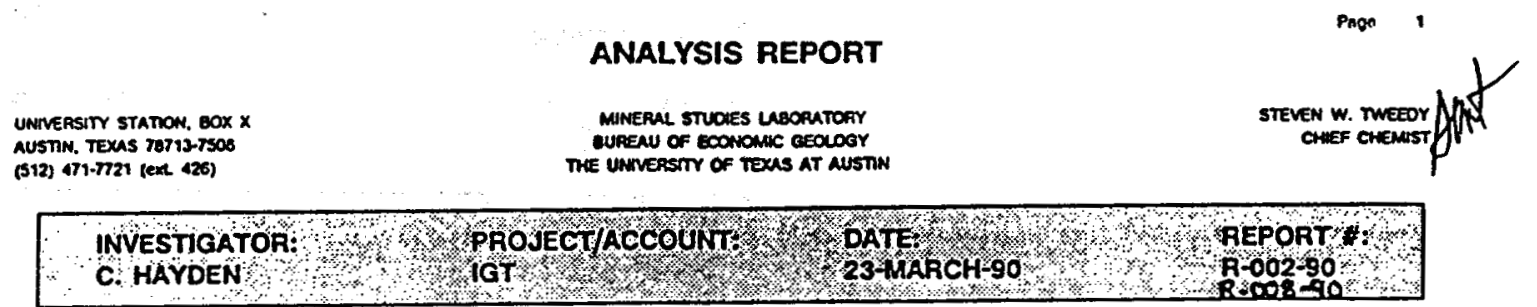

MSL IDH: $90-003,90-004,90-065$

BAMPLE PREPARATION / TREATMENT

These samples were analyzed on an as received basis. For all analyses, the samples were shaken prior to removing an aliquot for analysis to include any precipitated solids.

BAMPLE ANALYGIS METHODS

constituents

Techntque

$\mathrm{Na}, \mathrm{K}, \mathrm{Mg}, \mathrm{Ca}, \mathrm{Fe}, \mathrm{Mn}$,

$\mathrm{Sr}, \mathrm{Ba}, \mathrm{Zn}, \mathrm{Li}, \mathrm{SiO}, \mathrm{Cr}$

$\mathrm{Cu}, \mathrm{Ni}, \mathrm{As}, \mathrm{Cd}, \mathrm{Pb}, \mathrm{Sn}, \mathrm{B}$

Mercury

Ammonia (NH3)

chloride

sulfate

Bromide

Iodide

Fluoride

Alkalinity

Density, TDS

RESULTS
ICP-OES

Cold-Vapor AA

Distillation-

titration

Titration

Turbidimetric

spectrophotometric

spectrophotometric

Ion Electrode

pH Titration

Gravimetric
MSL Procedure *

SWI 1.6

SWI 1.5

MSL 001

SWI 1.1

SWI 1.3

SWI 1.2

SWI 1.4

SWI 1.11

- - -

Sample analysis results are presented in Table 1. The associated $Q A / Q C$ analysis results are presented in Table 2 . The replicate analysis was done on sample 90-061 from report $R-006-90$ since the samples were analyzed a the same time.

COMMENTS

This completes the requested analyses for these samples.

SAMPLE DISBOSITION:

The remains of these samples are being archived at the MSL.

ANALYSTS:

Herrera, Tweedy

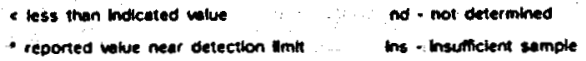

Exhibit A-2. BEG BRINE ANALYSIS REPORT COVER PAGE 


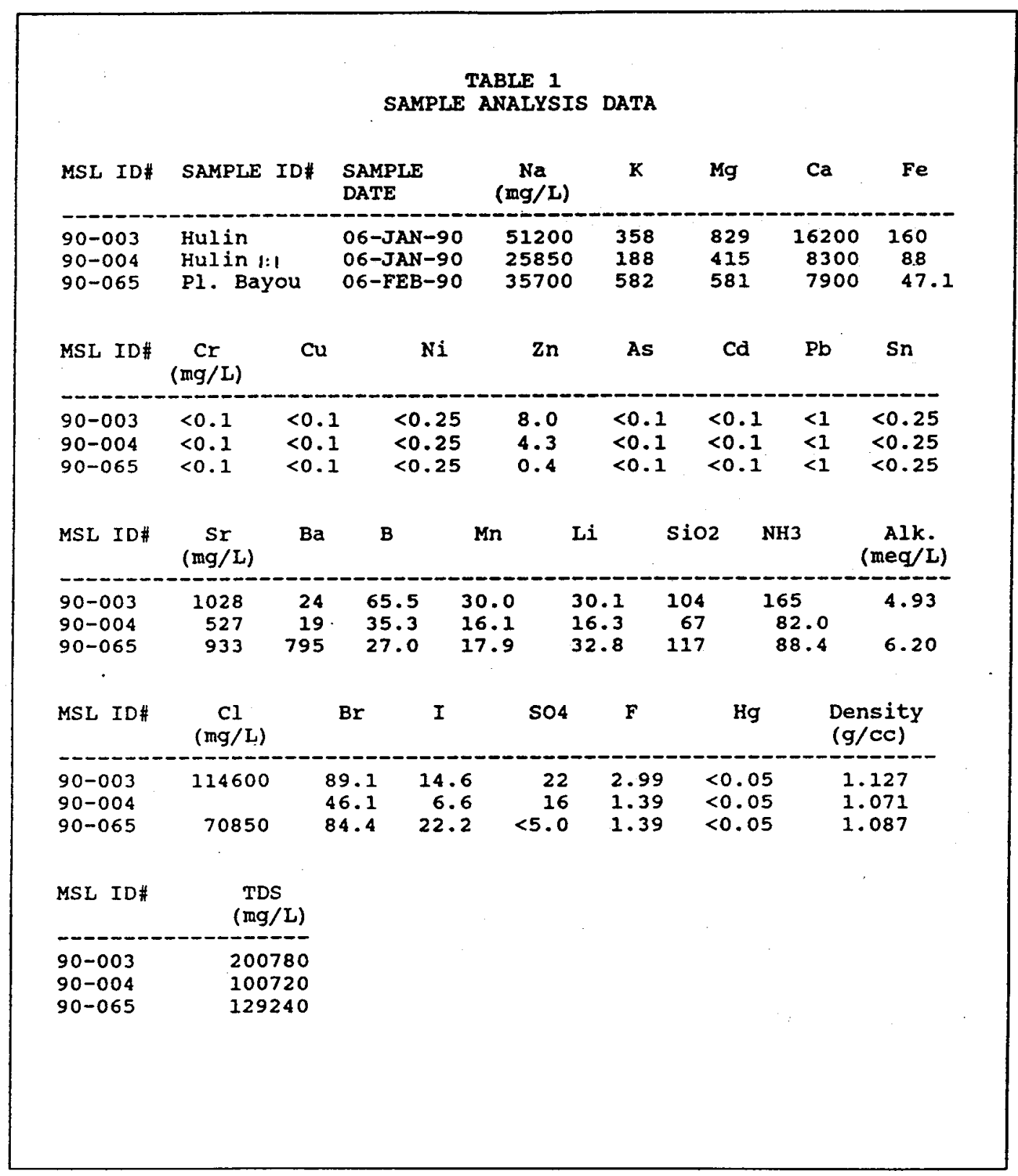

Exhibit A-3. BEG SAMPLE ANALYSIS DATA 


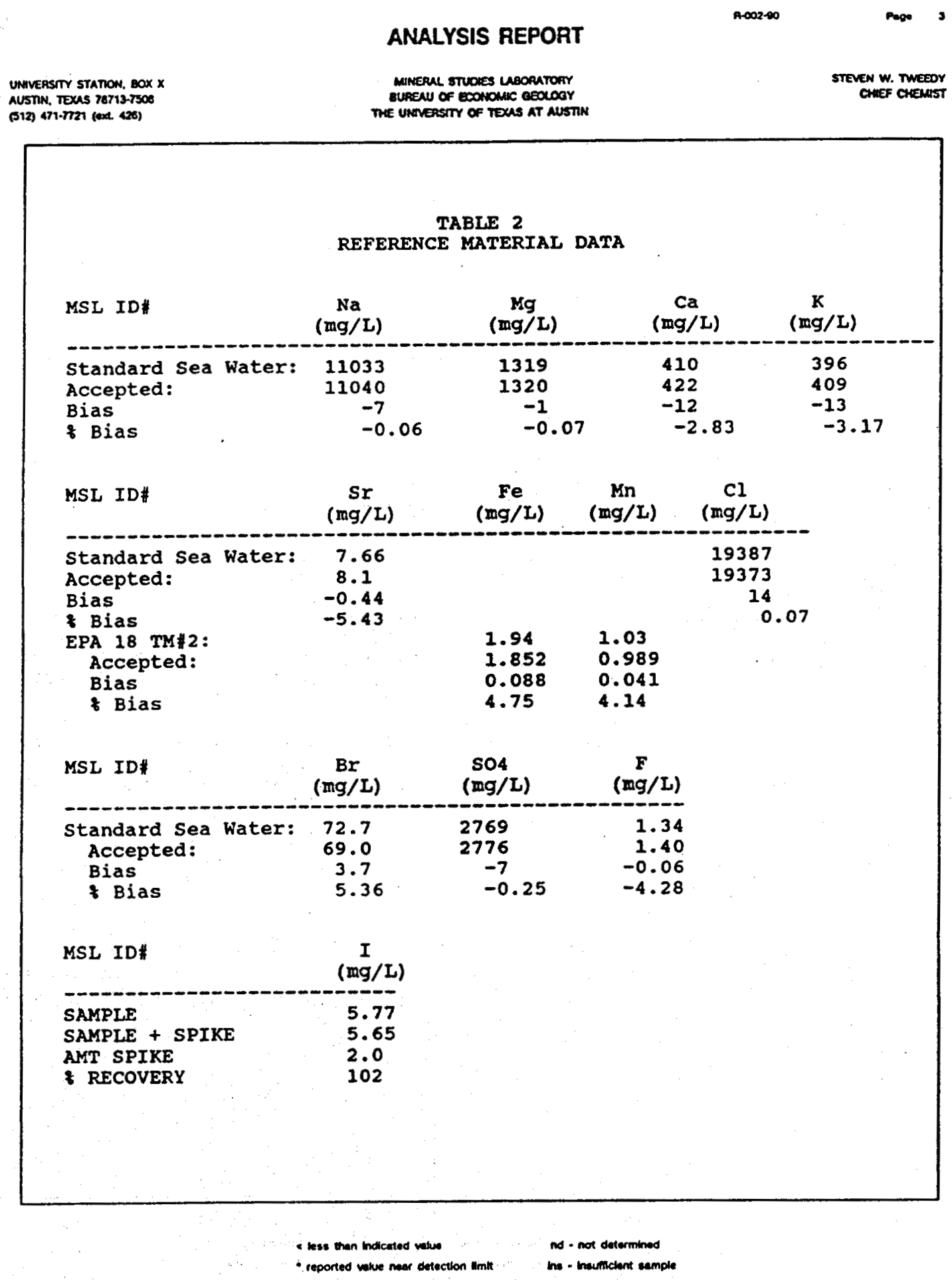

Exhibit A-4. BEG REFERENCE MATERIAL DATA

A-7

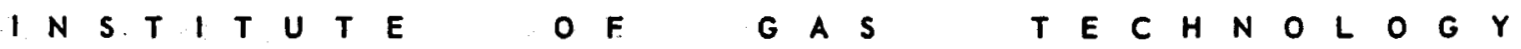




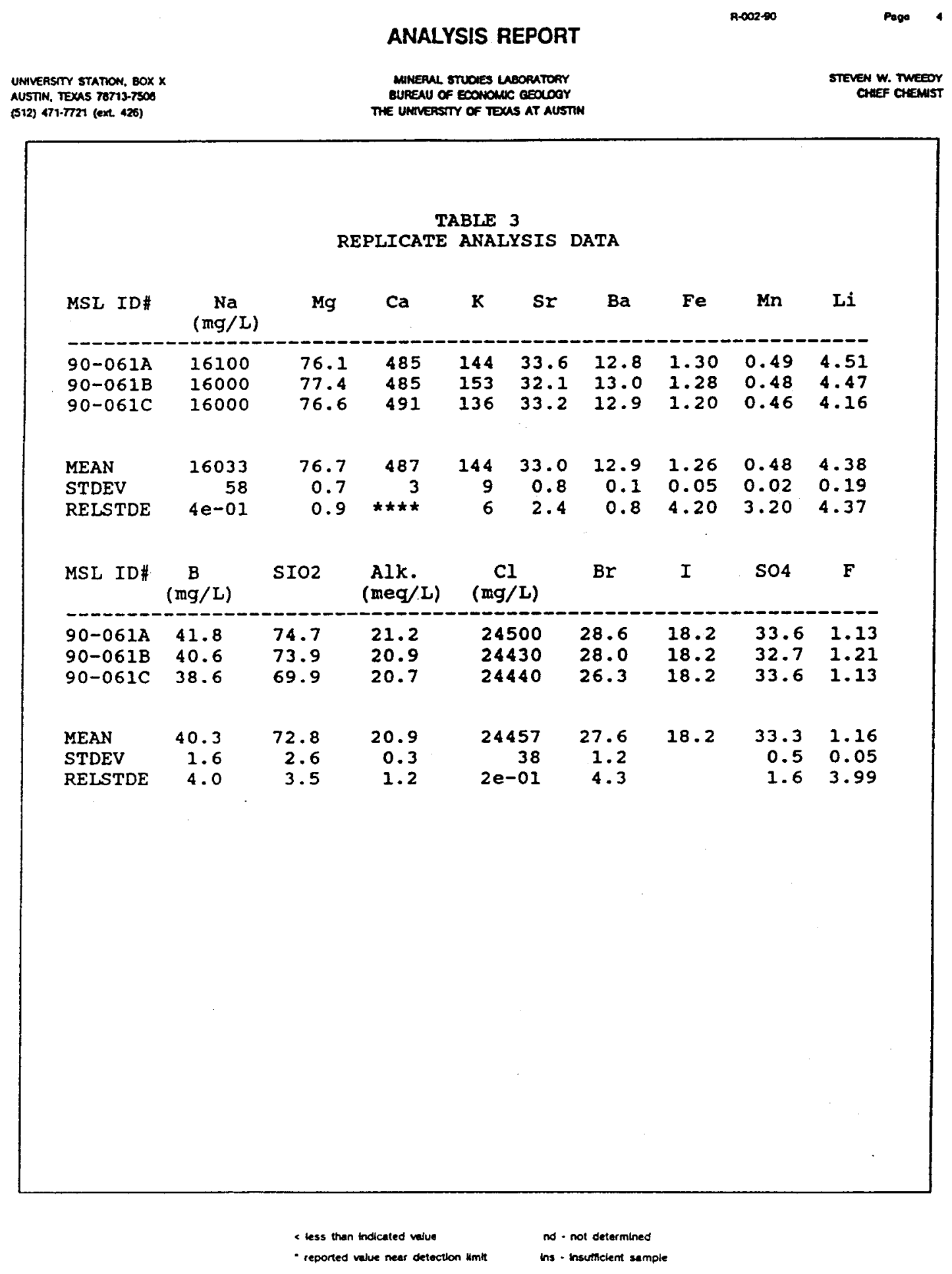

Exhibit A-5. BEG REPLICATE ANALYSIS DATA

A-8

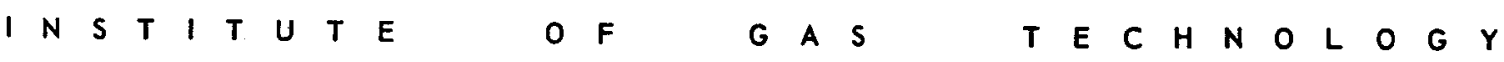


dot: $99-91-12$ time 18:94

$$
\begin{aligned}
& \text { हet } 24 \text { 21 \#1277 } \\
& \text { id. \#5 } 70-603 \\
& \text { In. \#2 } \\
& 6 i^{2}= \\
& \text { Pintil } \\
& 19 \mathrm{ml} \\
& 6.45 \\
& \text { EF1 } \quad 2.993 \quad 3.37
\end{aligned}
$$

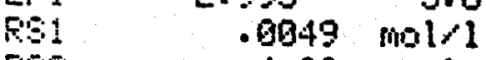

$$
\begin{aligned}
& \text { FE: } 4.93 \text { mmol } \\
& \text { \#EF non corresogndiria } \\
& \text { st:- yolt : reoched } \\
& =====
\end{aligned}
$$

$9 n:=90-91-12$ time $18: 05$ CLET $\because \mathrm{H}$ 21 \# 1277 1. Enlodis $\triangle \mathrm{BH}=1 / \mathrm{di} u$ $=1 \mathrm{art} y \quad 000 \mathrm{ml}$

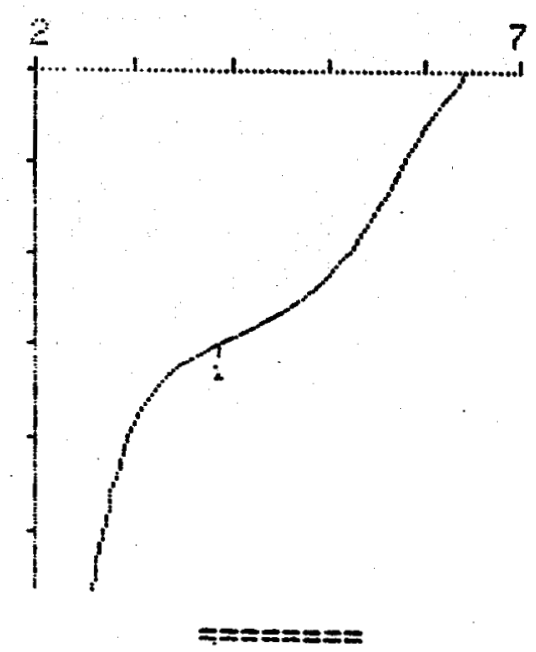

date $99-92-13$ time $16: 17$ GET R.H

Id. \#1

Id. \#2

$006=$

oH(init)

$99-965$

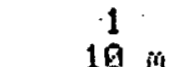

6.66

EF1 $3.764 \quad 3.6 \mathrm{~m}$

RS1 .0062 mol 1

Re2 $6.20 \mathrm{mmol}$.

\#EF not corresponding stop volt i reached

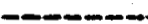

date $90-42-13$ time 16:17 GET FH $21 \# 4$ 1. Gml/jiy $\quad \triangle p H=1 / d i v$ stort $v^{.0900 \mathrm{ml}}$
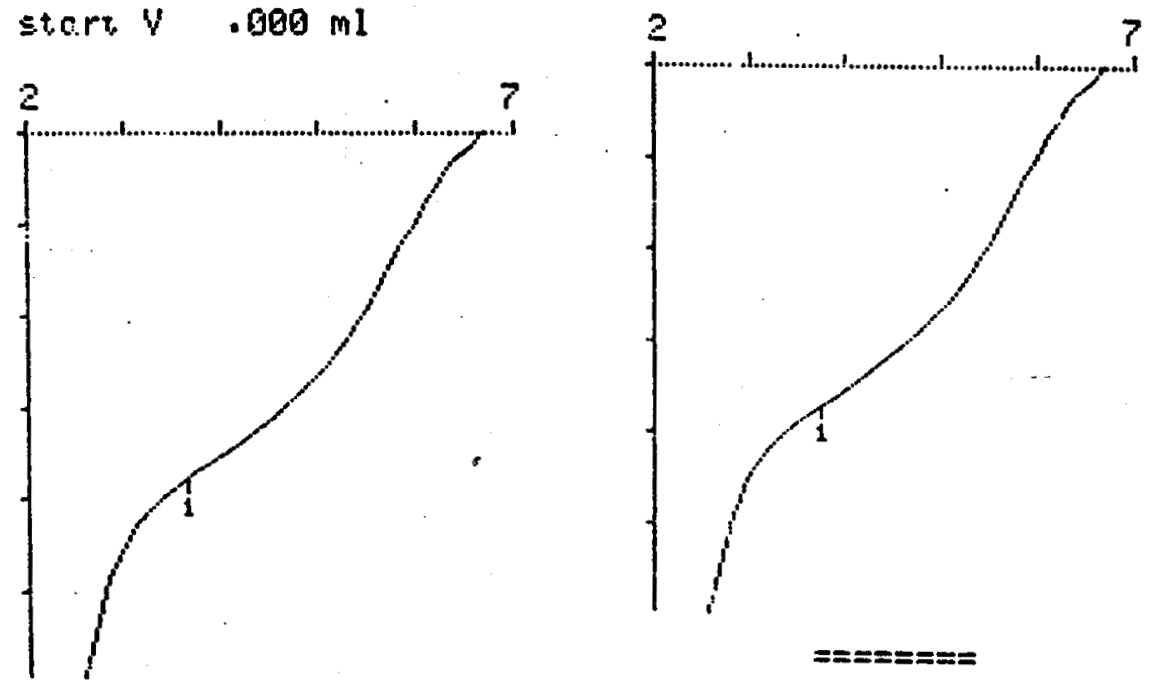

date $99-6 z-13$ time $17: 18$ CET FH

Id. \#I

Id. \#3

Cob= $19 \mathrm{ml}$

$30-955$

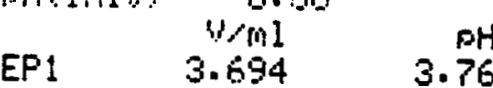

FS1 . OgS mold

\#EF not corresponding

stof volt. reoched $======$

date $90-32-13$ time $17: 19$ GET PH $21 \#$ \# 1. Sml.dju ds $H=1 / d i v$ stert $y$. $099 \mathrm{ml}$

Exhibit A-6. HULIN BRINE ALKALINITY 



\section{APPENDIX B}

\section{Hydrocarbon Sampling, Analysis Procedures, and Results}

B-1 


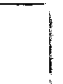


With the exception of the wellhead gas sample collected on February 9, 1989, gas samples destined for laboratory analyses by IGT were collected in evacuated, teflon-lined, 304 stainless steel cylinders rated at 1800 -psi working pressure. The samples were sealed and sent to the IGT laboratory in Chicago for analysis. At the laboratory, the sample cylinders were preheated to brine temperature prior to withdrawing an aliquot for analysis. This prevented liquid condensation from interfering with the analysis. The samples were analyzed by gas chromatography.

Most of the samples collected for local analysis by Southern Petroleum Laboratory (SPL) were colllected in stainless steel cylinders provided by SPL. Some were collected in the teflonlined IGT cylinders. The SPL role resulted from decisions made in the field in response to strong management interest in rapid determination of whether there was hydrocarbon production in excess of solubility in reservoir brine. The timing was such that detailed cross-checking of procedures was not practical. Unfortunately, one result was lack of implementation of the procedure of heating the cylinders to vaporize liquids before extracting aliquots for chromatographic analysis.

Onsite analyses for carbon dioxide and hydrogen sulfide were performed using Draeger tubes following the Gas Processors Association "Tentative Method of Test for Hydrogen Sulfide in Natural Gas Using Stain Tubes" (1977).

There was not enough oil produced to allow us the luxury of following a standard sampling routine. The first condensate sample, obtained during the cleanup flow in February 1989, was collected from a gas sample. During the December 1989 and January 1990 flow tests, condensate samples were obtained from the large and small separators and from holding tanks on location. Most samples were not analyzed. The samples that were analyzed were sent to IGT-Chicago and analyzed by capillary-column gas chromatography.

The results of several gas analyses from each of four sample collection points are presented in Exhibits B-1 through B-5. Exhibit B-1 presents the results of detailed analyses of large separator gas performed at IGT-Chicago. Exhibits B-2 through B-5 present results of conventional gas analyses performed at Southern Petroleum Laboratories, Inc., in Lafayette, Louisiana. These tables are for samples from the large separator, the small separator, flashing of gas from the brine leaving the large separator, and the gas accumulation at the disposal wellhead. The small separator gas is gas from the large separator that has undergone a pressure drop, been cooled to near ambient temperature, and had the resulting condensate and water removed by the small separator. The disposal well gas is gas that came out of solution from the brine in response to the pressure drop from separator pressure to disposal well injection pressure. With the exception of the gas from the small separator, the majority of these results were also in the body of the report. 
Exhibit B-1. LARGE SEPARATOR GAS ANALYSES, IGT ${ }^{a}$

\begin{tabular}{|c|c|c|c|c|c|c|}
\hline $\begin{array}{l}\text { Date } \\
\text { Time } \\
\text { Pressure, psia } \\
\text { Gas Temp, }{ }^{\circ} \mathrm{F} \\
\text { Brine Temp, }{ }^{\circ} \mathrm{F}\end{array}$ & $\begin{array}{c}\frac{12 / 06 / 89}{23: 30} \\
309 \\
133 \\
171\end{array}$ & $\begin{array}{c}12 / 07 / 89 \\
08: 15 \\
310 \\
134 \\
190\end{array}$ & $\begin{array}{c}12 / 20 / 89 \\
17: 40 \\
482 \\
221 \\
251\end{array}$ & $\begin{array}{c}\frac{1 / 6 / 90}{11: 00} \\
406 \\
208 \\
243\end{array}$ & $\begin{array}{r}\frac{1 / 6 / 90}{14: 45} \\
735 \\
210 \\
265\end{array}$ & $\begin{array}{r}\frac{1790}{09: 15} \\
295 \\
185 \\
221\end{array}$ \\
\hline \multicolumn{7}{|l|}{ Mole Percent of: } \\
\hline Helium & 0.008 & 0.008 & 0.006 & 0.006 & 0.006 & 0.005 \\
\hline Hydrogen & 0.064 & 0.071 & 0.025 & 0.029 & 0.029 & 0.047 \\
\hline Nitrogen & 0.29 & 0.15 & 0.12 & 0.15 & 0.13 & 0.11 \\
\hline Carbon Dioxide & 17.8 & 18.2 & 16.9 & 15.9 & 13.1 & 16.7 \\
\hline Methane & 80.1 & 79.4 & 80.3 & 82.0 & 84.6 & 81.2 \\
\hline Ethane & 1.59 & 1.65 & 2.17 & 1.68 & 1.78 & 1.68 \\
\hline Propane & 0.12 & 0.38 & 0.26 & 0.17 & 0.19 & 0.16 \\
\hline o-Butane & $<0.01$ & $<0.01$ & 0.03 & 0.02 & 0.02 & 0.01 \\
\hline Butane & $<0.01$ & $<0.01$ & 0.03 & 0.02 & 0.02 & 0.01 \\
\hline -Pentane & $<0.01$ & $<0.01$ & 0.02 & 0.004 & 0.004 & 0.003 \\
\hline Pentane & $<0.01$ & $<0.01$ & 0.01 & 0.001 & 0.002 & 0.001 \\
\hline o-Pentane & $<0.001$ & $<0.001$ & $<0.001$ & $<0.001$ & $<0.001$ & $<0.001$ \\
\hline xanes & 0.001 & 0.001 & 0.003 & 0.002 & 0.003 & 0.001 \\
\hline eptanes & 0.001 & 0.003 & 0.005 & 0.002 & 0.003 & 0.002 \\
\hline tanes & 0.001 & 0.003 & 0.006 & 0.001 & 0.002 & 0.001 \\
\hline Nonanes & 0.001 & 0.003 & 0.012 & 0.010 & 0.002 & 0.002 \\
\hline Decanes & 0.001 & 0.002 & 0.008 & 0.001 & 0.002 & 0.004 \\
\hline Undecanes & 0.002 & 0.001 & 0.011 & 0.004 & 0.006 & 0.006 \\
\hline Dodecanes & 0.005 & 0.002 & 0.015 & 0.004 & 0.008 & 0.005 \\
\hline Tridecanes & 0.007 & & & 0.0 & 0.003 & 0.002 \\
\hline Tetradecanes + & 0.003 & 0.003 & 0.009 & 0.002 & 0.002 & 0.001 \\
\hline Benzene & 0.009 & 0.010 & 0.015 & 0.025 & 0.032 & 0.030 \\
\hline Toluene & 0.002 & 0.005 & 0.019 & 0.008 & 0.009 & 0.012 \\
\hline C2 Benzenes & $<0.001$ & $<0.001$ & $<0.001$ & $<0.001$ & $<0.001$ & $<0.001$ \\
\hline C3 Benzenes & $<0.001$ & $<0.001$ & $<0.001$ & $<0.001$ & $<0.001$ & $<0.001$ \\
\hline Naphthalene & $<0.001$ & $<0.001$ & $<0.001$ & $<0.001$ & $<0.001$ & $<0.001$ \\
\hline C1 Naphthalenes & $<0.001$ & $<0.001$ & $<0.001$ & $<0.001$ & $<0.001$ & $<0.001$ \\
\hline C2 Naphthalenes + & $<0.001$ & $<0.001$ & $<0.001$ & $<0.001$ & $<0.001$ & $<0.001$ \\
\hline \multicolumn{7}{|l|}{ Heating Valu } \\
\hline I/SCFb & 862 & 864 & 885 & 887 & 918 & 879 \\
\hline $\begin{array}{l}\text { Gravity (air= } \\
\text { NGL, Gal/ }\end{array}$ & 0.738 & 0.74 & 0.736 & 0.720 & 0.695 & 0.728 \\
\hline $1000 \mathrm{SCF}$ & 0.484 & 0.575 & 0.758 & 0.551 & 0.590 & 0.544 \\
\hline
\end{tabular}

a Analyses performed at IGT using gas chromatography with TC and FID detectors.

$b^{b}$ Dry, 15.025 psia, $60^{\circ} \mathrm{F}$. 
Exhibit B-2. LARGE SEPARATOR GAS ANALYSES, SPL

Date

Time

Pressure, psia

Gas Temp, ${ }^{\circ} \mathrm{F}$

Brine Temp, ${ }^{\circ} \mathrm{F}$

Mole Percent of:

Nitrogen

Carbon Dioxide

Methane

Ethane

Propane

iso-Butane

n-Butane

iso-Pentane

n-Pentane

Hexanes

Heptanes+ $\frac{1 / 6900}{09 \cdot 30}$

09:30

405

208

242

0.15

12.49

85.22

1.85

0.16

0.01

0.02

$<0.01$

$<0.01$

$<0.01$

0.10 $\frac{1 / 6 / 90}{14: 45}$

735

210

265

0.17

14.19

83.66

1.75

0.17

0.01

0.01

$<0.01$

$<0.01$

$<0.01$

0.04 $\frac{1 / 6 / 90}{17: 00}$

735

235

265

0.16

14.53

83.31

1.76

0.17

0.02

0.01

$<0.01$

$<0.01$

$<0.01$

0.04

902

0.708

0.558 $\frac{17790}{09: 15}$

295

185

221

0.10

16.27

81.66

1.76

0.16

0.01

0.01

$<0.01$

$<0.01$

$<0.01$

0.03

Heating Value,

Btu/SCFa

927

905

0.705

0.551

0.691
0.608

NGL, Gal/1000 SCF

a Dry, $15.025 \mathrm{psia}, 60^{\circ} \mathrm{F}$.

\section{B-5}


Exhibit B-3. SMALL SEPARATOR GAS ANALYSES, SPL ${ }^{a}$

\begin{tabular}{|c|c|c|c|c|c|c|c|}
\hline \multirow{6}{*}{$\begin{array}{l}\text { Date } \\
\text { Time } \\
\text { Pressure, psia } \\
\text { Gas Temp, }{ }^{\circ} \mathrm{F} \\
\text { Large Separator } \\
\text { Pressure, psia } \\
\text { Brine Temp, }{ }^{\circ} \mathrm{F}\end{array}$} & $12 / 11 / 89$ & $1 / 4 / 90$ & $1 / 5 / 90$ & $1 / 6 / 90$ & $1 / 6 / 90$ & $1 / 7 / 90$ & $\frac{1 / 10 / 90}{17: 30}$ \\
\hline & $05: 30$ & $14: 15$ & $08: 30$ & $14: 45$ & $17: 00$ & $09: 15$ & $17: 30$ \\
\hline & 178 & 101 & 116 & 135 & 155 & 137 & 100 \\
\hline & 55 & 79 & 65 & 55 & 60 & 50 & 74 \\
\hline & 305 & 405 & 265 & 735 & 737 & 295 & 485 \\
\hline & 189 & 229 & 232 & 265 & 265 & 221 & 207 \\
\hline \multicolumn{8}{|l|}{ Mole Percent of: } \\
\hline Nitrogen & 0.13 & 0.19 & 0.17 & 0.14 & $1.67^{b}$ & 0.11 & 0.14 \\
\hline Carbon Dioxide & 17.90 & 17.68 & 20.12 & 14.25 & 13.31 & 16.53 & 14.04 \\
\hline Methar & 79.76 & 80.25 & 77.98 & 83.63 & 83.03 & 81.39 & 83.87 \\
\hline Ethane & 1.98 & 1.64 & 1.51 & 1.76 & 1.77 & 1.77 & 1.73 \\
\hline Propane & 0.18 & 0.16 & 0.14 & 0.17 & 0.17 & 0.16 & 0.16 \\
\hline iso-Butane & 0.01 & 0.01 & 0.01 & 0.01 & 0.01 & 0.01 & 0.01 \\
\hline Butane & 0.01 & 0.01 & 0.01 & 0.01 & 0.01 & 0.01 & 0.01 \\
\hline iso-Pentane & $<0.01$ & $<0.01$ & 0.01 & $<0.01$ & $<0.01$ & $<0.01$ & $<0.01$ \\
\hline n-Pentane & $<0.01$ & $<0.01$ & 0.01 & $<0.01$ & $<0.01$ & $<0.01$ & $<0.01$ \\
\hline Hexa & $<0.01$ & $<0.01$ & $<0.01$ & $<0.01$ & $<0.01$ & $<0.01$ & $<0.01$ \\
\hline Heptanest & 0.03 & 0.06 & 0.04 & 0.03 & 0.03 & 0.02 & 0.04 \\
\hline \multicolumn{8}{|l|}{ Heating Value, } \\
\hline Btu/SCFC & 869 & 869 & 84 & 904 & 898 & 880 & 907 \\
\hline Gravity (air= & 0.741 & 0.739 & 0.761 & 0.705 & 0.702 & 0.726 & 0.703 \\
\hline \multicolumn{8}{|l|}{$\begin{array}{l}\text { NGL, Gal/ } \\
1000 \text { SCF }\end{array}$} \\
\hline 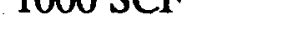 & 0.011 & & & & 0.532 & 0.344 & \\
\hline
\end{tabular}

a Analyses performed at Southern Petroleum Labs using gas chromatography.

$\mathrm{b}$ Analysis is questionable -- air contamination likely.

c Dry, 15.025 psia, $60^{\circ} \mathrm{F}$. 
Exhibit B-4. GAS FLASHED FROM SEPARATOR BRINE

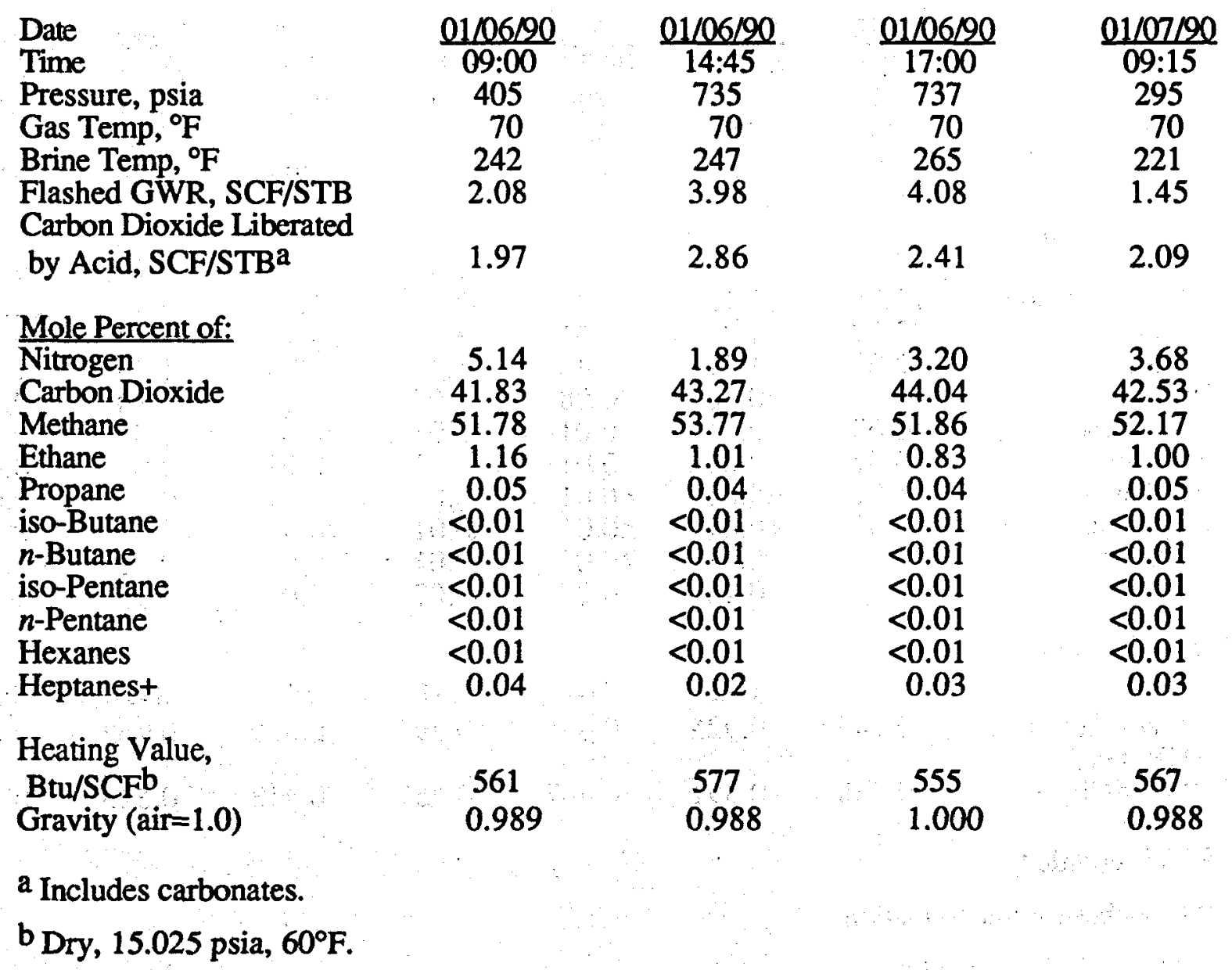


EXHIBIT B-5. GAS BLED FROM THE DISPOSAL WELLHEAD

Date

Time

Pressure, psia

Sep Pres, psia

Brine Temp, ${ }^{\circ} \mathrm{F}$

Mole Percent of:

Nitrogen

Carbon Dioxide

Methane

Ethane

Propane

iso-Butane

n-Butane

iso-Pentane

$n$-Pentane

Hexanes

Heptanes+

\begin{tabular}{|c|c|c|c|c|c|c|}
\hline $1 / 3 / 90$ & $1 / 5 / 90$ & $1 / 6 / 90$ & $1 / 6 / 90$ & $1 / 6190$ & $1 / 700$ & $1 / 10 / 90$ \\
\hline$N^{a}$ & $08: 30$ & $09: 30$ & $14: 45$ & $17: 00$ & $09: 15$ & $17: 30$ \\
\hline 55 & 95 & 206 & 202 & 327 & 173 & \\
\hline $\begin{array}{l}\text { NR } \\
\text { NR }\end{array}$ & $\begin{array}{l}264 \\
232\end{array}$ & $\begin{array}{l}405 \\
242\end{array}$ & $\begin{array}{l}737 \\
247\end{array}$ & $\begin{array}{l}737 \\
265\end{array}$ & $\begin{array}{l}295 \\
221\end{array}$ & $\begin{array}{l}487 \\
207\end{array}$ \\
\hline
\end{tabular}

0.19

17.75

79.37

2.23

0.26

0.03

0.02

0.01

0.01

0.01

0.12

0.06

37.18

61.41

1.17

0.06

0.01

0.01

$<0.01$

$<0.01$

$<0.01$

0.10

879

0.746

665

0.925

0.768

0.391

0.768

NGL, Gal/

0.07

27.77

$1.90^{\mathrm{b}}$

0.09

0.10

0.10

70.51

33.35

25.27

73.17

1.43

1.48

0.08

0.07

0.01

0.01

$<0.01$

$<0.01$

0.01

0.01

$<0.01$

$<0.01$

$<0.01$

$<0.01$

0.07

0.07

1.31

0.09

19.96

78.14

1.53

0.10

24.91

73.27

1.51

0.01

0.01

0.12

0.01

$<0.01$

$<0.01$

0.01

0.01

$<0.01$

0.01

$<0.01$

$<0.01<0.01$

0.01

0.05

0.15

$<0.01$

Heating Value,

Not recorded.

b Probable air contamination.

c Dry, 15.025 psia, $60^{\circ} \mathrm{F}$. 